\title{
ALEXANDRE PAZIAN
}

PROPOSTA DE PROCEDIMENTOS DE DESENVOLVIMENTO DE SUPORTES APLICADOS EM CHASSI VEICULAR 


\section{ALEXANDRE PAZIAN}

\section{PROPOSTA DE PROCEDIMENTOS DE DESENVOLVIMENTO DE SUPORTES APLICADOS EM CHASSI VEICULAR}

Dissertação apresentada à Escola Politécnica da Universidade de São Paulo para a obtenção do título de Mestre em Engenharia

Área de concentração:

Engenharia Mecânica

Orientador: Prof. Titular

Ronaldo de Breyne Salvagni 
Este exemplar foi revisado e alterado em relação à versão original, sob responsabilidade única do autor e com a anuência de seu orientador.

São Paulo, de janeiro de 2010.

Assinatura do autor

Assinatura do orientador

\section{FICHA CATALOGRÁFICA}

\section{Pazian, Alexandre}

Proposta de procedimentos de desenvolvimento de suportes aplicados em chassi veicular / A. Pazian. -- ed.rev.-- São Paulo, 2010.

$101 \mathrm{p}$.

Dissertação (Mestrado) - Escola Politécnica da Universidade de São Paulo. Departamento de Engenharia Mecânica.

1. Desenvolvimento de produtos 2. Estruturas (Otimização) 3. Chassis I. Universidade de São Paulo. Escola Politécnica. Departamento de Engenharia Mecânica II. t. 
DEDICATÓRIA

Dedico este estudo à minha esposa e filha. 


\section{AGRADECIMENTOS}

Ao Professor Dr. Ronaldo de Breyne Salvagni pela orientação e apoio para a realização deste estudo.

À minha esposa e filha pelo companheirismo, apoio e momentos de descontração, incentivando-me a seguir em frente.

Aos meus pais e irmãos.

Aos amigos Marcos Carazatto Gimenez, Dirceu Lavoisier G. Fernandes e Hélcio Matsuguma pela disponibilidade e vontade de ajudar.

Aos professores das disciplinas cursadas na EPUSP.

À gerência e supervisão da empresa em que trabalho, pela disponibilidade de cursar as disciplinas durante o expediente, e a todos que colaboraram, direta ou indiretamente, na execução deste estudo.

A Deus, por tudo. 


\section{RESUMO}

O objetivo deste estudo consiste em obter um procedimento de dimensionamento estrutural otimizado de suportes metálicos utilizados em chassi de veículos comerciais, o qual apresenta, na maioria dos casos, restrições referentes ao projeto do produto e à manufatura. Realizou-se a revisão bibliográfica dos principais métodos de otimização estrutural, abrangendo problemas e soluções relacionadas ao seu uso, e também foram considerados os conceitos do projeto para fabricação e montagem. Foi proposto um procedimento de dimensionamento de suportes estruturais, utilizando a análise de elementos finitos e otimização paramétrica, de forma e topológica. A proposta verifica também itens como estabilidade estrutural, tipo de elemento utilizado e facilidade de fabricação e montagem. O procedimento foi aplicado no estudo de caso do desenvolvimento de um suporte de amortecedor, o qual apresentou falha em campo. Foi possível fazer a representação da falha no suporte com o modelo de elementos finitos e foram propostas estruturas otimizadas, que resolveram a falha e confirmaram a eficácia do procedimento proposto no estudo. Um benefício da aplicação da otimização topológica é a capacidade do método para a obtenção de novas estruturas com menor peso e com aumento da rigidez, considerando ainda as necessidades de fabricação e montagem.

Palavras-chave: Desenvolvimento de produto, Otimização estrutural, Manufatura e Montagem. 


\section{ABSTRACT}

The objective of this work is to achieve a procedure for structural design optimized metal brackets used in the chassis of commercial vehicles, which have in the most of the cases limitations related to product design and manufacturing. Was carried out a bibliographic review of structural optimization main methods, covering problems and solutions related to their use, were also considered the concepts of design for manufacture and assembly. It was proposed a procedure for structural brackets design, using the finite element analysis, parametric, shape and topology optimization. The proposal also notes items such as structural stability; type of element used and to improvement of fabrication and assembly. The procedure was applied in the case study to the development of a shock absorber, which has failed in the field. It was possible to represent the brackets failure of support with the finite element model and optimized structures have been proposed to resolve the failure and confirmed the effectiveness of the proposed procedure at work. One application benefit for topology optimization is the ability of the method to obtain new structures with lower weight and higher stiffness level, and considering manufacturing and assembly need's.

Keywords: Product development, Structural optimization, Manufacturing and Assembly. 


\section{LISTA DE ILUSTRAÇÕES}

Figura 2.1 - Viga engastada, (a) Vista lateral e (b) Secção transversal (Haftka e Gurdal,

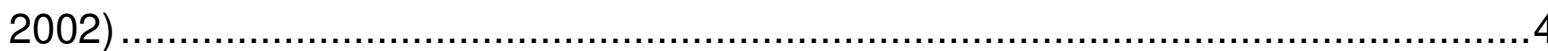

Figura 2.2 - Uso da otimização de forma (Haftka e Gurdal, 2002) ...............................4

Figura 2.3 - Uso da otimização topológica (Bruggi, 2008) ..........................................

Figura 2.4 - (a) Domínio de projeto, (b) Malha com 600 elementos e (c) Malha com 5400 elementos (Sigmund e Petersson, 1998) .........................................................

Figura 2.5 - (a) Domínio de projeto, (b) Solução com uma barra

e (c) Solução com múltiplas barras paralelas (Sigmund e Petersson, 1998)

Figura 2.6 - (a) Domínio do projeto, (b) Otimização topológica com checkerboard

(Bruggi, 2008)

Figura 2.7 - Peça isenta da ocorrência do problema do tabuleiro de xadrez (Bruggi, 2008) 10

Figura 2.8 - Domínio de projeto, placa de reforço (Khalaf e Saka, 2007). 12

Figura 2.9 - (a) Domínio discretizado e (b) Distribuição de tensão (Khalaf e Saka, 2007)

Figura 2.10 - Solução otimizada (Khalaf e Saka, 2007) 15

Figura 2.11 - Solução otimizada ESO - carga fixa, (a) Carregamento superior, (b)

Carregamento inferior (Yang, Xie e Steve, 2005) 17

Figura 2.12 - Solução otimizada ESO - cargas transmissíveis (Yang, Xie e Steve, 2005) 18

Figura 2.13 - Solução otimizada BESO - cargas transmissíveis (Yang, Xie e Steve, 2005)

Figura 2.14 - Solução otimizada, (a) Critério de rigidez (b) Critério de tensão (Yang, Xie e Steve, 2005) 19

Figura 2.15 - Domínio de projeto (Yang, Xie e Steve, 2005) 19

Figura 2.16 - Otimização topológica (Yang, Xie e Steve, 2005) 20

Figura 2.17 - (a) Domínio de projeto, (b) Otimização topológica BESO (Yang, Xie e Steve, 2005) 
Figura 2.18 - Otimização topológica para pequenos deslocamentos: (a) linear, (b) nãolinear (Huang e Xie, 2008) .23

Figura 2.19 - Otimização topológica não-linear para grandes deslocamentos:

(a) $\mathrm{d}=20 \mathrm{~mm}$, (b) $\mathrm{d}=50 \mathrm{~mm}$ e (c) $\mathrm{d}=100 \mathrm{~mm}$ (Huang e Xie, 2008) .23

Figura 2.20 - (a) Domínio do projeto, (b) Otimização topológica linear

e (c) Otimização topológica não-linear (Huang e Xie, 2008)...

Figura 2.21 - (a) Domínio de projeto, (b) Primeiro estágio algoritmo ESO, (c) Primeiro estágio algoritmo MESO (Tanskanen, 2006) .26

Figura 2.22 - Estágios típicos do uso da metodologia DFMA (Boothrod, Dewhurst e

Knight, 1994).

Figura 2.23 - Redução do tempo do projeto para a produção com o uso do DFMA

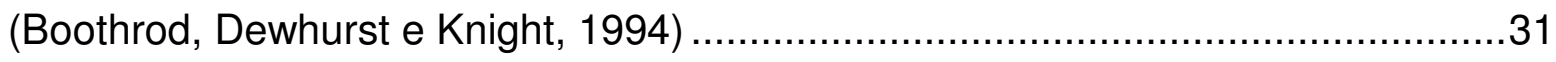

Figura 3.1 - Suporte do silencioso. .35

Figura 3.2 - Suportes para tubulações (direção hidráulica e combustível) e suporte da lanterna traseira .35

Figura 3.3 - Suporte da roda reserva .35

Figura 3.4 - Suporte dos reservatórios de ar comprimido .36

Figura 3.5 - Suporte da caixa de direção hidráulica .36

Figura 3.6 - Suporte do tanque de combustível. 39

Figura 3.7 - Suporte do amortecedor e suporte de apoio da bolsa de ar .40

Figura 3.8 - Suportes para a fixação de tubulação. 40

Figura 3.9 - Tipos de suporte de fixação do filtro de combustível e separador de água 41 Figura 3.10 - Suportes para a fixação de amortecedores (a) Tipo olhal e (b) Tipo haste rosacada 42

Figura 3.11 - Suporte de fixação do pára-barro ........................................................

Figura 4.1 - Fluxograma do conceito do suporte padrão..............................................49

Figura 4.2 - Elementos de placa. .53

Figura 4.3 - (a) Resultado do programa de otimização topológica e (b) Sugestão de geometria factível de produção .56

Figura 4.4 - Espiral de otimização .60

Figura 5.1 - Chassi de ônibus articulado de motor traseiro 68 
Figura 5.2 - Montagem do amortecedor e geometria do suporte do amortecedor 69

Figura 5.3 - Montagem do suporte com o amortecedor e detalhe da falha .70

Figura 5.4 - Modelo para teste de densidade da malha .71

Figura 5.5 - Dimensões do elemento .72

Figura 5.6 - Modelo de elementos finitos .73

Figura 5.7 - Coincidência de nós da malha .73

Figura 5.8 - Suporte fixo ao tubo (versão de projeto) .74

Figura 5.9 - Aplicação das restrições e do carregamento vertical (versão simplificada) 75 Figura 5.10 - Suporte falho com tubo (versão de projeto) - Tensões em MPa ................76

Figura 5.11 - Suporte falho (versão simplificada) - Tensões em MPa...........................76

Figura 5.12 - Suporte falho com carregamento calibrado - Tensões em MPa ...............78

Figura 5.13 - Suporte reforçado, (a) Suporte, (b) Disco, (c) Chapa traseira e (d) Chapa dianteira .79

Figura 5.14 - Suporte reforçado - Tensões em MPa 79

Figura 5.15 - Malha do suporte versão de chapas soldadas

Figura 5.16 - Suporte otimizado primeira proposta "A" (laterais de 2,5 mm) - Tensões em MPa .82

Figura 5.17 - Verificação quanto à flambagem do suporte. .83

Figura 5.18 - Suporte otimizado primeira proposta "B" (laterais de $5 \mathrm{~mm}$ ) - Tensões em MPa. .83

Figura 5.19 - Suporte otimizado segunda proposta "A" -Tensões em MPa....................84

Figura 5.20 - Suporte otimizado segunda proposta "B" - Tensões em MPa. .84

Figura 5.21 - (a) Malha suporte otimizado primeira proposta "B", (b) Malha com sobremetal ..... 86

Figura 5.22 - (a) $1^{\mathrm{a}}$ Interação, (b) $2^{\mathrm{a}}$ Interação e (c) $12^{\mathrm{a}}$ Interação..................................88

Figura 5.23 - (a) Malha obtida na $2^{\mathrm{a}}$ interação e (b) Nova malha. .88

Figura 5.24 - (a) Suporte otimizado $2^{\mathrm{a}}$ interação e (b) Suporte otimizado $2^{\mathrm{a}}$ interação modificada - Tensões em MPa.

Figura 5.25 - (a) Malha obtida na $12^{\mathrm{a}}$ interação e (b) Otimização topológica da $12^{\mathrm{a}}$ interação .90

Figura 5.26 - Propostas A, B e C 


\section{LISTA DE GRÁFICOS}

Gráfico 1 - Comparação entre otimização topológica linear e não-linear (Huang e Xie,

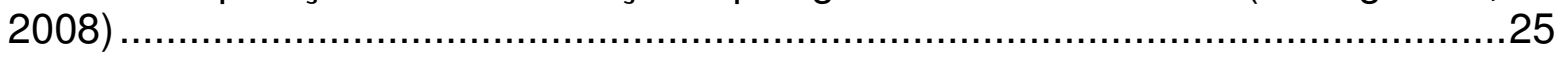




\section{LISTA DE TABELAS}

Tabela 2.1 - Comparação de resultados com diferentes densidades de malha (Khalaf e

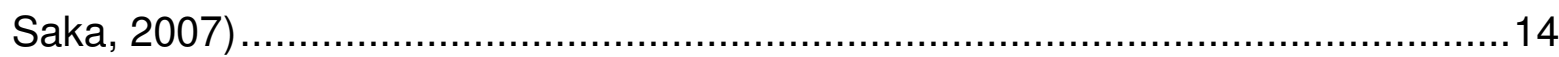

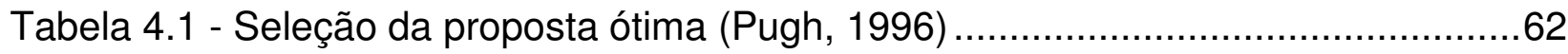

Tabela 4.2 - Critério de notas (Schuyler, 2001) .......................................................63

Tabela 4.3 - Seleção da proposta ótima (Schuyler, 2001) .........................................64

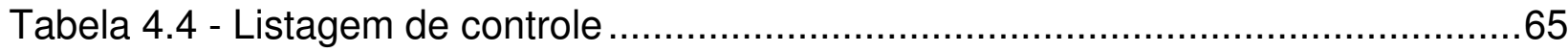

Tabela 5.1 - Testes de densidade de malha .........................................................

Tabela 5.2 - Tempo computacional das análises ..................................................77

Tabela 5.3 - Resultados das análises MEF e otimização paramétrica e de forma ..........85

Tabela 5.4 - Resultados das análises de otimização topológica ....................................90

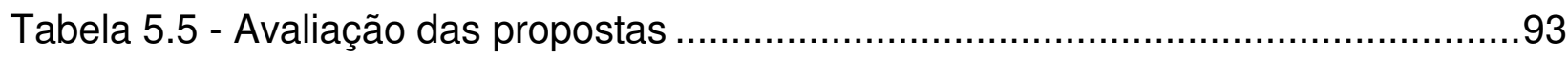

Tabela 5.6 - Listagem de controle ......................................................................94 


\title{
LISTA DE ABREVIATURAS E SIGLAS
}

\author{
AEM Assembly Evaluation Method \\ BESO Bi-directional Evolutionary Structural Optimization \\ CAD Computer-Aided Design \\ DAC Design for Assembly Cost Effectiveness \\ DFMA Design for Manufacture and Assembly \\ ESO Evolutionary Structural Optimization \\ FSD Full Stressed Design \\ MAG Metal Active Gas \\ MESO Modification of Evolutionary Structural Optimization \\ MEF Método dos Elementos Finitos \\ NBR Norma Brasileira \\ SKO Soft Kill Option
}




\section{LISTA DE SÍMBOLOS}
A
Área da secção transversal $\left[\mathrm{mm}^{2}\right]$
$B, b$
Largura [mm]
C
Cargas transmissíveis [N]
ER
Taxa evolucionária [\%]
E
Módulo de elasticidade do material [N/mm²]
$\mathrm{F}$
Carga vertical descendente $[\mathrm{N}]$
$\mathrm{H}, \mathrm{h}$
Altura $[\mathrm{mm}]$
i
Número de interações
I
Momento de inércia $\left[\mathrm{mm}^{4}\right]$
$l$
Tamanho do elemento da malha [mm]
L Comprimento [mm]
N
Número total de elementos da malha
$\mathrm{P}$
Carga atuante na estrutura $[\mathrm{N}]$
$r$
Raio do filtro [mm]
$r_{i j}$
Distância entre centros dos elementos $i$ e $j$ [mm]
RRi Taxa de remoção de material [\%]
Espessura do perfil ou do elemento [mm] 


$\begin{array}{ll}\text { ai } & \text { Número de sensibilidade } \\ \sigma & \text { Tensão atuante na estrutura [MPa] } \\ \sigma c r & \text { Tensão crítica de flambagem [MPa] } \\ \text { oel } & \text { Tensão em cada elemento [MPa] } \\ \text { omax } & \text { Valor máximo de tensão atuante }[\mathrm{MPa}] \\ \omega\left(\mathrm{r}_{\mathrm{ij}}\right) & \text { Fator de peso }\end{array}$




\section{SUMÁRIO}

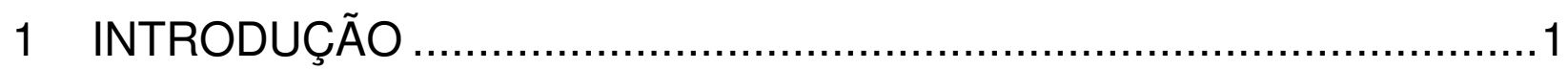

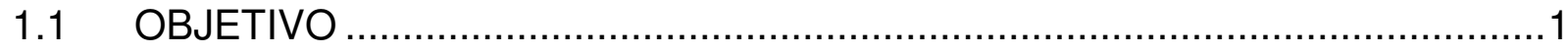

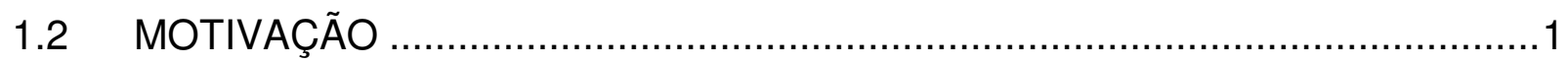

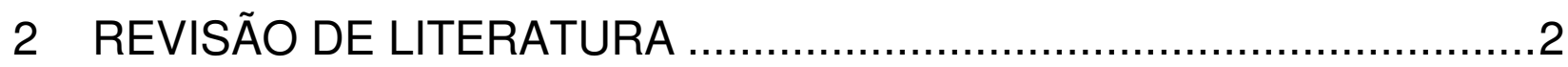

2.1 INTRODUÇÃO E CONCEITOS BÁSICOS EM OTIMIZAÇÃO .............................2

2.1.1 Otimização paramétrica ........................................................................

2.1.2 Otimização de forma.....................................................................

2.1.3 Otimização topológica......................................................................

2.2 PROBLEMAS E SOLUÇÕES RELACIONADOS AO USO DA OTIMIZAÇÃO

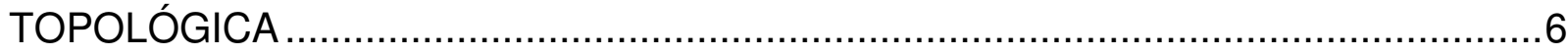

2.2.1 Dependência da qualidade da malha...................................................

2.2.2 Instabilidade do tabuleiro de xadrez - Checkerboad ....................................

2.2.3 Soluções dos problemas relativos ao uso de otimização topológica ..........9

2.3 MÉTODOS DE OTIMIZAÇÃO TOPOLÓGICA ………….............................11

2.3.1 Otimização estrutural evolucionária .......................................................12

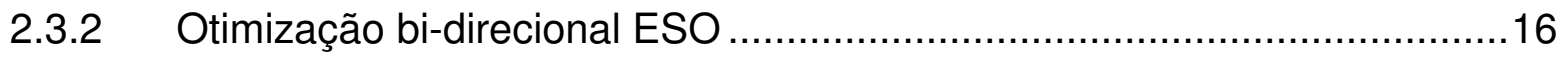

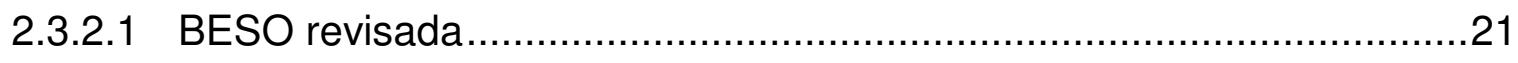

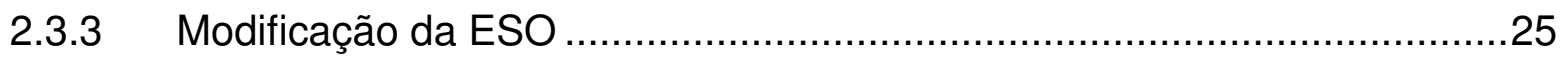

2.3.4 Características do programa PERMAS de otimização topológica .............27

2.4 ASPECTOS REFERENTES AOS PROCESSOS DE FABRICAÇÃO E

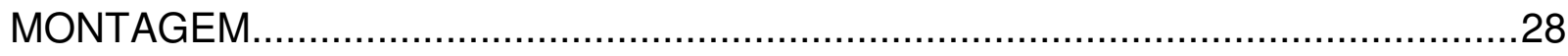

2.5 DISCUSSÕES REFERENTES À LITERATURA PESQUISADA......................32

3 SUPORTES EM CHASSIS AUTOMOTIVOS ........................................

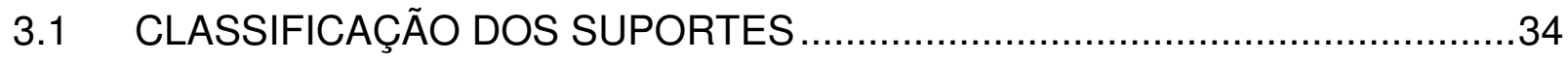

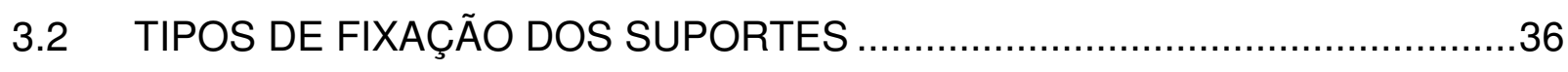

3.2.1 Problemas relacionados à aplicação das uniões .......................................37

3.3 EXEMPLOS DE APLICAÇÕES DE SUPORTES ……………….....................38 
3.4 UTILIZAÇÃO DE METODOLOGIAS DE OTIMIZAÇÃO ESTRUTURAL ...........41 4 PROCEDIMENTO DE DESENVOLVIMENTO DE SUPORTES..........45

4.1 ELABORAÇÃO DO CONCEITO DO SUPORTE PADRÃO ….........................47

4.2 PROCEDIMENTOS PARA A REALIZAÇÃO DA ANÁLISE MEF .....................49

4.2.1 Aplicabilidade de elementos de placa.................................................53

4.2.2 Procedimentos para a realização da análise de otimização paramétrica e

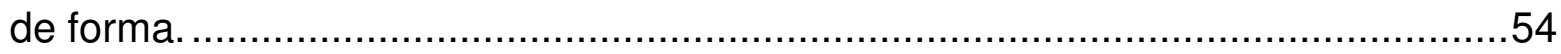

4.2.3 Procedimentos para a análise de otimização topológica ..........................55

4.2.4 Análise de estabilidade quanto à flambagem ........................................56

4.3 APLICAÇÃO DA ESPIRAL DE OTIMIZAÇÃO …....................................5

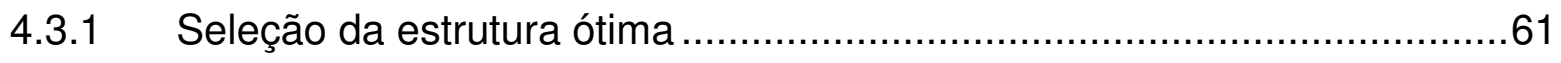

5 APLICAÇÃO DO PROCEDIMENTO DE DESENVOLVIMENTO DE SUPORTES NO ESTUDO DO SUPORTE DO AMORTECEDOR .............67

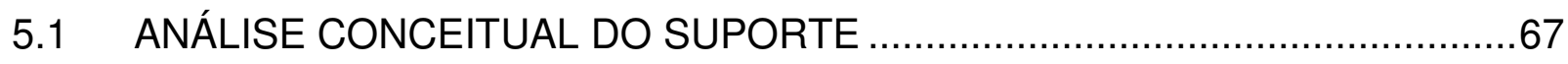

5.2 PROCEDIMENTOS PARA A REALIZACAO DA ANÁLISE MEF ....................70

5.2.1 Calibração do modelo de elementos finitos ........................................... 77

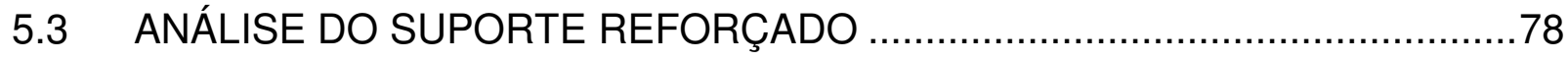

5.4 PROPOSTAS DE SUPORTES PADRÕES UTILIZANDO A METODOLOGIA

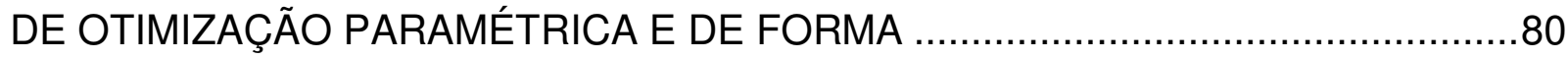

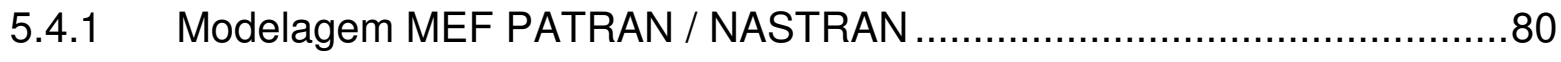

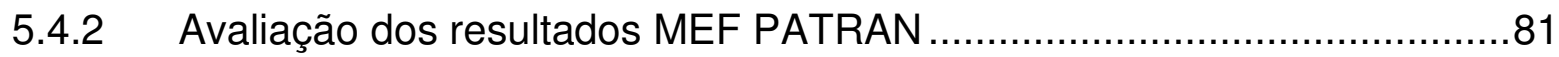

5.4.3 Análise de estabilidade quanto à flambagem ........................................

5.5 PROPOSTA DE SUPORTE PADRÃO UTILIZANDO A METODOLOGIA DE

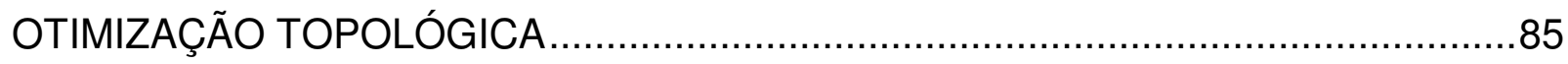

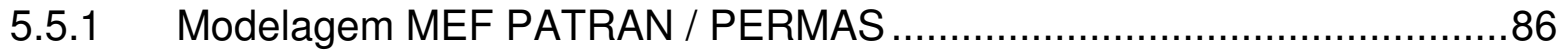

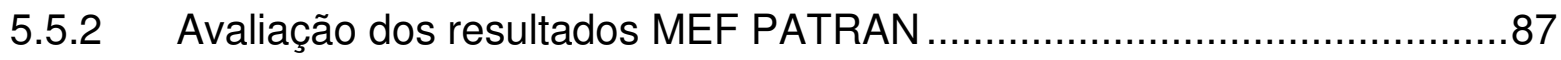

5.6 AVALIAÇÃO FINAL DAS PROPOSTAS ................................................90

6 CONCLUSÕES E TRABALHOS FUTUROS ….............................96

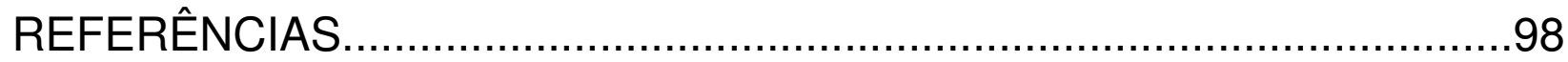




\section{INTRODUÇÃO}

\subsection{OBJETIVO}

O estudo tem como objetivo propor um procedimento a ser aplicado no dimensionamento otimizado de suportes estruturais com aplicação em veículos comerciais. Consiste na obtenção de um procedimento aplicado ao desenvolvimento de uma estrutura unificada otimizada, possibilitando o seu uso em diversas famílias de veículos, constituindo, portanto, um suporte padrão. Esse procedimento pode propiciar redução de custos, redução de peso e facilidade de fabricação e montagem. As propostas serão analisadas e selecionadas com a utilização de critérios de projeto para a fabricação e montagem.

\subsection{MOTIVAÇÃO}

No desenvolvimento de chassi nas empresas fabricantes de veículos automotores, diversos são os estudos e simulações realizadas despendendo recursos humanos e financeiros. Porém, em alguns casos negligencia-se um desenvolvimento mais detalhado de itens erroneamente considerados de menor importância, como no caso de suportes.

Os suportes são utilizados para o apoio de diversos itens no veículo, como reservatórios de ar, válvulas, tanques de combustível, baterias, amortecedores e chicotes elétricos. A falha de um suporte pode ocasionar problemas no funcionamento dos sistemas do veículo e na segurança, podendo acarretar prejuízos.

Para auxiliar o engenheiro de projetos no preenchimento dessa lacuna deixada no desenvolvimento de chassi foi idealizado este estudo, visando contribuir para o desenvolvimento do produto. 


\section{REVISÃO DE LITERATURA}

\subsection{INTRODUÇÃO E CONCEITOS BÁSICOS EM OTIMIZAÇÃO}

A otimização estrutural consiste basicamente na obtenção de uma solução que atenda a necessidades, restrições e carregamentos relativos ao projeto de forma ótima e sem desperdícios, podendo propiciar reduções de peso e custos do produto. Arora (2004) define a otimização estrutural com a seguinte frase: The best feasible design according to a preselected quantitative measure of effectiveness.

Os primeiros estudos relativos à otimização estrutural foram realizados por Michell (1904) e consistiam no dimensionamento estático de treliças sob condições específicas de contorno e carregamento. Esses estudos não tiveram aplicação prática na ocasião em decorrência da infinita gama de variações possíveis de comprimentos e seções transversais das vigas. Apresentavam-se viávies apenas para atividades de pesquisas em universidades devido aos complexos cálculos necessários.

Segundo Victoria; Martí e Querin (2009), a aplicação da otimização estrutural iniciou-se nos anos 60 com a introdução do ground structure approach desenvolvido por Dorn, Gomory e Greenberg (1964). A utilização da otimização estrutural está relacionada diretamente ao início da aplicação dos computadores.

As primeiras estruturas em que foram aplicadas as metodologias de otimização estrutural estavam vinculadas principalmente ao desenvolvimento aeronáutico e aeroespacial, no qual o principal objetivo era a redução de peso. A aplicação na iniciativa privada se difundiu após os anos 80 .

A utilização da otimização tem como o objetivo obter redução ou aumento do valor de variáveis, como aumento da rigidez estrutural e redução de peso. Além disso, 
pode propiciar redução de custos. No caso de estruturas veiculares, com a redução de peso, obtêm-se redução de consumo de combustível, aumento da capacidade de carga útil e melhora da competitividade da empresa no mercado.

Segundo Arora (2004), o processo de otimização possibilita que o engenheiro de projetos obtenha maior compreensão do problema, pois se torna necessária a identificação das variáveis de projeto da função a ser otimizada e das restrições do sistema. Isso leva à sistematização do processo de desenvolvimento, independentemente da experiência prévia do engenheiro projetista no desenvolvimento da estrutura em questão.

O método dos elementos finitos pode ser utilizado na otimização estrutural, no qual as estruturas contínuas são discretizadas em elementos finitos. A implementação dos métodos de otimização estrutural está vinculada à possibilidade de modificação da forma e das dimensões da estrutura. Caso existam regiões da estrutura em que não haja interesse de otimizar, podem-se aplicar restrições a elas.

De acordo com Haftka e Gürdal (1992), os métodos de otimização estrutural são subdivididos em três categorias conforme a natureza das variáveis envolvidas: otimização paramétrica, otimização de forma e otimização topológica. As principais características desses métodos são mencionadas a seguir, sendo apresentada com maior detalhe a metodologia de otimização topológica em razão de sua maior abrangência na obtenção de soluções otimizadas.

\subsubsection{Otimização paramétrica}

A otimização paramétrica consiste em uma das formas mais comuns de otimização na qual as variáveis de projeto (itens passíveis de alteração na estrutura, como espessuras e dimensões) são representadas pelas dimensões da secção transversal e do comprimento da peça. Os valores adotados para as variáveis 
necessariamente têm de ser maiores que zero, pois não existe a remoção de elementos, conforme demonstraram Haftka e Gürdal (1992).

Os resultados obtidos com o uso desse método são mais conservadores, uma vez que é mantido o formato original da estrutura. No exemplo da figura 2.1 as variáveis t1, t2 e t3 representam as espessuras do perfil: $h$ altura, b largura, $L$ comprimento e I o momento de inércia.

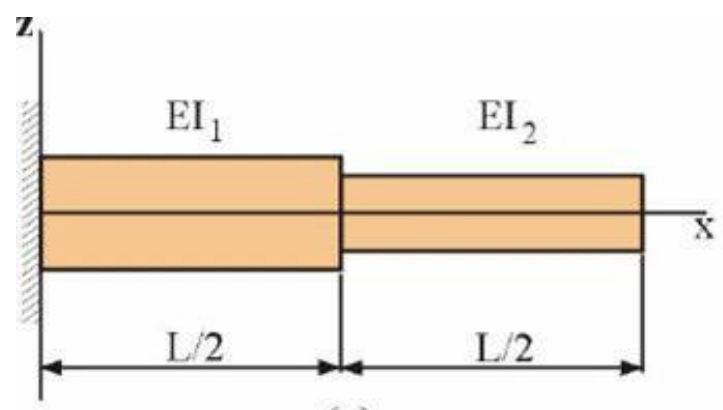

(a)

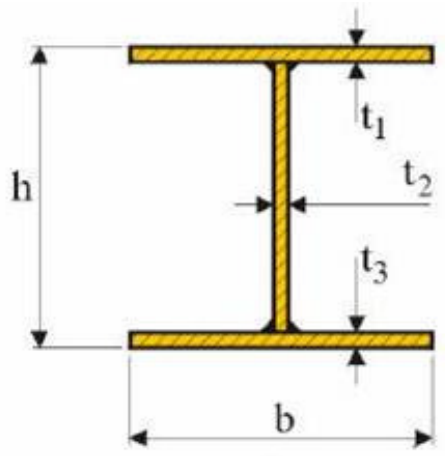

(b)

Figura 2.1 - Viga engastada, (a) Vista lateral e (b) Secção transversal (Haftka e Gurdal, 2002)

\subsubsection{Otimização de forma}

A solução otimizada depende da obtenção de novas formas da peça. Isso ocorre a partir da variação das coordenadas dos pontos pertencentes ao contorno. Segundo Haftka e Gürdal (1992), a otimização de forma tem como premissa a alteração da posição dos nós e a remoção de elementos no modelo de elementos finitos, conforme é indicado na figura 2.2.

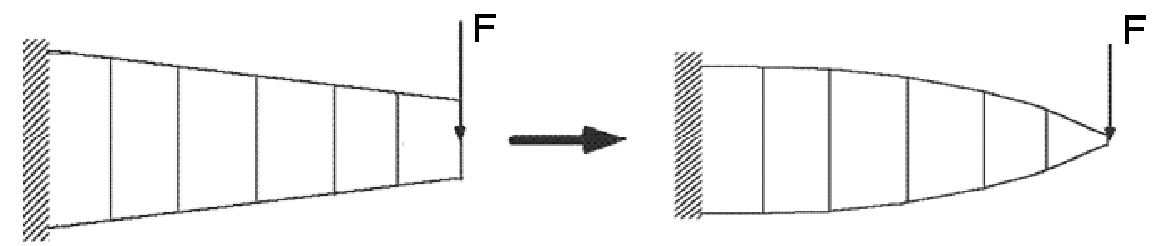

Figura 2.2 - Uso da otimização de forma (Haftka e Gurdal, 2002) 
O método pode encontrar a forma ótima de cavidades ou furos já existentes, porém, não consegue criar novas cavidades, limitando a utilização da solução.

\subsubsection{Otimização topológica}

O método de otimização topológica foi proposto inicialmente por Bendsøe e Kikuchi (1988) para a aplicação em otimização de estruturas contínuas. A partir de então, o método consolidou-se e está sendo utilizado em diversos problemas de otimização na área industrial e acadêmica, possibilitando aos engenheiros a obtenção da estruturas ótimas, segundo Huang e Xie (2008).

Esse método engloba as características das metodologias de otimização paramétrica e de forma, com a vantagem de possibilitar a criação de vazios (cavidades) no interior das estruturas. A modificação das variáveis de projeto na aplicação da otimização topológica resulta na alteração da forma e topologia das estruturas, conforme Huang e Xie (2008). A aplicação da otimização topológica permite que os engenheiros encontrem a melhor disposição da estrutura de acordo com os requisitos solicitados, como indica a figura 2.3.

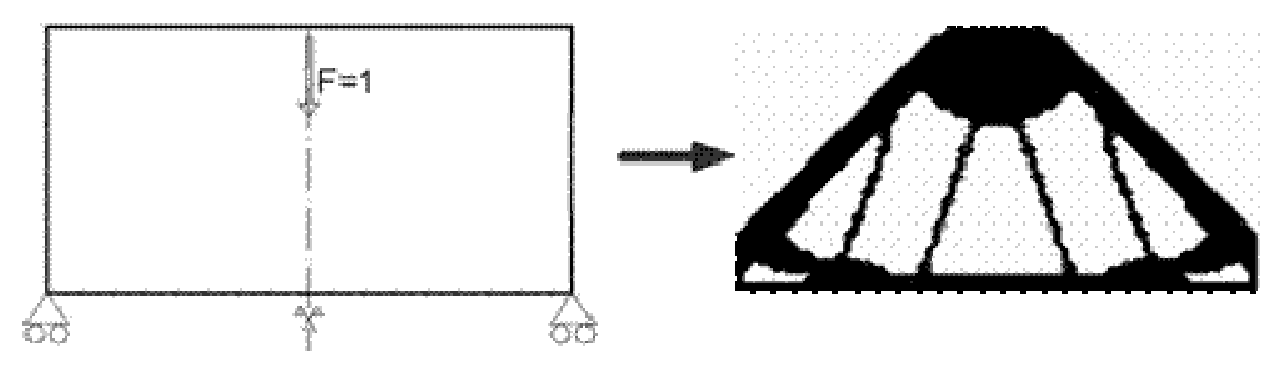

Figura 2.3 - Uso da otimização topológica (Bruggi, 2008)

O processo de otimização topológica é realizado por meio de interações. Após cada interação, é verificada se a taxa de redução foi atingida; caso contrário, realiza-se uma nova interação, até a obtenção da taxa preestabelecida de redução. Com o intuito 
de obter-se a forma ótima da estrutura, convém utilizar um algoritmo de otimização, tornando o processo de interações mais rápido.

Em decorrência dessas características e dos resultados favoráveis, a metodologia de otimização topológica torna-se bastante difundida nas aplicações de desenvolvimento nas indústrias aeronáuticas, aeroespaciais e de veículos.

\subsection{PROBLEMAS E SOLUÇÕES RELACIONADOS AO USO DA OTIMIZAÇÃO TOPOLÓGICA}

Há diversos problemas numéricos relacionados à aplicação da otimização topológica, sendo os mais comuns: dependência da qualidade da malha e checkerboard.

\subsubsection{Dependência da qualidade da malha}

A dependência da qualidade da malha resulta na obtenção de soluções qualitativas diferentes para o mesmo problema, devido a variações no tamanho da malha nas discretizações de elementos finitos, em vez de apenas melhorar os contornos da peça.

Sigmund e Petersson (1998) utilizam para exemplificar o problema de dependência da malha dois modelos MEF de uma viga bi-apoiada com a aplicação de uma carga vertical central descendente, de acordo com a figura 2.4 (a). Nesses modelos, varia-se a quantidade de elementos utilizada. Inicialmente é modelado com 600 elementos, conforme indica a figura 2.4 (b), e, em seguida, refina-se a malha para 
5400 elementos de acordo com a figura 2.4 (c), obtendo-se, dessa forma, resultados divergentes.

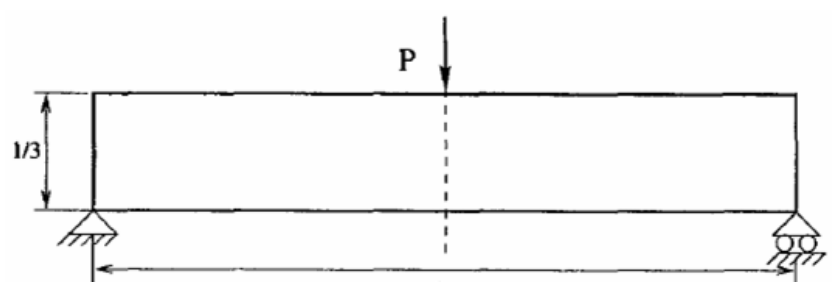

(a)

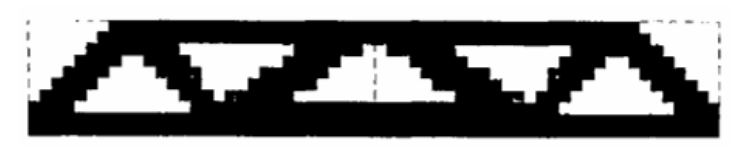

(b)

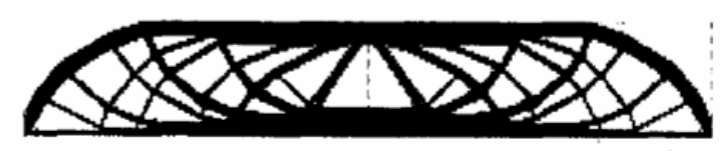

(c)

Figura 2.4 - (a) Domínio de projeto, (b) Malha com 600 elementos e (c) Malha com 5400 elementos (Sigmund e Petersson, 1998)

Os problemas de dependência de malha podem ser divididos em duas categorias. Conforme explicado anteriormente, uma delas está ligada ao refinamento da malha de elementos finitos, enquanto a outra se refere a um problema que não possui uma solução unificada, a exemplo da figura 2.5 na qual Sigmund e Petersson (1998) efetuam a aplicação de uma força de tração em apoios com rigidez infinita localizados nos extremos da barra, resultando em soluções indiferentes da distribuição de massa, o que pode ser solucionado com a aplicação de uma barra ou diversas barras paralelas. 


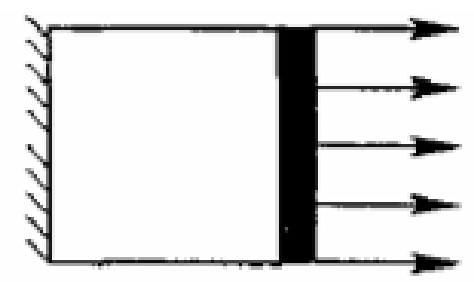

(a)

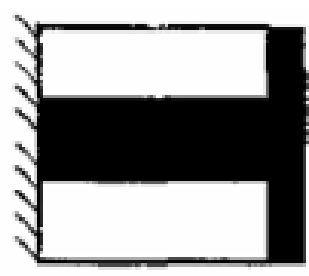

(b)

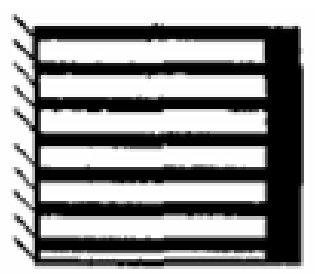

(c)

Figura 2.5 - (a) Domínio de projeto, (b) Solução com uma barra e (c) Solução com múltiplas barras paralelas (Sigmund e Petersson, 1998)

\subsubsection{Instabilidade do tabuleiro de xadrez - Checkerboad}

Os problemas relacionados à instabilidade do tabuleiro existem desde o início da aplicação da otimização topológica em razão das características relacionadas à discretização dos elementos finitos e não diretamente ligadas ao método de otimização topológica. Basicamente, o problema pode ser descrito como uma alternância entre regiões com material e regiões sem material, representadas pelo formato quadriculado preto (com material) e branco (sem material), resultando na aparência de um tabuleiro de xadrez segundo Sigmund e Petersson (1998).

De acordo com Díaz e Sigmund (1995), em decorrência das restrições impostas aos deslocamentos e das aproximações realizadas no cálculo de MEF, pode ocorrer aumento de rigidez em certos elementos causados pela indução numérica, ocasionando o aparecimento de problemas de instabilidade de tabuleiro na aplicação da solução de problemas de otimização topológica.

Bruggi (2008) relaciona o problema de instabilidade do tabuleiro aos tipos de elementos utilizados, os quais apresentam diferenças no valor de sua rigidez. Esse fenômeno ocorre principalmente em elementos quadriláteros com 4 nós e triangulares de 3 nós. Como exemplo, a figura 2.6 (a) representa a estrutura a ser otimizada, e a figura 2.6 (b) exemplifica o problema de instabilidade do tabuleiro ocorrido. Verifica-se a 
diferença na solução demonstrada na figura 2.7, na qual o resultado otimizado não apresenta problema de instabilidade de tabuleiro.

Uma estrutura obtida com o problema de tabuleiro promove a obtenção artificial de elevados valores de rigidez e torna impraticável a sua fabricação, constituindo-se um problema de otimização, conforme Diaz e Sigmund (1995).

Serão apresentadas a seguir algumas metodologias utilizadas na solução de problemas relacionados ao uso de otimização topológica.

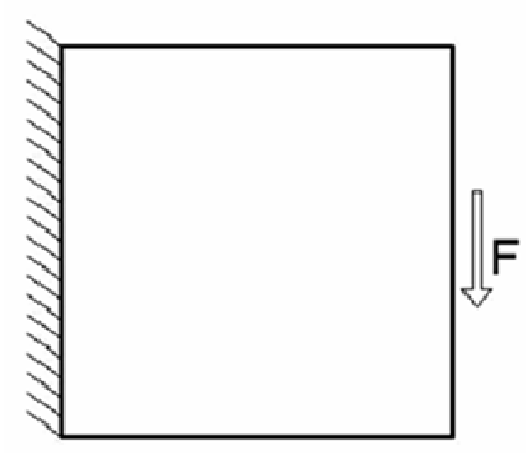

(a)

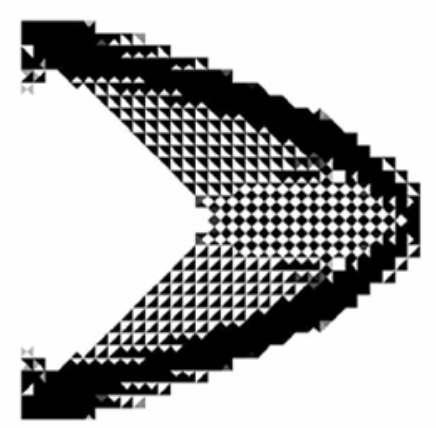

(b)

Figura 2.6 - (a) Domínio do projeto, (b) Otimização topológica com checkerboard (Bruggi, 2008)

2.2.3 Soluções dos problemas relativos ao uso de otimização topológica

As medidas que podem ser aplicadas para solucionar os problemas quanto ao uso dos métodos de otimização topológica, descritos anteriormente, servem de resolução para mais de um tipo de problema.

Verifica-se que a utilização de elementos finitos de ordem mais elevada, como, por exemplo, de quadriláteros de 8 ou 9 nós (elementos com menor rigidez), elimina a ocorrência do problema de instabilidade do tabuleiro de xadrez que ocorre, principalmente, em elementos de menor ordem, conforme descrito anteriormente. Esse 
artifício demanda maior capacidade computacional, sendo que, em casos complexos, pode tornar-se inviável, de acordo com Bruggi (2008).

Diversos são os estudos que tratam da solução do problema do tabuleiro de xadrez, como refinamentos da malha de elementos finitos e imposição de restrições adicionais, de acordo com Poulsen (2002). Bruggi (2008) propõem o uso de formulações baseadas no princípio variacional de Hellinger-Reissner e da formulação clássica dos problemas de otimização topológica.

Os métodos de relaxamento e métodos de restrição, como perímetro de controle utilizado primeiro por Ambrosio e Buttazzo (1993) e Haber, Jog e Bendsøe (1996), restrição local por Niordson (1983), restrição global de gradiente por Bendsøe (1995) e filtros por Sigmund $(1994,1997)$, foram desenvolvidos para resolver os problemas de dependência da malha. Segundo Sigmund e Petersson (1998), esses métodos também reduziram os problemas de instabilidade do tabuleiro.

A aplicação do método de relaxamento na otimização topológica resulta no aumento da dificuldade de fabricação. Os resultados obtidos com o uso dos métodos do perímetro, do gradiente local e dos filtros são similares, com pequenas variações. $O$ método do perímetro de controle restringe de forma global, permitindo a formação local de barras finas, enquanto o método do gradiente local e o dos filtros restringem de forma localizada, removendo as barras finas. A utilização de filtros representa uma melhor opção em relação ao tempo computacional, de acordo com Sigmund e Petersson (1998).

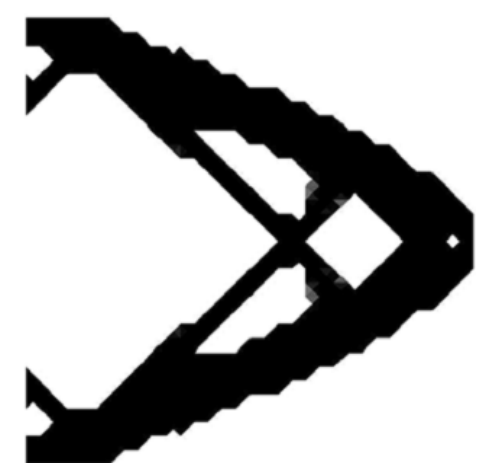

Figura 2.7 - Peça isenta da ocorrência do problema do tabuleiro de xadrez (Bruggi, 2008) 


\subsection{MÉTODOS DE OTIMIZAÇÃO TOPOLÓGICA}

Ao longo dos anos, diversos métodos foram propostos visando à obtenção da máxima rigidez e mínimo peso. Essas características são obtidas pela aplicação da otimização topológica, que alia, conforme já descrito, o ganho obtido da otimização de espessura e otimização de forma com a vantagem de proporcionar a criação de vazios no interior das estruturas.

Conforme descritos anteriormente, os estudos iniciais relacionados à otimização topológica foram introduzidos por Michell (1904) com suas análises sobre treliças, tornando-se um estudo acadêmico sem aplicação prática na época. Os estudos relacionados à otimização topológica só foram retomados a partir dos anos 60 .

Diversas metodologias (Ground structure approach, FSD, homogeneização, otimização evolucionária, uso de algoritmos genéticos, SKO, ESO, variações da ESO etc.) foram desenvolvidas ao longo dos anos, conforme citadas no estudo de Tanskanen (2006).

Essas metodologias são utilizadas para a solução de problemas específicos, sendo, em alguns casos, adaptadas para o uso. A aplicação de uma ou outra metodologia está aliada à disponibilidade de equipamentos, programas, pessoal treinado e recursos financeiros.

Segundo Khalaf e Saka (2007), alguns algoritmos baseados em programação matemática e em técnicas do critério ótimo deixaram de ser utilizados, pois consideravam as variáveis do projeto contínuas em vez de discretas, como é usual nas aplicações industriais. 


\subsubsection{Otimização estrutural evolucionária}

A aplicação do método de otimização topológica ESO (Evolucionary Structural Optmization), proposto por Xie e Steven (1993), tem como objetivo a obtenção de tensões uniformes ao longo de toda a estrutura, que passará a apresentar formas ótimas e sem excesso de material com a retirada de material ineficiente em um processo interativo.

Khalaf e Saka (2007) propuseram o uso da metodologia ESO para determinar o formato ótimo de placas de reforço sujeitas a um carregamento de tração. As placas são fixadas com parafusos e porcas na estrutura, conforme exposto na figura 2.8. Foram analisados taxa de remoção, tamanho da malha e criação de vazios.

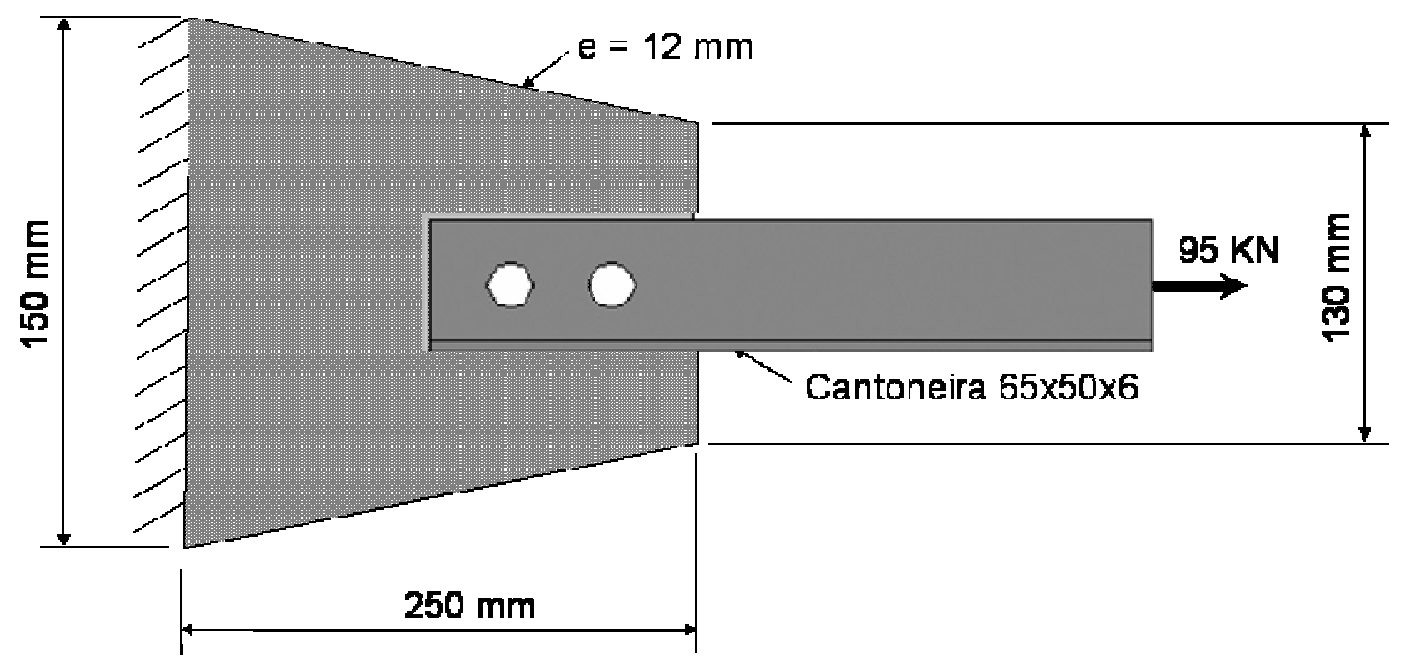

Figura 2.8 - Domínio de projeto, placa de reforço (Khalaf e Saka, 2007)

A utilização da metodologia ESO está vinculada à maior facilidade da aplicação do algoritmo, sem depender de complexos cálculos matemáticos. Os procedimentos utilizados na análise da metodologia ESO seguem basicamente os seguintes passos:

- Discretização da estrutura contínua com elementos finitos.

- Definição das condições de contorno e carregamentos. 
- Cálculo de elementos finitos.

- Eliminação dos elementos com baixa densidade de tensão.

- Repetição do ciclo de cálculo e retirada de elementos até a obtenção dos valores de redução preestabelecidos.

A seguir, são apresentadas as formulações utilizadas no estudo de Abolbashari e Keshavarsmanesh (2006). O algoritmo ESO realiza a comparação das tensões de cada elemento $\sigma e l$ com o valor máximo de tensão atuante $\sigma$ max da estrutura com o critério de Von Mises, no qual os elementos que satisfazem a relação da eq.(1) são eliminados.

$$
\frac{\sigma_{e l}}{\sigma_{\max }} \leq R R_{i}
$$

$\mathrm{Na}$ expressão, $R R_{\mathrm{i}}$ representa a taxa de remoção de material. Quando não for mais possível realizar as remoções de elementos redundantes do domínio de projeto com a taxa corrente de RRi, será acrescida na expressão a taxa evolucionária ER. Nela, "i" representa o número de interações. Esse processo terá o número de interações necessárias quando obtiver o volume de redução de material ou atingir a taxa de remoção predeterminada $R R_{i+1}=R R_{i}+E R_{i}$.

O domínio de projeto indicado na figura 2.8 é discretizado com malha quadrilátera de 4 nós, conforme ilustra a figura 2.9 (a). É característico da metodologia ESO apenas possibilitar a retirada de elementos. O modelo MEF discretizado possui, portanto, dimensões maiores que a do domínio de projeto. Esse modelo é constituído de uma chapa retangular de $250 \times 150 \mathrm{~mm}$. Com o objetivo de obter novas formas, inicialmente, utilizou-se $\mathrm{RR}=0 \%, \mathrm{ER}=0,1 \%$ até atingir os valores preestabelecidos de $R R=90 \%$ e $E R=15 \%$. 


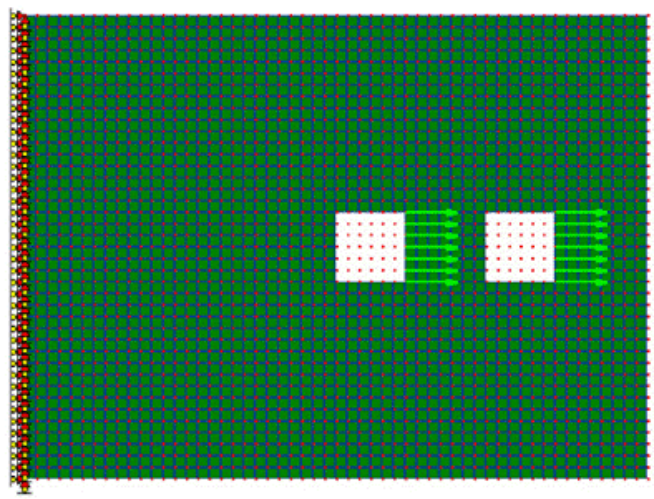

(a)
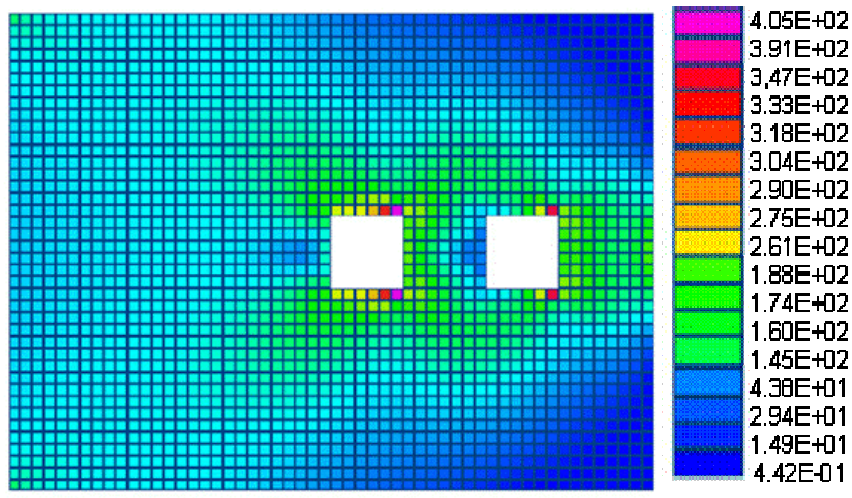

(b)

Figura 2.9 - (a) Domínio discretizado e (b) Distribuição de tensão (Khalaf e Saka, 2007)

A aplicação dos parâmetros RR e ER, conforme proposto, resultaram, no caso apresentado, aumento de tensão da ordem de $11 \%$ e redução de volume em torno de $32 \%$. No estudo, obteve-se uma maior taxa de remoção de material com a utilização de uma malha mais refinada, como indica a tabela 2.1.

Tabela 2.1 - Comparação de resultados com diferentes densidades de malha (Khalaf e Saka, 2007)

\begin{tabular}{ccc}
\hline Densidade da malha & $\begin{array}{c}\text { Aumento de tensão } \\
\text { máxima atuante } \%\end{array}$ & $\begin{array}{c}\text { Redução de volume } \\
\%\end{array}$ \\
\hline $40 \times 25$ & 8,7 & 25 \\
$88 \times 55$ & 17,65 & 43 \\
\hline
\end{tabular}

A solução ilustrada na figura 2.10 apresenta problemas relacionados ao aumento do tempo computacional em decorrência do refinamento da malha. 


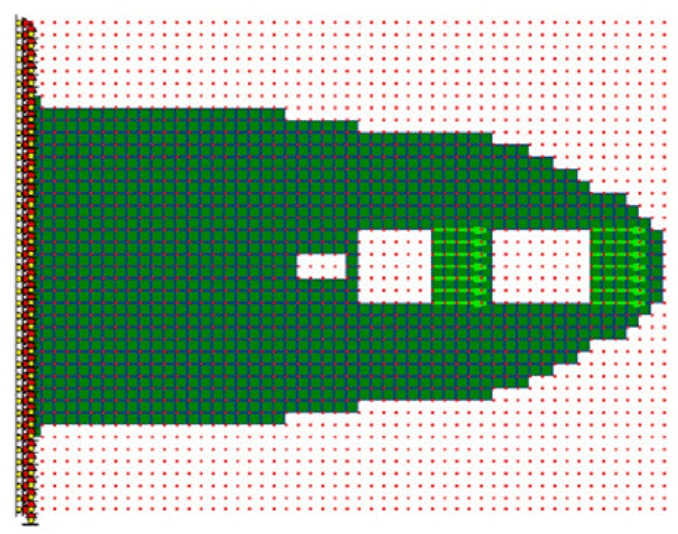

Figura 2.10 - Solução otimizada (Khalaf e Saka, 2007)

No estudo realizado por Abolbashari e Keshavarsmanesh (2006), utilizou-se o programa ANSYS para o cálculo MEF em conjunto ao algoritmo ESO escrito no programa MATLAB. São realizados ensaios 2D e 3D. Para o ensaio em duas dimensões, são simuladas placas com diferentes engastamentos.

Observa-se, também, que a redução no tamanho da malha traz vantagens na redução de volume retirado, porém, contrário ao estudo de Khalaf e Saka (2007), obteve-se redução no valor de tensão máxima. Deve-se avaliar o ganho que pode ser obtido em detrimento ao aumento do tempo computacional.

Abolbashari e Keshavarsmanesh (2006) propõem um estudo tridimensional com a utilização de um cubo com carregamento central na face superior, variando-se os tipos de engastamento e sendo discretizado com malha sólida hexaédrica de 8 nós. Iniciou-se a interação com uma taxa $\mathrm{RRi}=1 \%$ e $E R=5 \%$. Durante as interações necessárias à obtenção da estrutura otimizada, verificou-se que os valores de tensão mínimos aumentaram enquanto os valores das tensões máximas diminuíram, tornandose quase constante ao atingir a taxa de $\mathrm{RR} i=20 \%$.

Nota-se, conforme salientado no estudo de Abolbashari e Keshavarsmanesh (2006), que alterações de valor da taxa de remoção de elementos $R R$ e da taxa 
evolucionária ER apresentam maior importância na obtenção de estruturas $2 \mathrm{~d}$. No entanto, a otimização topológica é mais sensível à variação da taxa ER.

Vale ressaltar que o tamanho da malha apresenta grande influência nos resultados obtidos. Verificam-se, nos exemplos apresentados, valores significantes de redução de peso, porém, com aumento mínimo nos valores máximos de tensão de Von Mises. Uma das grandes características do algoritmo ESO, segundo Abolbashari e Keshavarsmanesh (2006), é a facilidade de ser aplicado a qualquer programa MEF.

\subsubsection{Otimização bi-direcional ESO}

A aplicação da metodologia bi-direcional ESO tem como principal característica a inserção e retirada de material conforme a necessidade. Na metodologia ESO, eliminam-se os elementos com baixos níveis de tensão, porém sem a capacidade de adicionar material, tornando-se necessário o desenvolvimento da metodologia BESO.

O uso da metodologia BESO segue basicamente os mesmos passos já apresentados para o uso da metodologia ESO, porém, após o cálculo de elementos finitos, realiza-se o cálculo do número de sensibilidade de todos os elementos. Em seguida, procede-se a eliminação ou adição de elementos, repetindo-se os passos anteriormente citados até a obtenção da redução de peso descrita.

No estudo de Yang, Xie e Steve (2005) sobre estruturas em arco bidimensionais e tridimensionais e a análise tridimensional de cubos, são comparadas as soluções topológicas obtidas com os métodos ESO e BESO. Os estudos de Fuchs e Moses (2000) e Hammer e Olhof (2000) são referências no uso da metodologia ESO e BESO, porque apresentam a generalidade do método para diferentes aplicações e a facilidade de uso. 
Para a realização dos estudos bidimensionais, o domínio de projeto é representado por uma área retangular de $5 \times 2,5 \mathrm{~m}$ com uma malha de 50×25 elementos quadriláteros de 4 nós, com uma taxa de redução de peso de $20 \%$. No caso de condições de carga fixa, o carregamento vertical é localizado no primeiro caso na região superior e, no segundo, na inferior, resultando nas estruturas indicadas na figura 2.11 .

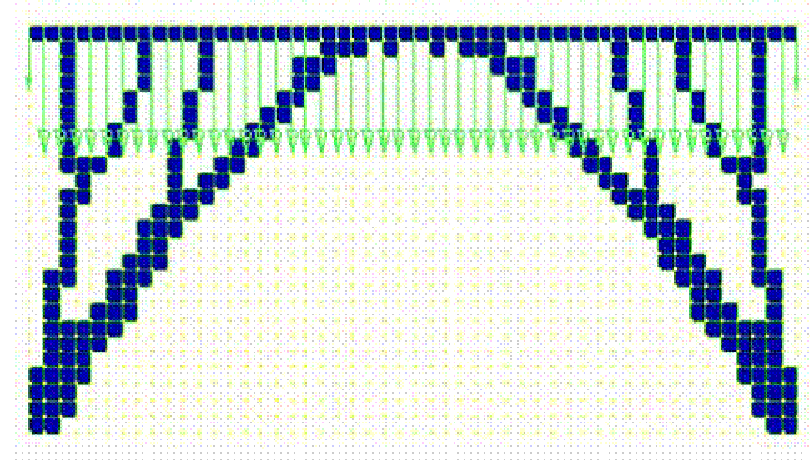

(a)

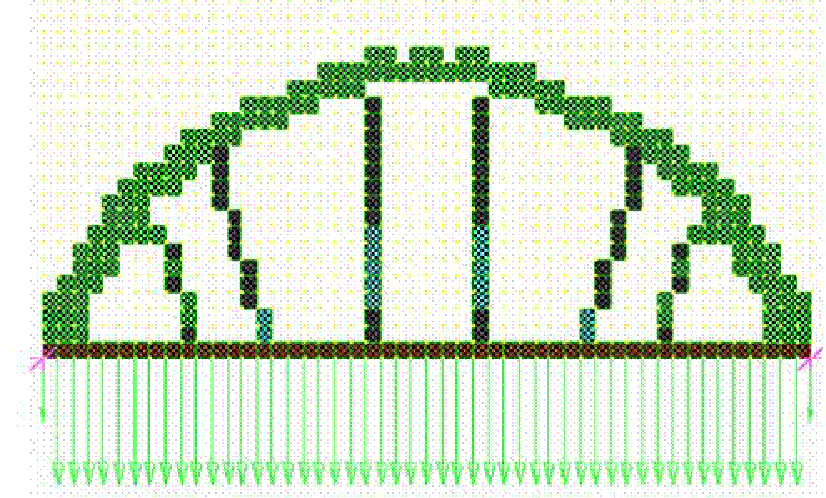

(b)

Figura 2.11 - Solução otimizada ESO - carga fixa, (a) Carregamento superior, (b) Carregamento inferior (Yang, Xie e Steve, 2005)

A análise do caso de carregamentos transmissíveis é realizada sobre o domínio de projeto já apresentado, porém, com a utilização de ambas as metodologias ESO e BESO, obtendo-se as estruturas ótimas indicadas na figura 2.12 e na figura 2.13. A taxa $H / L$ das soluções ESO e BESO é similar. Nos casos de cargas transmissíveis, verifica-se a tendência obtida no valor de energia de tensão do elemento: $C=13,82 \mathrm{Nm}$ (ESO) e $C=13,97 \mathrm{Nm}$ (BESO), que é menor que o do caso cargas fixas $C=45,06 \mathrm{Nm}$ (carregamento superior) e $\mathrm{C}=51,79 \mathrm{Nm}$ (carregamento inferior). 


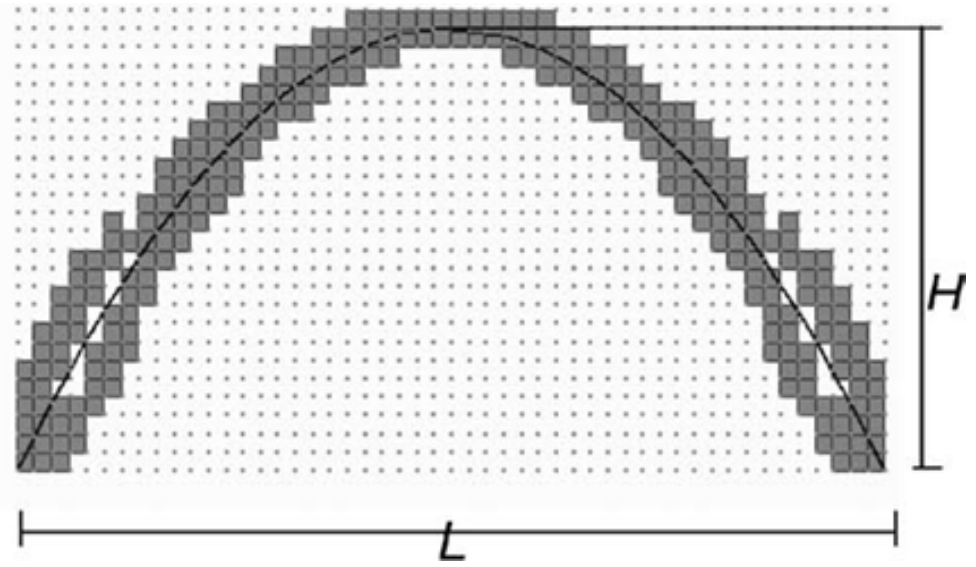

Figura 2.12 - Solução otimizada ESO - cargas transmissíveis (Yang, Xie e Steve, 2005)

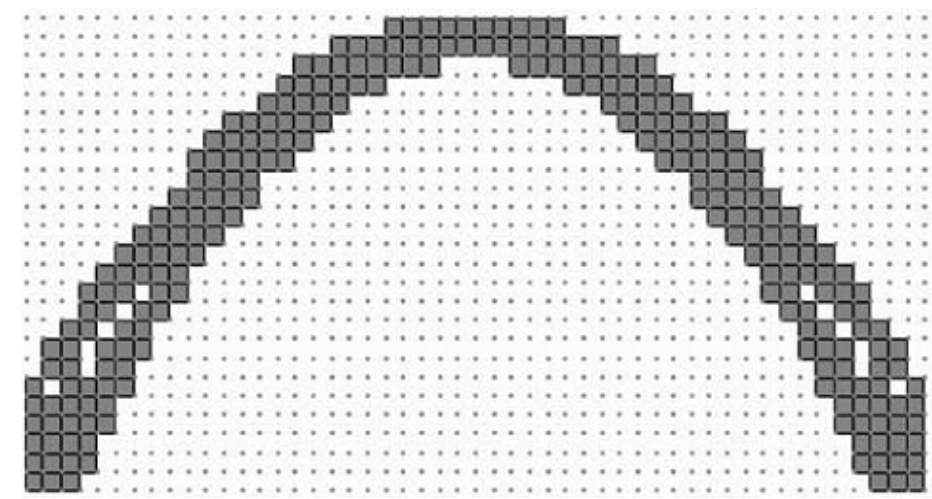

Figura 2.13 - Solução otimizada BESO - cargas transmissíveis (Yang, Xie e Steve, 2005)

No estudo, são propostos diferentes critérios de análises, como os da tensão e da rigidez. Nota-se que a redução de massa no caso calculado com o critério de tensão é maior que o valor obtido a partir do critério de máxima rigidez. O critério de tensão apresenta melhor distribuição de tensão com a redução da tensão máxima atuante, conforme indicado na figura 2.14 (b). 


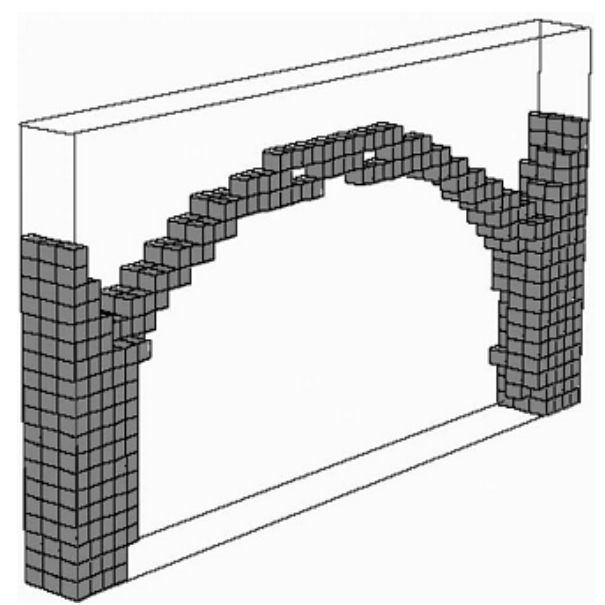

(a)

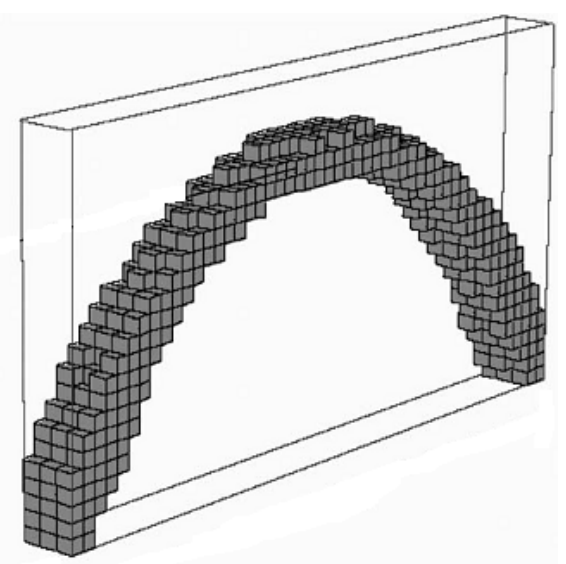

(b)

Figura 2.14 - Solução otimizada, (a) Critério de rigidez (b) Critério de tensão (Yang, Xie e Steve, 2005)

Outra análise realizada foi o da estrutura de uma ponte. Em decorrência de sua simetria, foi feita a simulação de apenas $1 / 4$ da estrutura, reduzindo-se 0 tempo de processamento computacional na mesma proporção. A estrutura apresentada na figura 2.15 é apoiada nas extremidades e está sujeita a carregamentos verticais em sua base e ao peso próprio. Na figura 2.16, obtém-se o valor $\mathrm{C}=0,575 \mathrm{Nm}$.

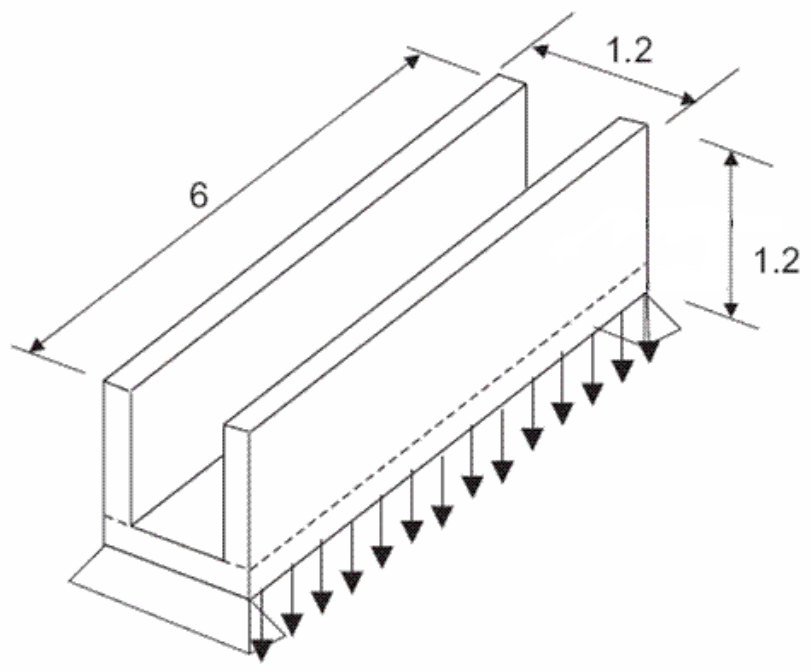

Figura 2.15 - Domínio de projeto (Yang, Xie e Steve, 2005) 


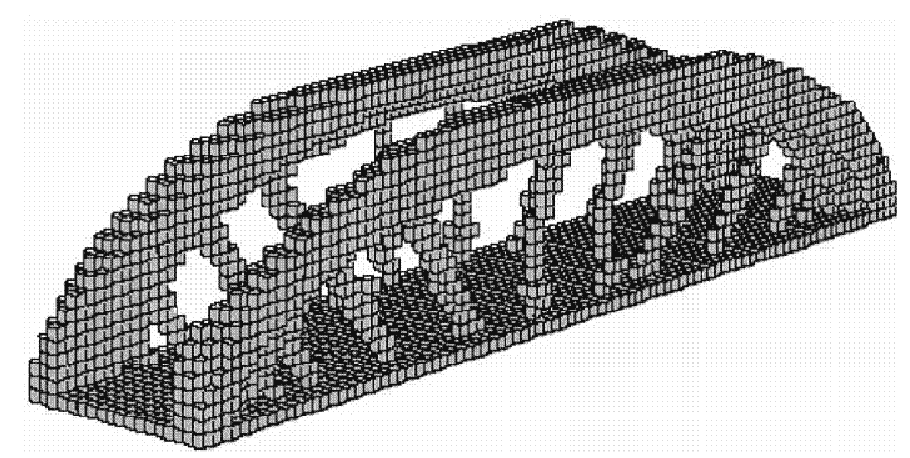

Figura 2.16 - Otimização topológica (Yang, Xie e Steve, 2005)

A análise do cubo sujeito a uma carga distribuída no topo e engastado nos quatro cantos da base é tratada inicialmente como caso de carregamento transmissível. Devido à demanda de um tempo computacional elevado para resolver as equações de restrição, o problema é reformulado com condições de carregamento de superfície. Realizam-se as análises ESO e BESO do cubo ilustrado na figura 2.17 e obtêm-se resultados similares, porém, a metodologia BESO apresenta menor tempo computacional, tornando-se viável sua utilização.

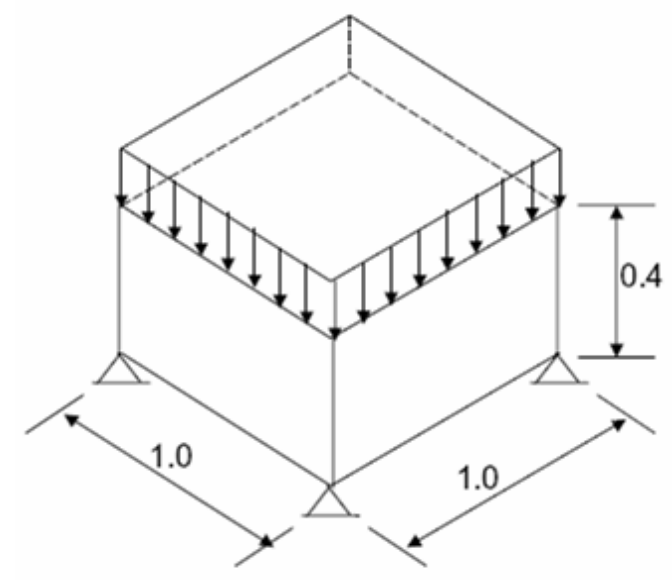

(a)

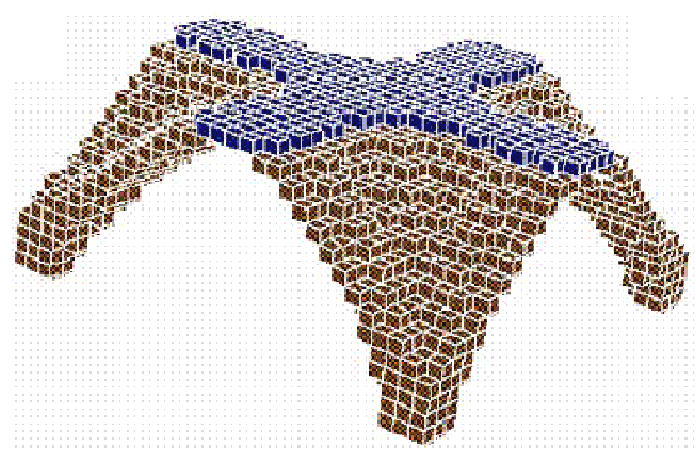

(b)

Figura 2.17 - (a) Domínio de projeto, (b) Otimização topológica BESO (Yang, Xie e Steve, 2005) 


\subsubsection{BESO revisada}

A metodologia BESO refere-se a soluções não convergentes e com dependência da qualidade da malha. A revisão do método tem como premissa tornar as soluções convergentes e independentes da qualidade da malha, tornando-o um método mais robusto. O refinamento do método envolve a utilização de filtros, a melhora da análise de sensibilidade e a aplicação de um novo algoritmo de adição e remoção de material.

Com o intuito de obter uma estrutura ótima, é realizada na pesquisa de Huang e Xie (2008) uma revisão da metodologia de otimização topológica de estruturas BESO, comparando os resultados de soluções lineares e não-lineares.

As análises lineares são normalmente utilizadas no dimensionamento de estruturas sujeitas a pequenos deslocamentos, trabalhando no regime elástico do material. Porém, a análise não-linear é utilizada nos deslocamentos maiores, trabalhando no regime elasto-plástico.

O número de sensibilidade referente à adição de material não é obtido diretamente dos resultados do MEF, mas sim dependente do uso de algoritmos como: extrapolação linear do campo de deslocamentos proposto por Yang et al. $(1999,2003)$ e adição de elementos sobre região com tensões elevadas (Querim et al., 2000). Observa-se a ocorrência de problemas relacionados à dependência da malha no uso desses algoritmos sem a aplicação de controle de perímetro.

Huang e Xie (2008) utilizaram em seu estudo um filtro independente da qualidade da malha com o objetivo de validar o número de sensibilidade do elemento candidato a ser adicionado à estrutura. Esse filtro poderia ser substituído por um filtro aplicado para a eliminação dos problemas referentes à instabilidade do tabuleiro. 
A expressão do número de sensibilidade do elemento i, definido por Huang e Xie (2008) é dada pela eq.(2).

$$
\alpha_{i}=\frac{\sum_{j=1}^{N} \omega\left(r_{i j}\right) \alpha_{i}}{\sum_{j=1}^{N} \omega\left(r_{i j}\right)}
$$

Onde $N$ é o número total de elementos da malha e $\omega\left(r_{i j}\right)$ é o fator de peso dado pela eq. (3).

$$
\begin{gathered}
\omega\left(r_{i j}\right)=\frac{\exp \left(-\left(r_{i j}^{2} / 2\left(\frac{r}{3}\right)^{2}\right)\right)}{2 \pi\left(\frac{r}{3}\right)} \\
\left\{i \in N \mid r_{i j} \leq r\right\}, j=1,2,3, \ldots . ., N
\end{gathered}
$$

Onde $r_{i j}$ é definido como a distância dos centros dos elementos $i \mathrm{e}_{j}, r$ é o raio do filtro especificado pelo usuário, conforme eq.(4). A aplicação do filtro serve para evitar problemas de instabilidade do tabuleiro de xadrez e dependência de malha.

O estudo proposto por Huang e Xie (2008) é realizado em uma viga bi-apoiada de $400 \mathrm{~mm}$ de comprimento e $100 \mathrm{~mm}$ de altura, sujeita a um pequeno deslocamento central de $5 \mathrm{~mm}$. São realizadas duas simulações, uma com análise linear e outra com a análise não-linear. Com o intuito de obter uma redução do tempo computacional, aplica-se um valor inicial de redução de $30 \%$ de material na metodologia BESO. Portanto, apenas $30 \%$ dos elementos do domínio de projeto estão envolvidos em cada ciclo.

Obtêm-se resultados conhecidos e convergentes após 120 interações na pesquisa de Huang e Xie (2008), podendo ser repetidos com o uso de outros métodos matemáticos de otimização topológica. Verifica-se que os resultados obtidos com a análise linear e não-linear são similares, conforme mostra a figura 2.18. 


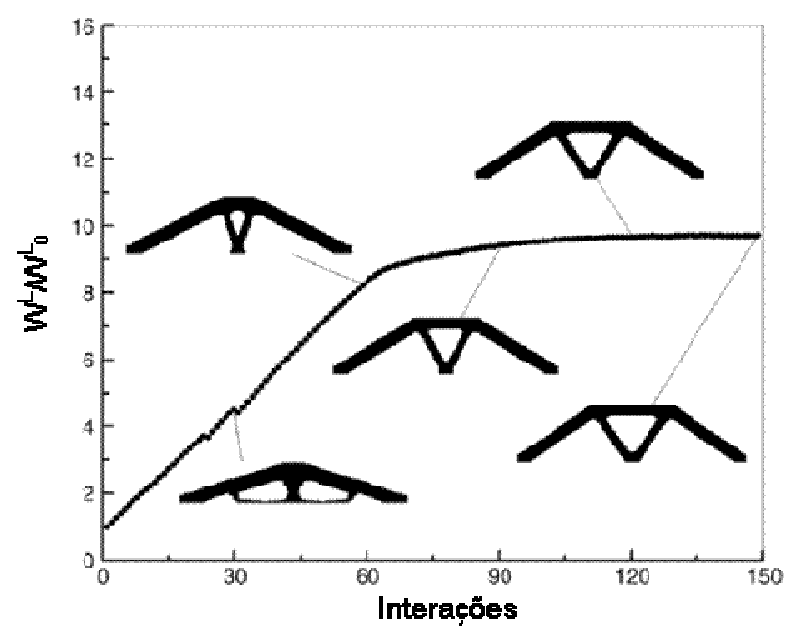

(a)

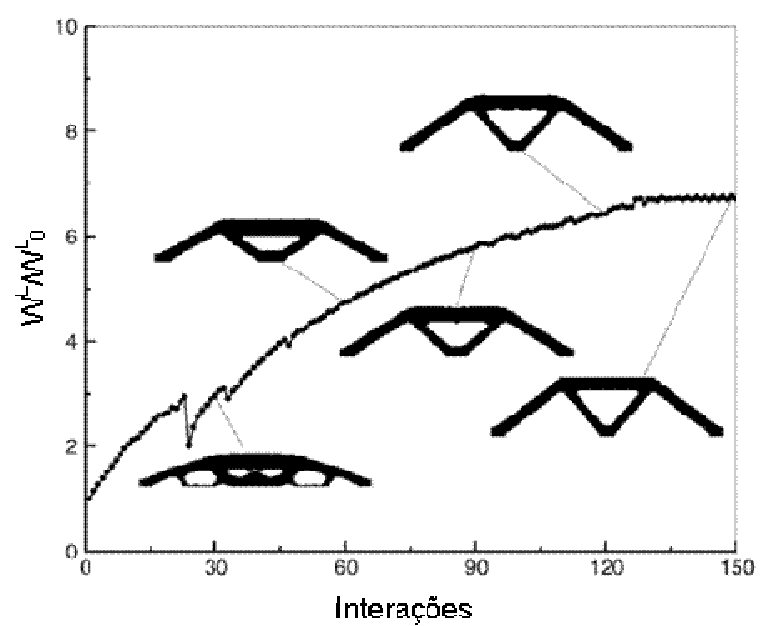

(b)

Figura 2.18 - Otimização topológica para pequenos deslocamentos: (a) linear, (b) não-linear (Huang e Xie, 2008)

São realizadas as mesmas análises do caso acima, porém com aplicação de grandes deslocamentos 20,50 e $100 \mathrm{~mm}$. Nota-se nestes casos que as geometrias apresentam secção transversal variável para resistir aos esforços atuantes. Conforme abaixo na figura 2.19.
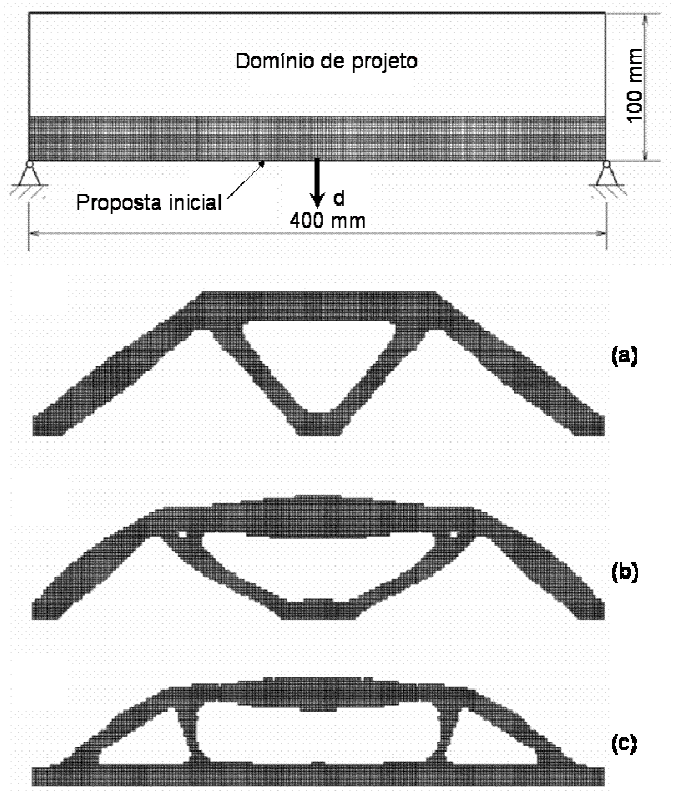

Figura 2.19 - Otimização topológica não-linear para grandes deslocamentos:

(a) $d=20 \mathrm{~mm}$, (b) $d=50 \mathrm{~mm} \mathrm{e} \mathrm{(c)} d=100 \mathrm{~mm}$ (Huang e Xie, 2008) 
Huang e Xie (2008) realizaram também a simulação de uma estrutura em três dimensões conforme mostra a figura 2.20 (a), a qual consiste basicamente em uma viga com uma extremidade engastada e a outra em balanço. Um deslocamento de $50 \mathrm{~mm}$ é aplicado ao lado livre da viga, cujo objetivo é a redução de $20 \%$ de volume de material.

O ensaio resulta na obtenção de formas ótimas apresentadas na figura 2.20 (b) e (c). Após 40 interações realizadas em 74,3 min, obtém-se a solução linear. A solução não-linear é obtida após 29 interações e 107,3 min de trabalho computacional. Verificase o maior consumo de tempo computacional utilizado para a análise não-linear, o que demonstra a necessidade de melhora na eficiência do método.
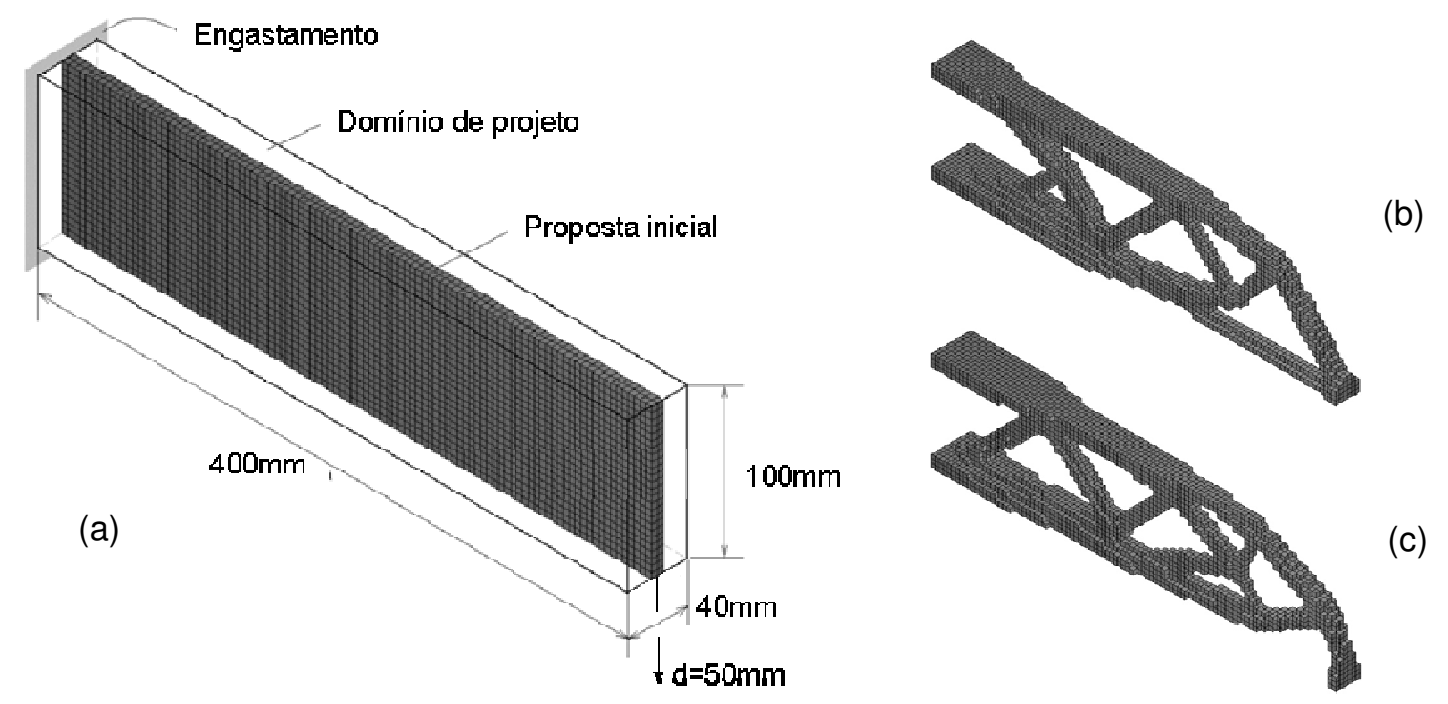

Figura 2.20 - (a) Domínio do projeto, (b) Otimização topológica linear e (c) Otimização topológica não-linear (Huang e Xie, 2008)

Realiza-se a comparação entre as duas soluções e nota-se que a análise linear é ligeiramente melhor que a não-linear para pequenos deslocamentos, porém, para deslocamentos maiores, a análise não-linear possui uma solução muito superior à linear, conforme indica o gráfico 1. Verifica-se, de acordo com Huang e Xie (2008), a possibilidade de aplicação prática da pesquisa no desenvolvimento de estruturas utilizadas para a absorção de energia. 


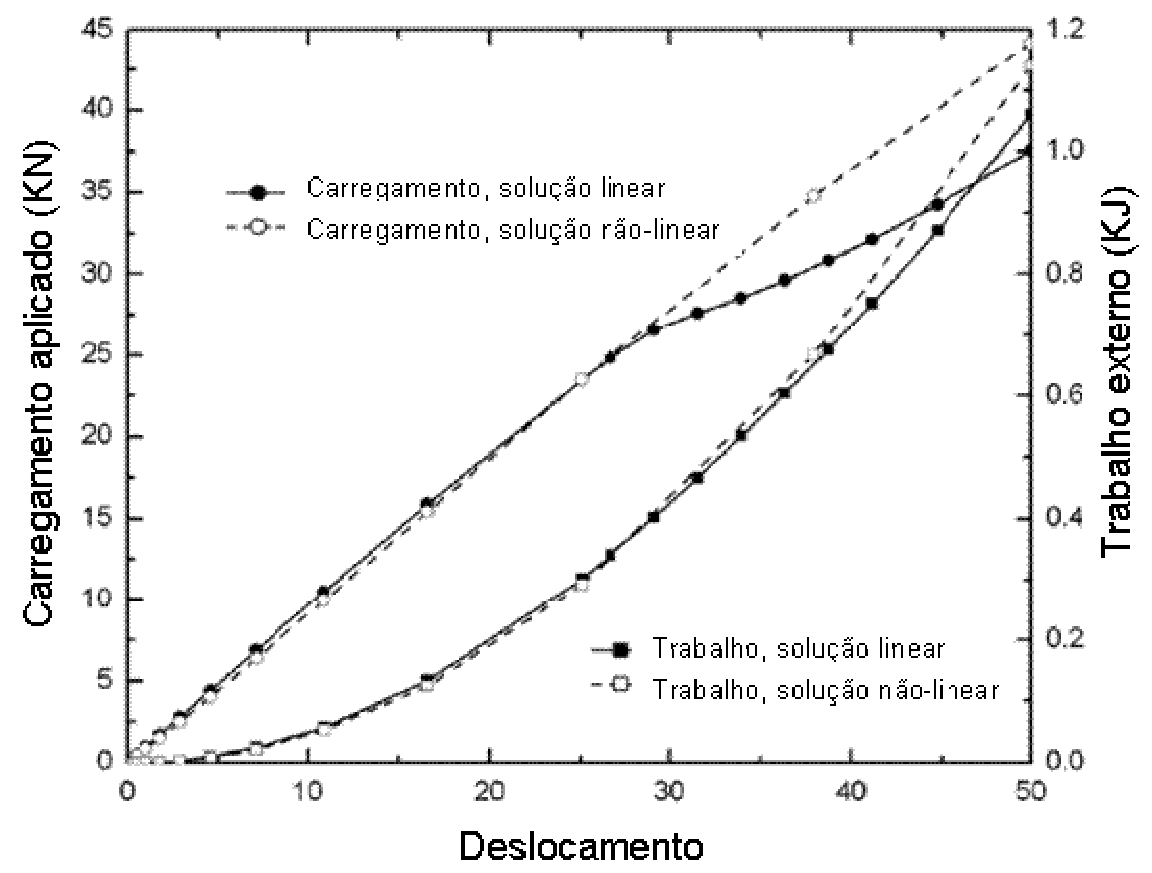

Gráfico 1 - Comparação entre otimização topológica linear e não-linear (Huang e Xie, 2008)

\subsubsection{Modificação da ESO}

A metodologia ESO está ligada à sua facilidade de aplicação com programas MEF e baixo consumo computacional, porém apresenta problemas referentes à convergência e à adição de restrições. Com o objetivo de refinar o método, Tanskanen (2006) propôs a modificação da metodologia ESO. O estudo desse autor inicia-se com uma breve revisão sobre os principais métodos de otimização topológica, nos quais a aplicação da metodologia ESO pode ter resultados próximos aos obtidos com métodos analíticos, como o do estudo de treliças proposto por Michell (1904).

Para a aplicação da MESO, é proposta a divisão em dois estágios de análise: no primeiro, determina-se a forma geral da geometria; no segundo, analisam-se as tensões e restrições para obter a geometria otimizada. As variáveis de projeto principais são congeladas durante a análise MESO. 
Tanskanen (2006) compara os resultados obtidos na análise ESO e MESO da treliça da figura 2.21 (a). Utiliza-se o programa ANSYS para a análise MEF dos problemas de minimização de peso de estruturas.

A metodologia ESO é utilizada com êxito na solução do primeiro estágio de otimização. Entretanto, se não forem consideradas algumas restrições contidas no projeto, a metodologia ESO pode falhar no segundo estágio de otimização topológica.

Houve diferenças nos resultados obtidos após o primeiro estágio de análise conforme se verifica na figura 2.21 (b) e (c). A solução obtida por meio da metodologia ESO apresenta-se mais rígida e pesada que a solução MESO. Nota-se que o elemento vertical da estrutura obtida pela MESO encontra-se mais tensionado que o elemento vertical resultante da utilização da ESO.

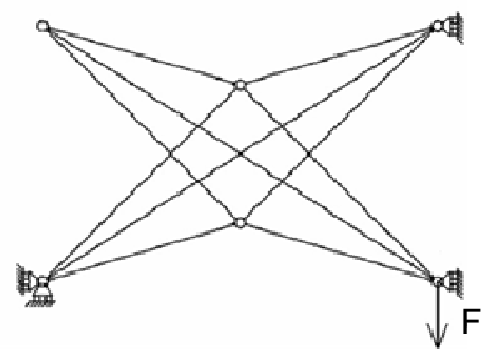

(a)

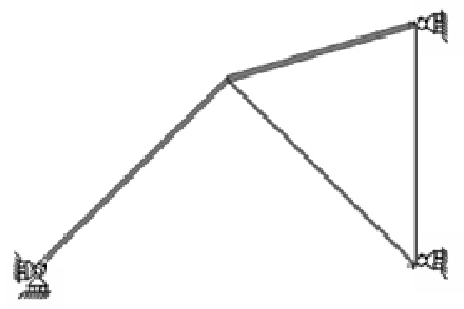

(b)

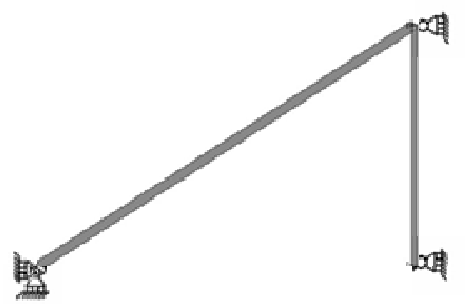

(c)

Figura 2.21 - (a) Domínio de projeto, (b) Primeiro estágio algoritmo ESO, (c) Primeiro estágio algoritmo MESO (Tanskanen, 2006) 
Verifica-se no estudo de Tanskanen (2006) uma rápida elevação dos valores de tensão da estrutura nas interações iniciais ocorridas no primeiro estágio MESO, ao passo que os valores de rigidez diminuem simultaneamente. Apenas nas interações finais do primeiro estágio ocorre uma elevação dos valores de rigidez da estrutura obtida por meio da MESO. Porém, não alcança os valores resultantes do uso do algoritmo ESO.

Com o estudo sobre treliças, Tanskanen (2006) conclui que há possibilidade de melhorar o desempenho da otimização topológica ao aplicar a MESO em vez da ESO.

Diversas foram as metodologias de otimização estrutural expostas ao longo da revisão de literatura, porém, com o objetivo de realizar as análises topológicas no capítulo referente à aplicação do procedimento de desenvolvimento de suportes, será aplicado o programa PERMAS.

\subsubsection{Características do programa PERMAS de otimização topológica}

Basicamente o programa PERMAS permite que o engenheiro realize diversos tipos de análises $M E F$, tais como análises de tensão, rigidez e determinação da freqüência natural. Porém, para os estudos do capítulo 5 será utilizado o módulo de otimização topológica do programa PERMAS.

O programa PERMAS utiliza o algoritmo de aproximação global convexa ou o algoritmo de solução primária na realização da otimização topológica. As interações da otimização podem ser controladas simultaneamente pela convergência da função objetivo ou pelo número máximo de interações.

A aplicação automática desses algoritmos possibilita a redução dos problemas relativos à instabilidade do tabuleiro e de dependência da densidade da malha. Após um dado número de interações, obtém-se a forma da estrutura otimizada, tornando-se 
necessária a realização de simulações MEF para a determinação da espessura das partes da estrutura.

Verifica-se na revisão de literatura a ausência da verificação dos critérios de fabricação e montagem para a obtenção de estruturas otimizadas. A estrutura ótima deve possibilitar também ser facilmente fabricada e montada, portanto, serão expostos na seqüência alguns procedimentos a serem verificados.

\subsection{ASPECTOS REFERENTES AOS PROCESSOS DE FABRICAÇÃO E MONTAGEM}

Com o objetivo de verificar os critérios de fabricação e montagem das propostas otimizadas, serão aplicados alguns conceitos da metodologia DFMA. Algumas considerações e verificações dessa metodologia serão mencionadas a seguir.

O objetivo básico da aplicação da metodologia DFMA consiste em maximizar o processo de manufatura e minimizar o número de componentes do produto. Essa metodologia deve ser aplicada em todas as fases do desenvolvimento do produto, considerando-se a facilidade de fabricação e montagem.

De acordo com Edwards (2002), convém que o engenheiro projetista faça a aplicação de peças e processos padronizados em famílias de produtos, o que torna possível a utilização de processos de fabricação para maiores volumes de produção, resultando normalmente em produtos de menor custo.

Decisões que impactam no custo final do produto referente à manufatura e à montagem devem ser definidas ainda na fase de projeto, pois o projeto é o primeiro passo na fabricação, iniciado com os primeiros desenhos de peças e conjuntos enviados à oficina de protótipos. A função dos engenheiros é obter produtos e 
processos otimizados, o que evita os custos e atrasos referentes ao ciclo de modificações do projeto.

Segundo Boothrod, Dewhurst e Knight (1994), a utilização da metodologia DFMA promove o uso de um procedimento sistemático de análise das propostas de projeto do ponto de vista da fabricação e montagem, resultando em produtos mais simples, confiáveis e com menor custo, além de melhorar a comunicação entre as áreas (engenharia, fabricação e custos) com necessidade de execução de tarefas em conjunto, como indicado na figura 2.22.

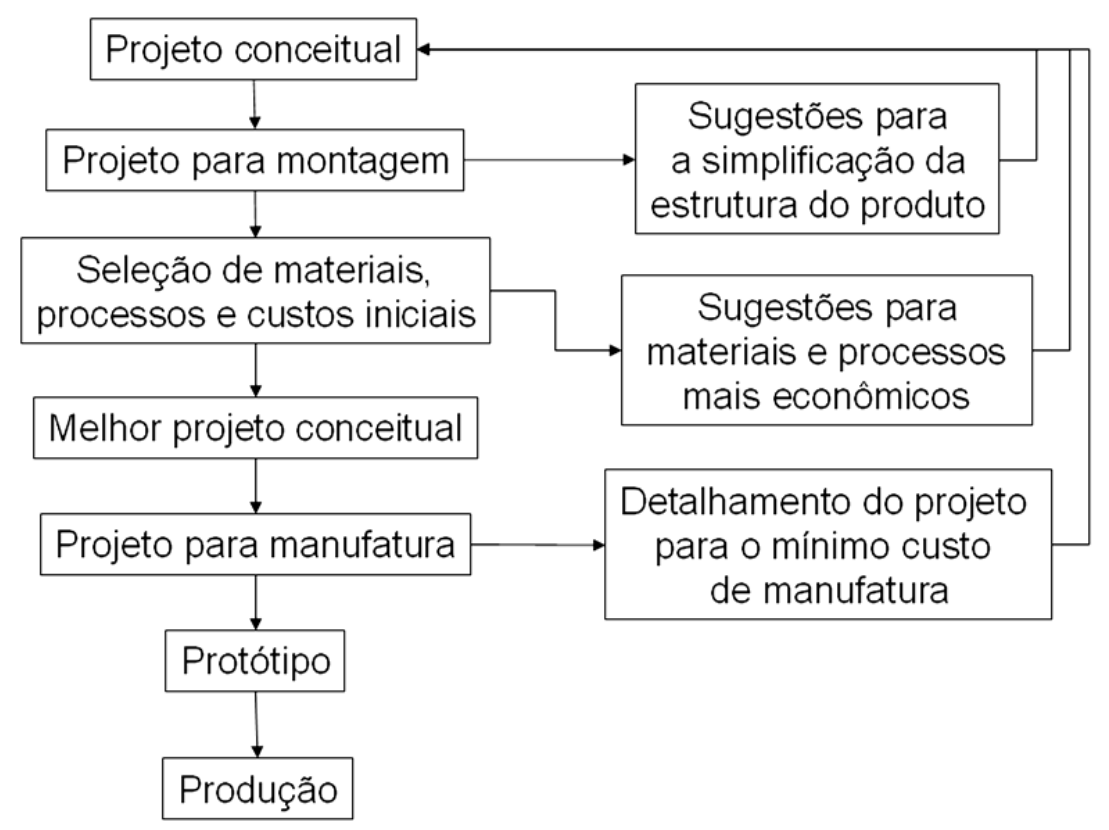

Figura 2.22 - Estágios típicos do uso da metodologia DFMA (Boothrod, Dewhurst e Knight, 1994)

A análise dos valores de custos no início do processo de desenvolvimento leva a uma melhor adequação do produto, o que evita problemas na fase final do ciclo de desenvolvimento. O estudo de Browning e Heath (2009) apresenta os problemas relacionados ao uso do DFMA, que ocorreram próximos ao final do ciclo de desenvolvimento de uma aeronave militar. Um dos problemas apontados foi a redução de peso próximo ao final do desenvolvimento, interferindo nas soluções obtidas no início do projeto com o uso do DFMA. 
Diversas metodologias similares foram desenvolvidas: The Hitachi Method, AEM, Assembly-Oriented Product Design, Lucas method, DAC entre outras, segundo Boothrod (1994).

A aplicação da metodologia DFMA deve ser considerada ao longo do processo de desenvolvimento, ou seja, do conceito até a produção. A análise sistemática de montabilidade deve ser realizada rotineiramente em conjunto com análises de custos.

Durante o detalhamento do projeto, devem ser consideradas as dimensões e tolerâncias compatíveis com a montagem, pois aquelas mais fechadas ocasionam aumento significativo dos custos do produto.

Basicamente, o processo de montagem manual é dividido em duas partes: 1 . manuseio e movimento; 2. inserção e fixação da peça (com o auxílio de dispositivos, parafusos, rebites, pinos etc.). Boothroyd, Dewhust e Knight (1994) definiram diretrizes visando à melhora desses processos, que serão expostas a seguir.

1. Para o movimento e manuseio da peça, o engenheiro deve estar atento aos seguintes passos:

- Definir as peças simétricas.

- Verificar as peças sem simetria. Nesse caso, deve-se considerar a assimetria óbvia.

- Evitar que as peças sejam escorregadias, delicadas, flexíveis, pontiagudas, muito pequenas ou grandes e que se enrosquem quando armazenada em quantidade, favorecendo a segurança das pessoas que as manuseiam.

2. Para a inserção e fixação, deve-se:

- utilizar chanfros.

- especificar as folgas para evitar o emperramento das peças.

- padronizar o uso de peças, processos e métodos. 
- possibilitar a montagem progressiva sobre um eixo de referência.

- evitar segurar as peças para manter a sua orientação durante a manipulação.

- localizar a peça antes de ser solta.

Apesar de o uso da metodologia apresentar vantagens, encontram-se barreiras à sua aplicação, principalmente na área de projetos, devido a prazos cada vez menores de desenvolvimento. Alguns engenheiros consideram a metodologia DFMA como mais uma a ser seguida, uma vez que consome um tempo de desenvolvimento do produto já escasso. Porém, conforme apresentado no estudo de Boothroyd (1994), diversas são as empresas que obtiveram significativa redução no tempo de desenvolvimento de produto com o uso da metodologia DFMA, aplicando-a na fase conceitual do projeto.

O tempo extra utilizado na fase do projeto em razão da aplicação da metodologia DFMA é compensado com a redução de tempo na fase de protótipo, antecipando o lançamento do produto no mercado. Verifica-se na figura 2.23 que o tempo $B$ é sensivelmente reduzido com o uso da metodologia DFMA, obtendo-se o tempo A.

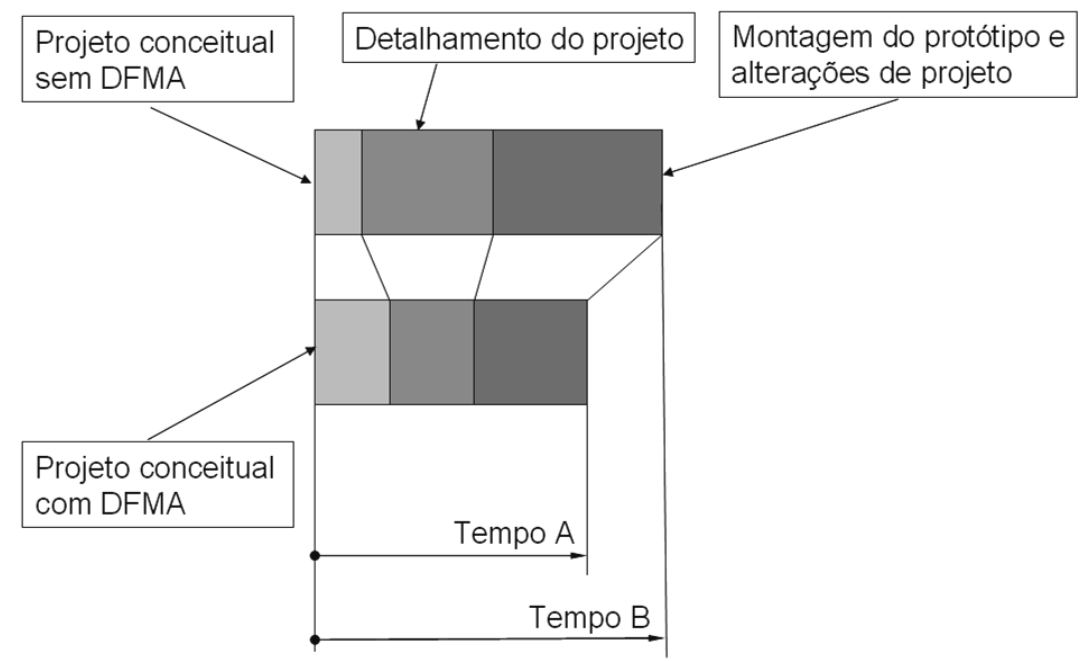

Figura 2.23 - Redução do tempo do projeto para a produção com o uso do DFMA (Boothrod, Dewhurst e Knight, 1994) 
Com o objetivo de auxiliar o engenheiro de desenvolvimento, serão utilizadas partes do conceito do DFMA, possibilitando obter estruturas otimizadas que são fabricadas e montadas com relativa facilidade. Ao longo do procedimento de desenvolvimento de suportes, serão aplicados a redução do número de componentes, a padronização do suporte, a análise dimensional da estrutura, os passos para a montagem manual e a verificação de custos.

\subsection{DISCUSSÕES REFERENTES À LITERATURA PESQUISADA}

Os artigos analisados ao longo do levantamento bibliográfico servem de base teórica a este estudo. Neles, foram discutidas as diversas técnicas desenvolvidas ao longo dos anos com o objetivo de obter produtos otimizados. $\mathrm{Na}$ aplicação da otimização topológica, surgiram novos problemas e soluções relacionadas ao seu uso. Muito foi desenvolvido desde os primeiros estudos de Michell (1904), avançando rapidamente com a utilização dos computadores. Porém, alguns autores tratam de maneira superficial os temas, apresentando estudos simplificados sem aplicação imediata.

Verifica-se no transcorrer do levantamento bibliográfico a ausência de uma metodologia específica ao desenvolvimento de suportes, tornando importante o desenvolvimento e a utilização de uma metodologia que associe a aplicação racional das metodologias de otimização estrutural com os critérios de fabricação e montagem. Essa proposta de metodologia poderá ser utilizada na obtenção de suportes padrões (unificados).

São empregadas em conjunto diversas técnicas abordadas na revisão bibliográfica, tais como: o aumento das dimensões da peça a ser otimizada devido à impossibilidade do algoritmo do programa de otimização acrescentar elementos, a simplificação do modelo de elementos finitos e a aplicação de refinamento de malha localizado conforme necessidade. 
O programa de otimização topológica selecionado utiliza filtros com o objetivo de, conforme já exposto, reduzir problemas relativos à dependência da qualidade da malha e problemas de chekerboard. O programa de otimização topológica realiza também a análise de sensibilidade na seleção dos elementos a serem eliminados. Aplica-se a análise linear estática devido aos pequenos deslocamentos atuantes na estrutura.

Considera-se a necessidade de simplificação do modelo MEF para obter redução do tempo de processamento. Isso é importante na análise de estruturas complexas. No entanto, caso a estrutura seja simples, a simplificação do modelo MEF estará relacionada principalmente à redução do volume no trabalho para a obtenção do modelo. Nesse caso, a redução do tempo computacional obtida pode ser insignificante quando comparado ao ganho obtido pela simplificação de estruturas complexas.

Utiliza-se também a verificação dos critérios de fabricação e montagem na análise das propostas, o que possibilita redução no tempo de lançamento de um produto e obtenção de produtos mais fáceis de produzir, montar e com menor custo. 


\section{SUPORTES EM CHASSIS AUTOMOTIVOS}

Em decorrência das características da aplicação do veículo, pode-se tornar necessária a inclusão de componentes específicos unidos ao chassi por meio de diversos tipos de suportes. Os suportes aplicados ao chassi de ônibus e caminhões são normalmente fabricados com chapas de aço laminado, porém, podem ser fundidos ou forjados conforme necessidade e recursos disponíveis.

As funções dos suportes veiculares são basicamente definidas por verbos $\mathrm{e}$ substantivos: unir as peças, suportar peso, posicionar as peças e resistir a esforços. A definição das funções de um produto auxilia no direcionamento do seu desenvolvimento, obtendo-se novas soluções, conforme Miles (1989).

Os produtos obtidos com a análise das funções devem ser associados à facilidade de fabricação e ao peso reduzido, ou seja, torna-se necessária a aplicação de uma metodologia de desenvolvimento de suportes otimizados para a obtenção dessas estruturas.

\subsection{CLASSIFICAÇÃO DOS SUPORTES}

Conforme sua aplicação, os tipos de suporte podem ser separados basicamente em dois grupos: estruturais e não estruturais. Os suportes estruturais têm a função de resistir a esforços provenientes das entradas de carga do veículo, ou seja, fixação ao chassi de componentes da suspensão, direção, trem de força, apoio da cabina, apoio do tanque de combustível, apoio da carroçaria, apoio de silenciosos, entre outros, de acordo com os exemplos das figuras 3.1, 3.5 e 3.6. 

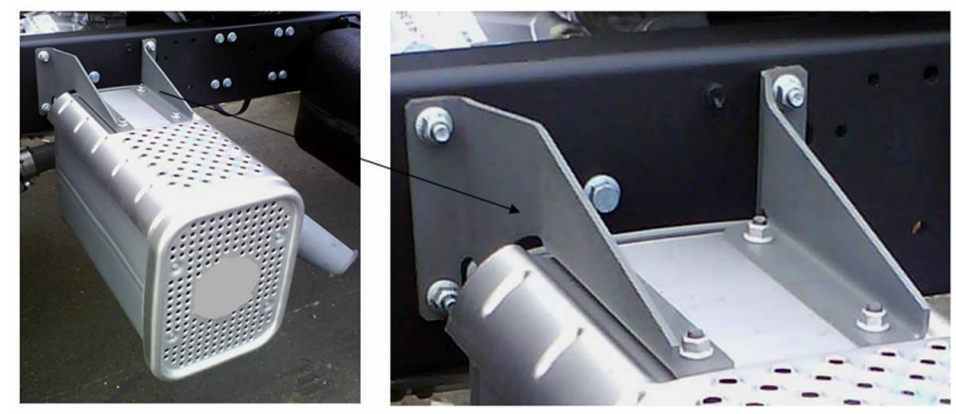

Figura 3.1 - Suporte do silencioso

Por outro lado, os suportes não estruturais são aplicados no apoio e nas fixações de tubulações (direção hidráulica, arrefecimento, combustível e calefação), cabos elétricos, filtro de combustível, buzina, extintor de incêndio, apoio de roda reserva, pára-barros, ou seja, itens que necessitam apenas serem unidos ao chassi sem exercer função estrutural, conforme é mostrado nas figuras 3.2, 3.3 e 3.4.
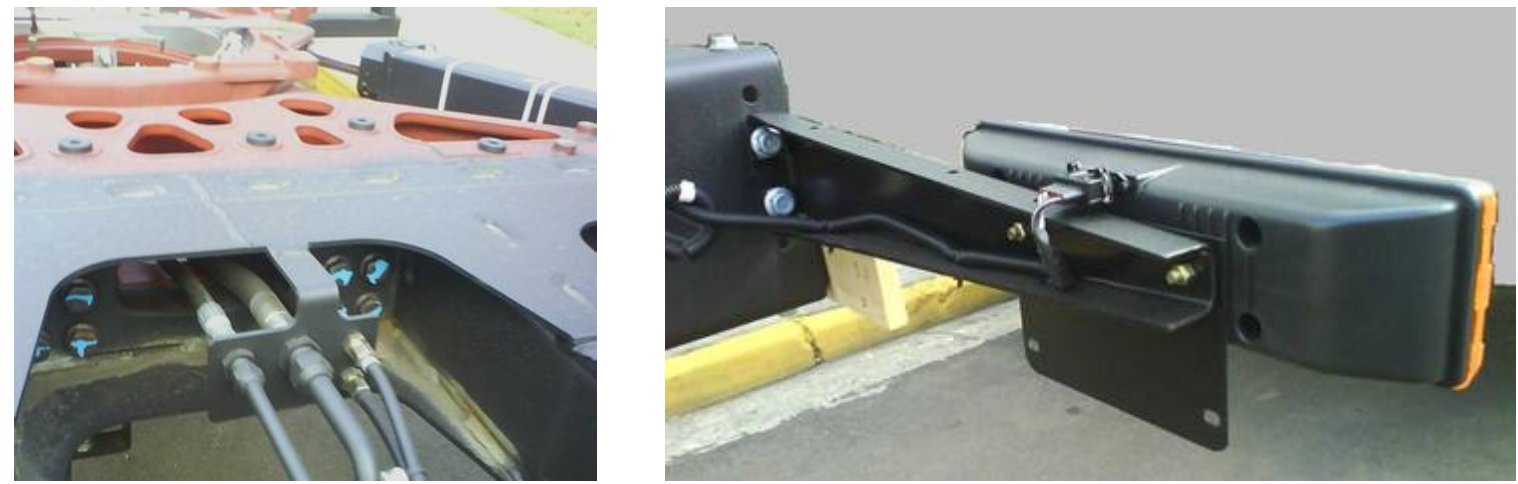

Figura 3.2 - Suportes para tubulações (direção hidráulica e combustível) e suporte da lanterna traseira

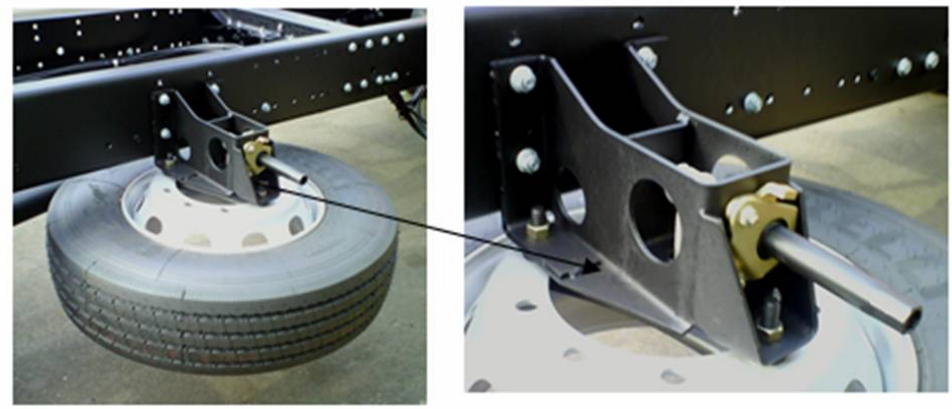

Figura 3.3 - Suporte da roda reserva 


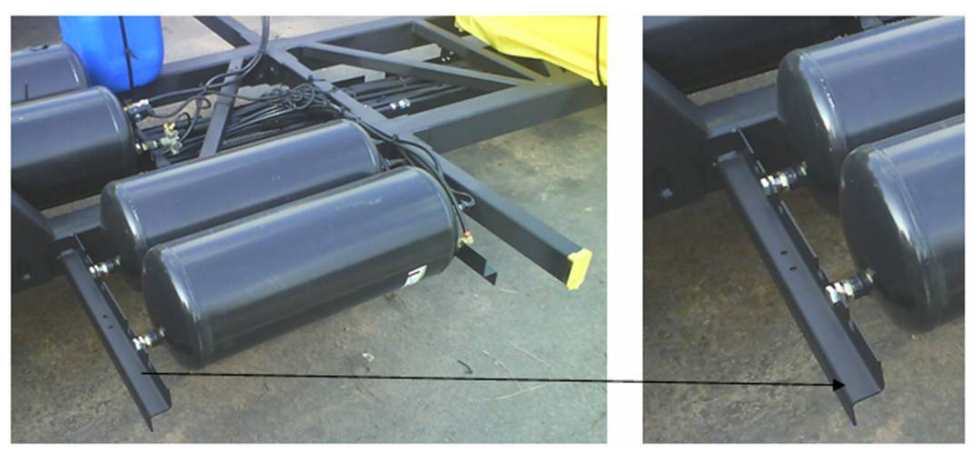

Figura 3.4 - Suporte dos reservatórios de ar comprimido

Os dois grupos podem ser divididos em itens de segurança ou não, conforme 0 componente a ser montado. Nesse caso, deve-se verificar se a falha do suporte ou de sua fixação coloca em risco a integridade dos passageiros ou mercadorias. Como exemplo de um item de segurança, pode-se citar o suporte que fixa a caixa de direção hidráulica à estrutura do chassi, pois a sua falha pode ocasionar acidentes, conforme é observado na figura 3.5 .

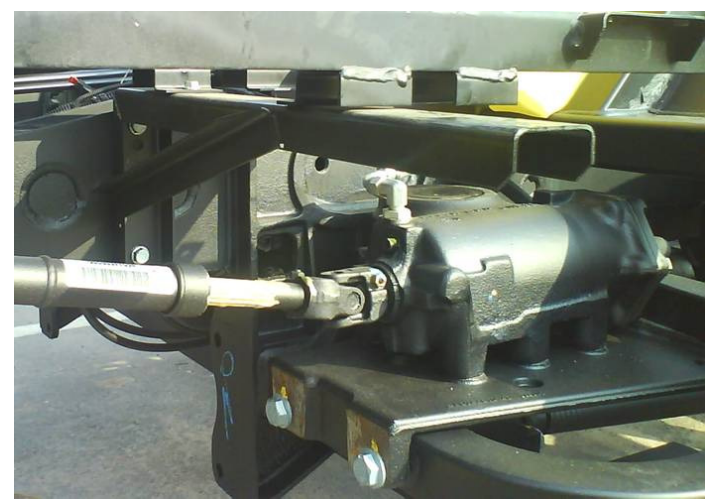

Figura 3.5 - Suporte da caixa de direção hidráulica

\subsection{TIPOS DE FIXAÇÃO DOS SUPORTES}

Os suportes podem ser fixados ao chassi do veículo de diversas maneiras, porém, normalmente são utilizados elementos removíveis (parafusos e porcas) ou a aplicação de uniões soldadas. A seleção do melhor tipo de união está vinculada a 
vários fatores, como necessidade de manutenção, peso, custos e processo produtivo. Ambos os tipos de união apresentam características próprias, por isso elas devem ser verificadas antes da definição do tipo de união a ser utilizada.

As estruturas soldadas normalmente são mais leves em comparação com as similares parafusadas, porém requerem a aplicação de equipamentos e dispositivos de solda e mão-de-obra especializada. Por outro lado, as estruturas parafusadas apresentam a vantagem de serem desmontáveis e normalmente possuem um processo produtivo mais simples relacionado ao estado das superfícies de contanto da união e ao controle da força de aperto.

\subsubsection{Problemas relacionados à aplicação das uniões}

Tanto a aplicação de uniões parafusadas quanto a de uniões soldadas podem apresentar problemas relativos ao projeto e ao processo produtivo envolvido. A seguir, será realizada uma pequena descrição dos problemas apresentados.

Os problemas relativos ao projeto de uniões parafusadas ocorrem em decorrência de falhas no dimensionamento estrutural, da falta de acesso necessário para a montagem dos parafusos e porcas, da falta de concentricidade das furações, entre outras causas.

Quanto aos problemas de projeto relativos às uniões soldadas, verificam-se também falhas no dimensionamento, falta de acesso à pistola de solda e problemas de penetração devido à aplicação de chapas com espessuras diferentes na união. A concentração de cordões de solda em uma certa região da estrutura pode provocar o empenamento dela, e a especificação de cordões próximos à extremidade da estrutura pode ocasionar problemas de moderdura. 
Nas uniões parafusadas, podem ocorrer problemas de processo produtivo relativos à perda de torque da união, o que ocasiona a soltura do parafuso e da porca e a movimentação relativa das peças, podendo provocar falha na união, no suporte ou na peça suportada por ele. Esse problema pode estar ligado ao coeficiente de atrito da rosca, à planicidade das peças parafusadas, à camada de pintura, à utilização de torquímetros desregulados etc. Em alguns casos, pode aparecer a ruptura de parafusos devido ao excesso de torque ou ao cisalhamento devido a sobrecargas. Com o objetivo de minimizar os problemas de soltura da fixação, podem-se aplicar nas uniões parafusadas porcas auto-travantes, travas químicas, cupilhas, entre outros.

As falhas referentes ao processo produtivo apresentado nas uniões soldadas estão relacionadas a trincas, porosidade, mordedura, falta de fusão, falta de penetração, respingos e empenamentos. Basicamente, esses problemas estão ligados, por exemplo, à falta de treinamento de soldadores, ao uso de equipamentos inadequados ou desregulados e a superfícies a serem unidas oleadas ou sujas.

Os problemas relacionados a uniões podem ocasionar falha do suporte com a possível perda de função do componente. Caso o componente a ser montado com esse suporte seja um item de segurança, pode acarretar risco na aplicação do veículo. A eliminação desses problemas possibilita a obtenção de um suporte mais robusto.

\subsection{EXEMPLOS DE APLICAÇÕES DE SUPORTES}

Com o intuito de salientar a importância relacionada à aplicação de suportes otimizados, serão relacionados a seguir alguns exemplos de utilização e as atribuições necessárias para desempenhar suas respectivas funções.

Para a montagem do tanque de combustível de um veículo comercial, utilizouse um suporte feito de chapas de aço soldadas, que foi fixado na lateral da longarina do 
veículo com parafusos e porcas, conforme mostra a figura 3.6. Esse suporte deve resistir aos esforços devido às torções do chassi e ao peso do tanque cheio de combustível sujeito às acelerações relativas ao veículo em ordem de marcha. Alguns veículos podem ser equipados com tanques de combustível de até 600 litros de capacidade.

A falha do suporte ou de sua fixação pode provocar rachaduras ou a queda do tanque, ocasionando o derramamento de combustível. O vazamento de óleo diesel pode ocasionar acidentes devido à derrapagem de veículos, incêndios e danos ambientais. Esse suporte é considerado um item estrutural e de segurança.

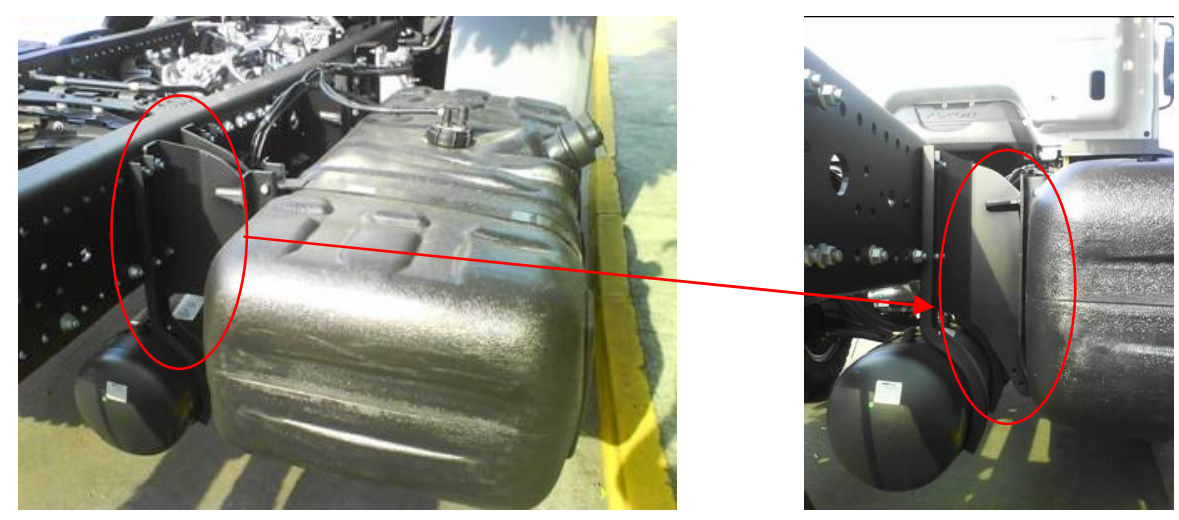

Figura 3.6 - Suporte do tanque de combustível

Os suportes mostrados na figura 3.7 são utilizados no apoio da bolsa de ar da suspensão e na fixação do amortecedor de um chassi de ônibus. Eles são unidos à estrutura do veículo com a utilização de solda, ambos os suportes possuem funções estruturais e de segurança. O suporte da bolsa de ar constitui-se de três chapas soldadas mais a peça que permite o encaixe da bolsa de ar, enquanto o suporte do amortecedor é formado por uma peça única. A falha de qualquer um dos suportes prejudicaria a dirigibilidade do veículo, colocando a sua aplicação em situação de risco. 

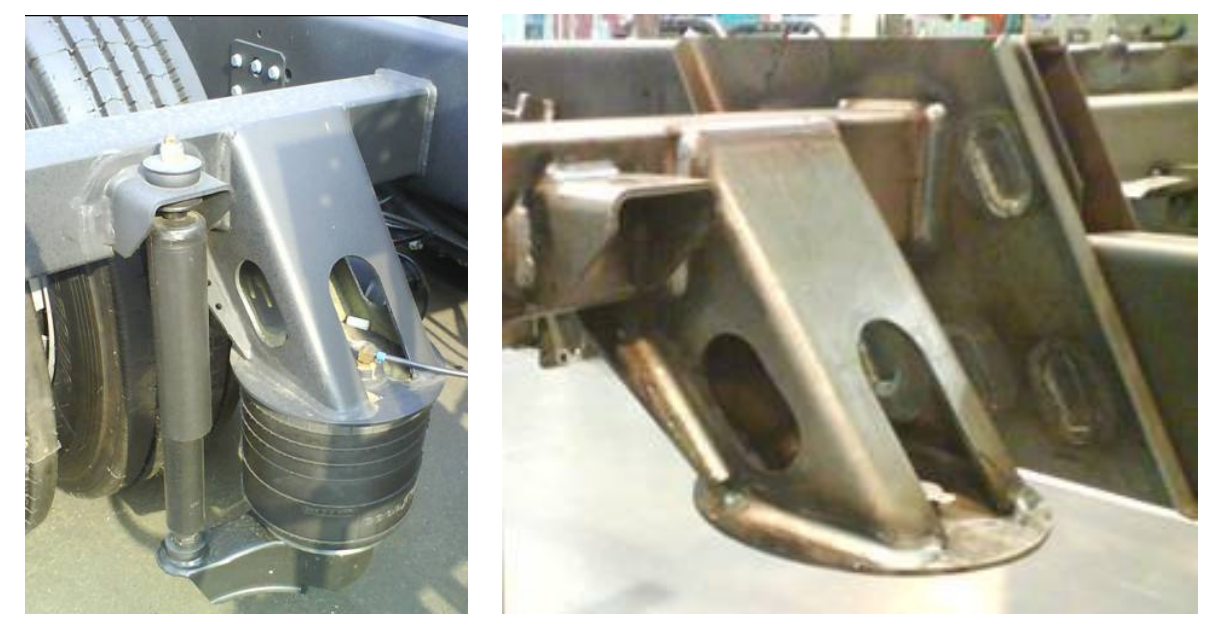

Figura 3.7 - Suporte do amortecedor e suporte de apoio da bolsa de ar

Verifica-se, na montagem ilustrada na figura 3.8, a fixação na longarina do chassi das tubulações de direção hidráulica de pressão e retorno ao reservatório de óleo e tubulações plásticas de ar comprimido.

Em decorrência da localização do motor, do sistema de bombeamento de óleo hidráulico da direção e do sistema de compressor de ar encontrar-se na parte traseira do chassi, torna-se necessária a inclusão de diversos suportes similares ao ilustrado na figura 3.8 para a sustentação da tubulação até a entrada da caixa de direção (na parte frontal do veículo) e válvulas e atuadores do sistema de freio.

Nota-se que a falha de algum desses suportes pode acarretar instabilidades nas tubulações, porém, dificilmente provocaria falha nos sistemas dependentes das tubulações, tratando-se, portanto, de um suporte não estrutural.

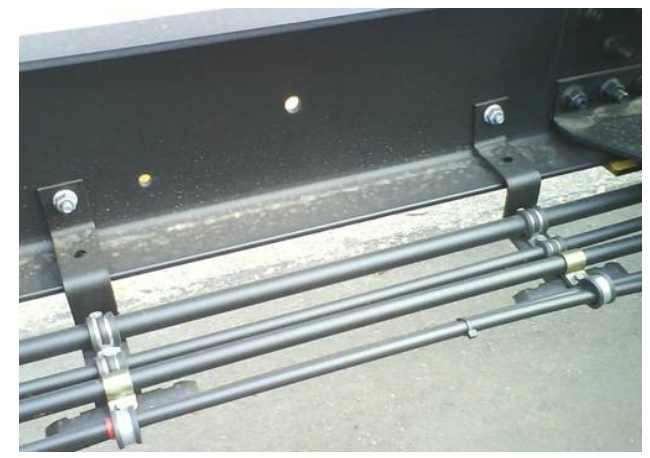

Figura 3.8 - Suportes para a fixação de tubulação 


\subsection{UTILIZAÇÃO DE METODOLOGIAS DE OTIMIZAÇÃO ESTRUTURAL}

Os suportes normalmente devem apresentar baixo peso e elevada resistência mecânica e possibilitar a fabricação conforme descrito anteriormente. Para isso, tornase necessária a aplicação de metodologias de otimização estrutural em conjunto com os critérios de fabricação e montagem, visando à obtenção de soluções ótimas e viáveis do ponto de vista de custos e de fabricação.

$\mathrm{Na}$ figura 3.9, verificam-se diferentes execuções de suportes de fixação do filtro de combustível e separador de água. Todos apresentam a mesma função: suportar filtro, uni-lo à longarina, prover rigidez e, em alguns casos, desviar de outras peças. Nota-se, além da diferença de forma dos suportes, uma variação de espessuras de 5 a $8 \mathrm{~mm}$. Há, portanto, um potencial para otimizar as construções e obter um único suporte otimizado padrão, que atenda a todas as necessidades.
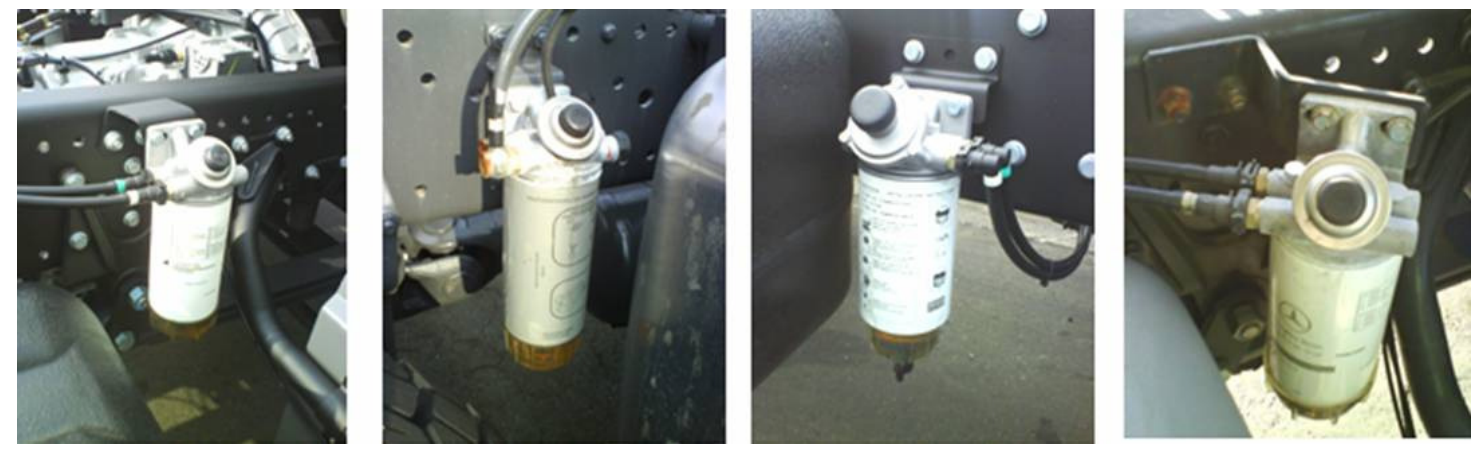

Figura 3.9 - Tipos de suporte de fixação do filtro de combustível e separador de água

Os suportes ilustrados na figura 3.10 são utilizados para a fixação de amortecedores e apresentam a mesma função, ou seja, suportar o amortecedor, unir o amortecedor do eixo à estrutura do veículo, suportar os carregamentos e prover resistência mecânica. 

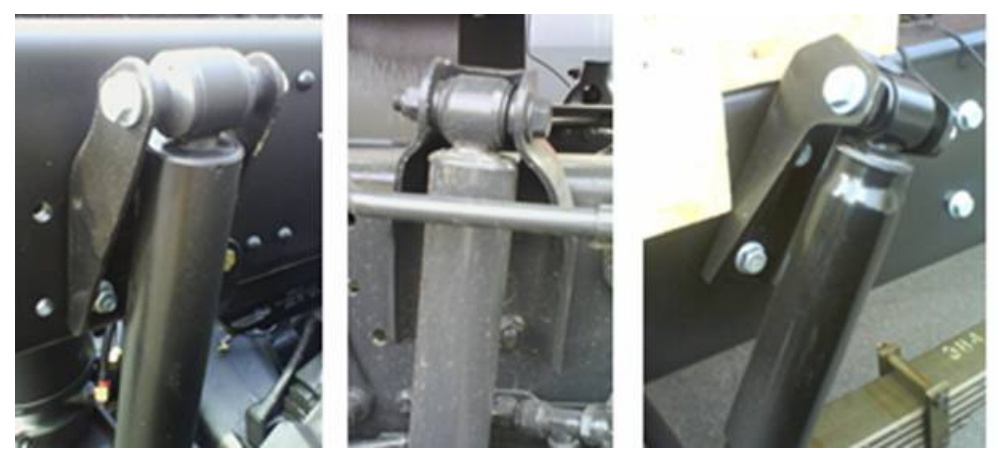

(a)
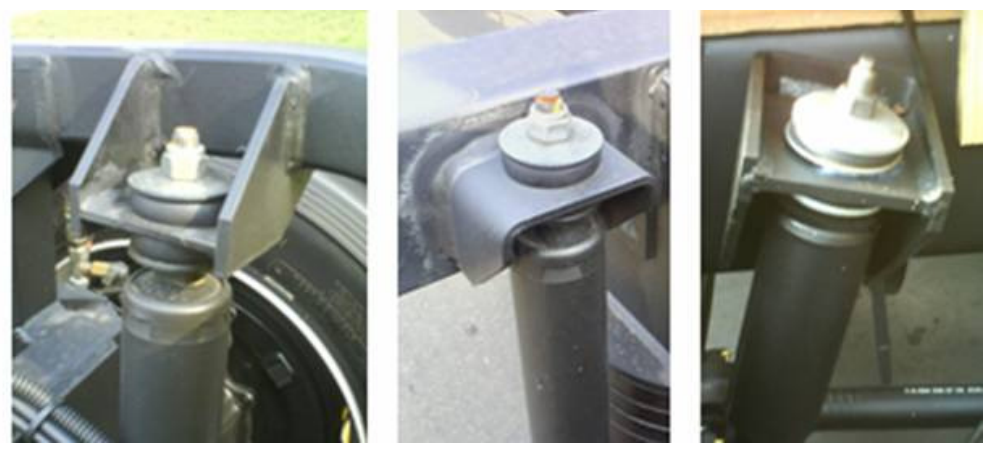

(b)

Figura 3.10 - Suportes para a fixação de amortecedores (a) Tipo olhal e (b) Tipo haste rosacada

Esses suportes apresentam formas com diferenças acentuadas, variam de peças estampadas a conjuntos soldados. Em alguns casos, as variações ocorrem em decorrência das características de montabilidade do amortecedor. Há amortecedores com fixações do tipo olhal e do tipo haste com rosca. Esses suportes apresentam variações também nas fixações da estrutura do veículo, sendo aplicadas uniões parafusadas e uniões soldadas diretamente ao chassi.

É possível, portanto, prever a redução na quantidade de soluções, de forma otimizada e racional, obtendo-se dois suportes padrões, um para o amortecedor com fixação do tipo olhal e outro para o amortecedor com fixação do tipo haste roscada.

$\mathrm{Na}$ montagem ilustrada na figura 3.11, verificam-se variações no formato dos suportes de fixação do pára-barro, os quais possuem a mesma função, ou seja, suportar o pára-barro, unir o pára-barro à longarina e prover posição. 
Os suportes em questão são conjuntos de chapas e tubos soldados e fixos ao chassi com parafusos e porcas. Devido às variações do tipo de suporte do pára-barro, nota-se a necessidade da aplicação de uma metodologia de desenvolvimento de suportes, padronizando uma solução.
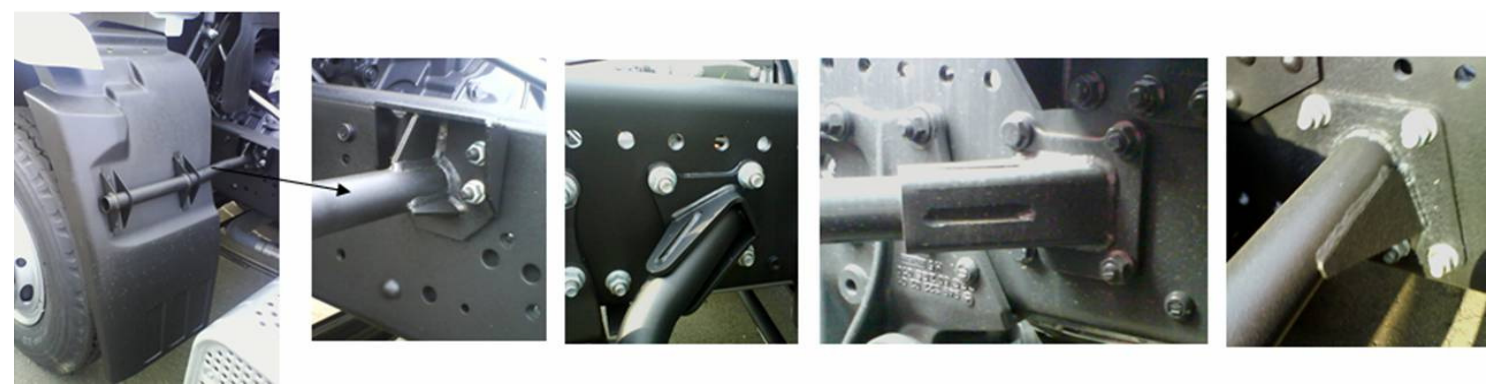

Figura 3.11 - Suporte de fixação do pára-barro

Ao longo deste capítulo, notou-se claramente a necessidade da aplicação do procedimento de desenvolvimento de suportes em razão do uso de suportes de forma empírica e desordenada. A ausência de uma seqüência lógica e racional de desenvolvimento resulta, como exposto anteriormente, na criação e no uso de suportes diferentes para a mesma função.

Em alguns casos, esses problemas estão relacionados à falta de conhecimento do veículo completo por parte do engenheiro, mas também em decorrência da divisão das tarefas de desenvolvimento entre os engenheiros, que pode ocasionar a utilização de suportes diferentes para a mesma função no mesmo veículo.

As variações geram aumento desnecessário no tempo e no custo de desenvolvimento do veículo, pois, conforme já citado, aumenta a ocorrência de alterações de projeto devido a problemas em veículos em testes na fase final de desenvolvimento.

Com a aplicação do procedimento de desenvolvimento de suportes, obtêm-se suportes padrões, porém adaptações podem promover a obtenção de suportes ótimos para cada aplicação ou família de suportes. As adaptações podem ser necessárias, 
pois o suporte padrão é otimizado para o carregamento mais severo de uma família de veículos, sendo utilizado em seguida para toda a família. Essa solução permite reduzir a quantidade de componentes na empresa e, conseqüentemente, os custos, porém, pode ocasionar acréscimo de peso para aplicações com menores carregamentos.

A utilização do suporte ótimo consiste na obtenção de um suporte dedicado e otimizado à certa aplicação e permite uma redução de peso maior, porém pode gerar aumento no custo do produto devido a diversas variações de suportes existentes (observação: esta variação é referente às dimensões do suporte, mantendo-se a forma otimizada).

A proposta da família de suportes localiza-se entre as duas propostas anteriormente mencionadas, pois se tratam de soluções prontas para serem aplicadas. A família pode ser subdividida, por exemplo, para atender a um carregamento severo, médio e leve, evitando um superdimensionamento da estrutura, porém, sem aumentar demasiadamente o número de componentes da empresa. Porém, o objetivo deste estudo é propor um procedimento de desenvolvimento de suportes padrões aplicados em chassi veicular. 


\section{PROCEDIMENTO DE DESENVOLVIMENTO DE SUPORTES}

Para iniciar o desenvolvimento de suportes, é fundamental definir o conceito do suporte a ser aplicado e, na seqüência, o ciclo de dimensionamento estrutural. A análise de elementos finitos e a otimização estrutural estão vinculadas a diversos fatores, como econômicos, posicionamento de venda, disponibilidade de pessoal treinado e equipamentos, conforme já mencionado. A necessidade da análise estrutural de elementos finitos pode ser oriunda de um novo desenvolvimento ou da modificação de projetos existentes.

As modificações normalmente estão vinculadas a soluções de falhas, otimização estrutural, adequações a novas necessidades do produto, alterações de legislação, entre outros. As alterações em projetos existentes podem possuir uma quantidade maior de restrições quando comparado ao desenvolvimento de novos projetos, pois existe a interação da estrutura com outras peças existentes.

No caso da montagem de conjuntos, há limitações porque o processo produtivo já está definido. Torna-se, portanto, mais simples realizar alterações ainda no ciclo de desenvolvimento do produto em razão, principalmente, da menor quantidade de restrições, sendo necessária a definição de um procedimento de desenvolvimento.

A aplicação da otimização estrutural segue uma seqüência lógica durante cada fase da análise. Inicia-se com a seleção da estrutura a ser examinada e, em seguida, determina-se o objetivo a ser atendido, como redução de peso e aumento da rigidez. Após isso, realiza-se a modelagem da malha MEF, determinam-se as condições de

contorno e esforços atuantes, bem como efetuam-se a otimização estrutural, as alterações da malha e a análise MEF. Realizados esses procedimentos, obtém-se uma estrutura otimizada empregada à certa aplicação. 
No processo de otimização, inicialmente, deve-se definir a finalidade da estrutura obtida, que se divide basicamente em: um suporte dedicado, suporte padrão e família de suportes.

O suporte dedicado trata da melhor solução encontrada para um uso específico, sendo que, para cada necessidade, devem ser realizadas uma nova análise e a determinação do suporte ótimo.

O suporte padrão é otimizado para ser aplicado na condição de maior severidade de utilização de uma família de veículos, sendo, portanto, empregado como uma solução pronta em situação de igual ou menor exigência. Ele se encontra superdimensionado para as aplicações de menores carregamentos.

Quanto à família de suportes, está em uma posição intermediária entre a solução dedicada e a solução padrão, pois a sua aplicação é viável caso haja elevadas variações no valor dos carregamentos. Pode-se, a exemplo da família de veículos, subdividir a família de suportes conforme a sua aplicação em: leve, média e pesada, criando-se, no caso, três suportes otimizados, podendo representar bem a necessidade dos veículos.

Conforme descrito anteriormente, o intuito desta pesquisa é a obtenção de suportes padrões, possibilitando redução dos custos de produção e logística em decorrência do aumento do volume de produção e da administração de apenas um item (suporte). Caso o procedimento seja aplicado para a obtenção de uma família de suportes ou na obtenção de um suporte dedicado, torna-se necessária a sua alteração. A aplicação de uma ou outra solução depende da análise de custos (tema não abordado aqui), da análise dos critérios de fabricação e montagem e deve estar em conformidade com a política de desenvolvimento adotada pela empresa. 


\subsection{ELABORAÇÃO DO CONCEITO DO SUPORTE PADRÃO}

O conceito do produto (suporte) tem como premissa propor uma estrutura básica que será aplicada ao longo do ciclo de desenvolvimento, sendo modificada até a obtenção do suporte padrão.

Inicialmente, realiza-se uma análise das funções que o suporte deve atender conforme descrito no capítulo referente aos suportes em chassis automotivos. A obtenção das funções permite que o engenheiro proponha novas soluções ao conceito do suporte, possibilitando o pleno desempenho das necessidades do produto, eliminando detalhes inúteis da estrutura que atendam a funções desnecessárias. No desenvolvimento do conceito do suporte, convém levar em consideração itens como:

- Atendimento das necessidades do projeto, como redução de peso, modificações e funções.

- Tipo de estrutura a ser adotada (estampada, fundida etc.).

- Tipo de união a ser adotado (parafusada ou soldada).

- Análise de montabilidade, estudo cinemático das partes móveis próximas, evitando colisões e interferências.

- Análise dimensional das peças, prevendo o uso racional das tolerâncias.

- Verificação da facilidade de fabricação e montagem, pois se torna mais fácil a alteração da proposta ainda no estágio conceitual.

- Análise de custos (não contemplada nesta pesquisa).

Como o intuito de auxiliar o engenheiro de desenvolvimento na definição das funções da estrutura, serão descritos alguns passos a serem seguidos. Verifica-se no estudo de Miles (1989) que as funções são abordadas com o objetivo de definir o que o cliente deseja. Normalmente esse desejo possui intensidade variável para diferentes tipos de produtos e serviços. 
Realizam-se algumas questões com o objetivo de gerar idéias para a definição das funções (Miles, 1989). Essas perguntas foram adaptadas para a obtenção das funções do suporte aplicado no chassi veicular, conforme a seguir:

O que exatamente o suporte faz para o chassi do veículo?

O que exatamente o cliente quer que o suporte faça?

O cliente acredita que está pagando o quê?

As respostas deverão conter um verbo e um substantivo, como exemplo, prover resistência mecânica, prover leveza, unir o componente à estrutura do veículo, entre outras. As funções ainda podem ser subdivididas em básicas e secundárias. As funções básicas são aquelas que fazem o cliente comprar o veículo, enquanto as funções secundárias existem para auxiliar a obtenção da função básica.

Realizadas as verificações e atendidos os requisitos do projeto, obtém-se o conceito do suporte padrão; caso contrário, é fundamental realizar modificações ao conceito da estrutura, conforme ilustrado na figura 4.1. Na seqüência, inicia-se o ciclo de dimensionamento e otimização até a obtenção do suporte padrão. 


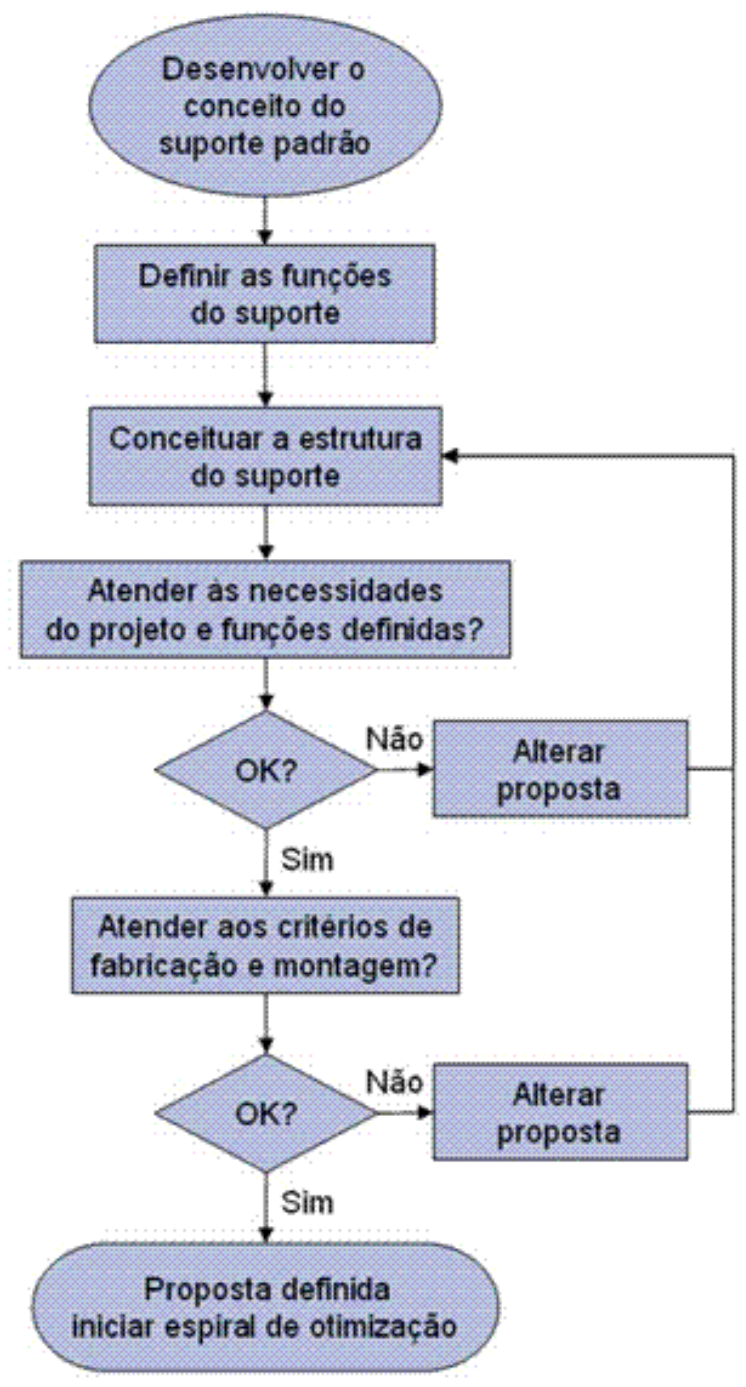

Figura 4.1 - Fluxograma do conceito do suporte padrão

\subsection{PROCEDIMENTOS PARA A REALIZAÇÃO DA ANÁLISE MEF}

O objetivo principal da análise de elementos finitos é prever o comportamento de um produto antes de sua fabricação e testes, podendo, com isso, tomar ações ainda no desenvolvimento do produto. Basicamente, a análise de elementos finitos consiste nos seguintes passos: modelagem da geometria selecionada para análise, análise do modelo e verificação dos resultados. 
A modelagem dos elementos finitos consiste na criação das malhas de elementos finitos, na aplicação de condições de contorno, na inclusão de carregamentos e no emprego das características do material.

A geração das malhas pode ser realizada de forma automatizada pelo préprocessador, porém, nessa etapa, é importante a inclusão do refinamento da malha em certas regiões do modelo. Pode-se, por exemplo, criar uma malha geral com elementos de placa quadriláteros de quatro nós mais grosseira e, em regiões específicas, reduzir no local o tamanho da malha.

A densidade da malha está vinculada ao tamanho da estrutura a ser analisada, e fica a cargo do engenheiro definir o tamanho da malha geral e local. O objetivo do refinamento localizado consiste em melhorar a precisão dos resultados, evitar a existência de gradientes de tensão no mesmo elemento e reduzir o tempo computacional.

A simplificação do modelo de elementos finitos consiste na redução do tamanho da geometria, modelando apenas as regiões de maior relevância no dimensionamento da estrutura, que apresenta valor significativo de índice de sensibilidade e diminui o volume de trabalho de modelagem das malhas devido à eliminação dos itens pouco relevantes. O refinamento local da malha e a simplificação da geometria propiciam redução do tamanho do modelo MEF e permite a diminuição do tempo computacional, resultando na diminuição de custos de simulação.

O modelo de elementos finitos deve, portanto, apresentar-se o mais próximo possível do domínio de projeto, pois as soluções ou problemas estão vinculados à exatidão dos modelos. A inclusão das condições de contorno ao modelo de elementos finitos visa representar o modo como ele é fixo ao sistema ou apoio, basicamente restringe-se ou não os graus de liberdade (rotação e translação) em relação ao eixo cartesiano definido no modelo. 
Os carregamentos devem representar os esforços ou a combinação dos esforços a que a estrutura esteja sujeita, como tração, compressão e acelerações. A definição dos valores de esforços atuantes pode ser obtida de diversas maneiras, porém, em alguns casos, adotam-se no desenvolvimento de um novo produto carregamentos conhecidos de produtos existentes similares.

É fundamental atualizar os carregamentos após a montagem do protótipo e a medição do nível de tensão. Outra forma de obter o carregamento é por meio de cálculos analíticos, porém a dificuldade de obtenção dos esforços atuantes aumenta conforme a complexidade da estrutura a ser analisada. Como exemplo, pode-se utilizar o desenvolvimento de um suporte para a fixação da bolsa de ar de um veículo com suspensão pneumática.

$\mathrm{Na}$ determinação do carregamento atuante, considera-se a capacidade técnica do eixo (ou seja, o valor teórico de carregamento no qual o eixo foi dimensionado) dividido pela quantidade de bolsas de ar utilizadas na suspensão. Obtém-se, dessa forma, o carregamento teórico para o início da análise MEF. Com a montagem do protótipo, as regiões de interesse devem ser previamente instrumentadas com extensômetros e acelerômetros, visando à aquisição de dados de campo (deslocamentos, acelerações e tensões atuantes).

Para tanto, o veículo deverá ser utilizado em condições pré-estipuladas de carregamentos e de trajeto. As informações obtidas são utilizadas na calibração do modelo de elementos finitos por meio de modificações nos valores de carregamentos ou das condições de contorno até a obtenção de valores de tensão similares aos valores obtidos em campo.

A exatidão dos resultados a serem obtidos após as análises está vinculada à calibração dos modelos de elementos finitos. O uso do modelo calibrado, que serve como base, torna-se o referencial para as demais alterações que o modelo vier a sofrer. Esse procedimento aumenta a credibilidade da análise, aproximando-a da realidade. 
A inclusão das características do material influencia nos resultados obtidos, pois o comportamento estrutural é uma função da relação tensão-deformação do material. Basicamente, os programas de elementos finitos permitem a utilização de materiais isotrópicos, ortotrópicos e compostos, segundo Kaminski (2000).

Para a especificação do material no modelo de elementos finitos, deve ser verificada a disponibilidade de obtenção e o lote mínimo de entrega para a fabricação da estrutura, pois, em alguns casos, torna-se viável a substituição do material por outro equivalente ou de qualidade superior. Realizando-se os procedimentos descritos, obtém-se o modelo de elementos finitos propriamente dito.

A análise do modelo consiste na solução automática de sistemas de equações com a utilização de um programa solver e depende do tipo de análise solicitada podendo ser: análise linear estática, análise linear dinâmica, análise não-linear, etc. A análise linear estática é considerada um dos tipos mais utilizados de análise e consiste na obtenção de resultados de tensão e deformação que variam linearmente conforme a aplicação do carregamento, sem apresentar variação ao longo do tempo, de acordo com Kaminski (2000).

A estrutura submetida à análise MEF encontra-se aprovada quando o valor máximo de tensão atuante obtido com o programa pós-processador for menor ou igual ao valor de tensão admissível do material. Caso a relação mencionada anteriormente não seja atendida, pode-se efetuar a substituição do material ou modificar a geometria do modelo MEF. Feitas as alterações, torna-se necessário efetuar novamente a análise MEF. A exatidão dos resultados obtidos na análise MEF está vinculada principalmente à capacidade do modelo de elementos finitos de representar a estrutura física. 


\subsubsection{Aplicabilidade de elementos de placa}

A aplicação de elementos de placa permite uma simplificação da modelagem MEF em decorrência, principalmente, da facilidade de alterar a espessura do modelo, modificando-se somente a propriedade referente à espessura sem a necessidade de alteração da malha. Porém, segundo Macneal (1994), deve-se respeitar a relação $l>t$ para a aplicação da teoria de placa, ou seja, o menor lado do elemento $l$ deve ser maior que a sua espessura $t$ do elemento.

De acordo com Spyrakos (1996), o elemento de placa deve obedecer à relação geométrica de $t / l \leq 0,1$. Essa restrição na aplicação da teoria de placas ocorre devido às simplificações e aproximações da teoria da elasticidade tri-dimensional na obtenção da teoria de placas.

Comparando-se os dois critérios de análise, nota-se que a relação proposta por Spyrakos é 10 vezes mais restritiva que a proposta por Macneal. Sendo, portanto, aplicada a relação de $t / l \leq 0,1$ no procedimento de desenvolvimento de suportes. $\mathrm{Na}$ figura 4.2 verifica-se um exemplo das dimensões $l$ e $t$ de uma malha qualquer.

No caso de a espessura do modelo encontrar-se superior a essa relação, devese empregar o modelamento com a utilização de elementos sólidos, em que, segundo Spyrakos (1996), a aplicação de elementos sólidos permite a obtenção de valores de variação de tensão tri-dimensional.

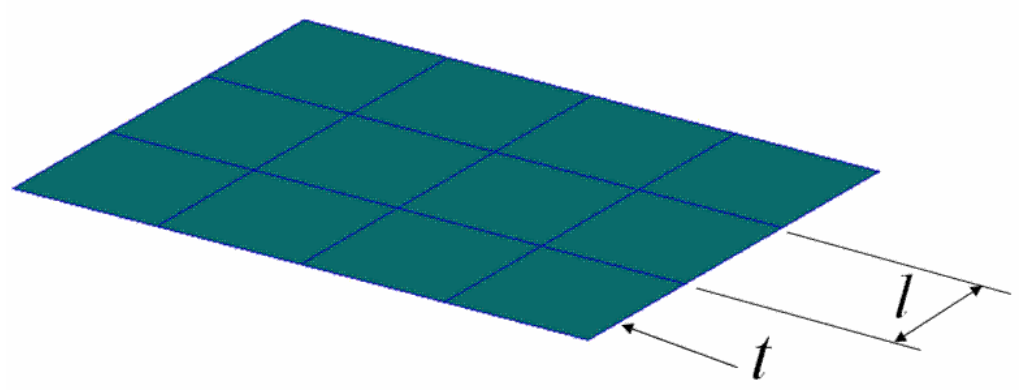

Figura 4.2 - Elementos de placa 


\subsubsection{Procedimentos para a realização da análise de otimização paramétrica e de forma}

Basicamente, são utilizados métodos analíticos, numéricos MEF, genéricos e gráficos na análise de problemas de otimização paramétrica, de acordo com Silva (S/D). Nesse caso, o uso do método analítico está relacionado à solução de problemas de baixa complexidade e à aplicação dele principalmente no meio acadêmico.

A utilização de métodos numéricos está difundida nas indústrias e representa um dos principais métodos utilizados no dimensionamento estrutural. Os métodos genéricos são basicamente programas dedicados à otimização de maneira genérica e não somente à otimização estrutural e, por fim, os métodos gráficos apenas podem solucionar problemas com duas variáveis de projeto.

No desenvolvimento desta pesquisa, será adotado o método numérico de elementos finitos, seguindo os passos descritos anteriormente para o procedimento de modelagem, aplicação de condições de contorno e carregamentos, aplicação de material e análise dos resultados.

Ao aplicar o MEF no processo de otimização paramétrica e de forma, a principal diferença encontrada se dá na quantidade de interações realizadas para a obtenção da estrutura ótima. Alteram-se parâmetros como espessura, comprimento, largura e dimensões básicas de forma combinada ou isolada até resultar no objetivo preestabelecido do processo de otimização, que é atingir a taxa de remoção de material estipulada ou rigidez. Para isso, deve-se priorizar a variação de parâmetros que possuam influência direta na variação dos resultados finais.

A aplicação da metodologia de otimização paramétrica e de forma, como já descrito anteriormente, ocorre na área de desenvolvimento de produtos das indústrias e possibilitam a obtenção de estruturas otimizadas. 


\subsubsection{Procedimentos para a análise de otimização topológica}

Existem diversos programas de otimização topológica no mercado, sendo que alguns interagem diretamente com a geometria CAD da estrutura. Como descrito anteriormente no processo MEF, devem ser informadas as condições de contorno e carregamentos, material, taxa de remoção de material entre outros. Realizadas as parametrizações, o programa gera as interações necessárias à obtenção da taxa de remoção pré-selecionada, submete à análise MEF e disponibiliza no final o modelo MEF com o formato suavizado e a geometria CAD do suporte. Trata-se, portanto, de um método automatizado.

Algumas empresas adotam a inclusão de módulos de otimização topológica em conjunto com programas MEF existentes, tornando o seu uso mais trabalhoso. Inicia-se o processo de otimização com o procedimento de preparação do modelo MEF, conforme descrito anteriormente. Caso o algoritmo do programa de otimização topológica utilizado não possibilite acrescentar material, deve-se proceder ao aumento das dimensões da estrutura, visando apenas à retirada de elementos.

Na seqüência, o modelo é submetido ao programa de otimização topológica resultando, após certo número de interações, em um modelo que represente a estrutura com maior rigidez para uma dada taxa de remoção de material estipulada. É de suma importância a adequada interpretação do modelo gerado com o programa de otimização topológica, definindo a área referente à peça e a área relativa ao material retirado, conforme mostra a figura 4.3 .

Após a análise, efetua-se a adequação do modelo MEF, que consiste na modelagem da nova topologia proposta, e submete-o à análise MEF, obtendo-se a estrutura otimizada de acordo com os limites de tensão estabelecidos. 


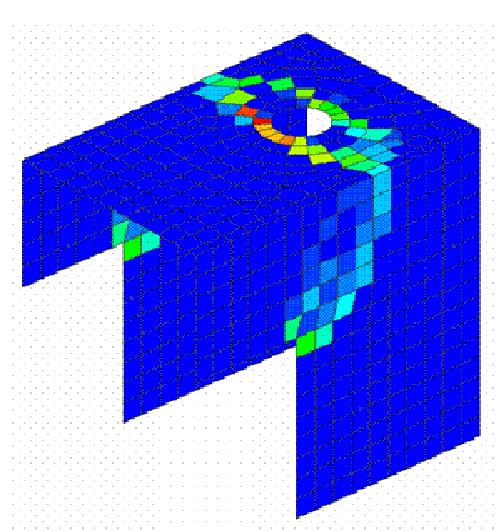

(a)

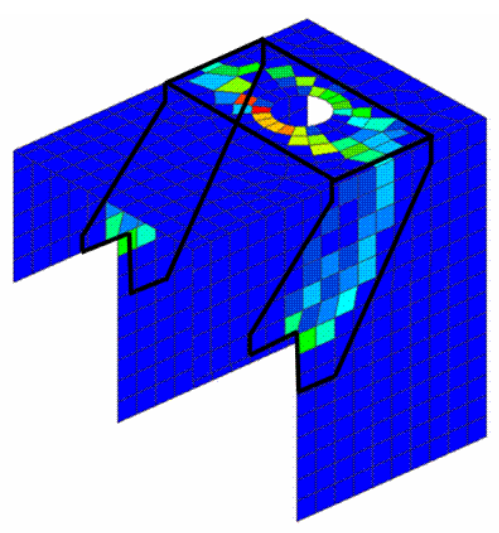

(b)

Figura 4.3 - (a) Resultado do programa de otimização topológica e (b) Sugestão de geometria factível de produção

Utilizando-se a metodologia de otimização topológica, pretende-se conseguir novas soluções com melhores resultados em comparação com a otimização paramétrica e de forma. A implementação da metodologia de otimização topológica, conforme já citada, está vinculada à disponibilidade de equipamento e pessoal capacitado.

Em ambos os casos de otimização estrutural, convém evitar a concentração de tensões nas regiões de solda do suporte e da estrutura que irá recebê-lo, evitando a ocorrência de problemas futuros relativos à fadiga da união soldada.

\subsubsection{Análise de estabilidade quanto à flambagem}

Os processos de otimização resultam normalmente em estruturas com novos formatos, o que possibilita, em alguns casos, acentuada redução das espessuras. É fundamental verificar a estabilidade quanto à flambagem das estruturas obtidas com paredes delgadas sujeitas à compressão, pois pode ocorrer o fenômeno de flambagem mesmo que a estrutura apresente níveis de tensões atuantes abaixo do limite admissível do material. 
Os conceitos da teoria de flambagem podem ser verificados no estudo de Niemann (1971), no qual a flambagem com deformações elásticas é calculada pelo método de Euler, obtendo-se a carga crítica de flambagem. Porém, para o dimensionamento de estruturas, é usual a utilização de programas de elementos finitos, obtendo-se o valor de tensão crítica de flambagem.

O critério adotado para a análise de flambagem consiste, basicamente, na análise da tensão crítica de flambagem $(\sigma c r)$ e na tensão atuante da estrutura $(\sigma)$ de acordo com a relação $\sigma<\sigma c r$. Portanto, atendendo a essa relação, a estrutura encontra-se aprovada pelo critério de flambagem.

Caso a estrutura a ser verificada apresente problemas relacionados à flambagem, convém verificar a viabilidade da introdução de elementos enrijecedores, o aumento da espessura ou a redução do comprimento suscetível à flambagem, segundo Chodraui e Malite (2007). Essa análise deve considerar fatores como fabricação, montagem, quantidade de componentes e massa. Caso sejam aplicados elementos estruturais enrijecedores, convém realizar novamente o ciclo de otimização.

\subsection{APLICAÇÃO DA ESPIRAL DE OTIMIZAÇÃO}

O ciclo de otimização é um processo interativo, no qual cada requisito interfere no desempenho dos outros de maneira não-linear, sendo oportuno, portanto, a aplicação do conceito de espiral no procedimento de desenvolvimento do suporte padrão.

Basicamente inicia-se a aplicação da espiral realizando as tarefas descritas no sentido anti-horário, de maneira grosseira no início e aumentando-se o nível de detalhamento a cada ciclo, possibilitando a adequação de todas as variáveis, segundo 
Silva (2007). Inicia-se a espiral com o conceito predefinido do suporte padrão. A cada volta da espiral, deve-se verificar a obtenção de melhorias, como:

- Criação do modelo MEF do conceito do suporte padrão para a análise de otimização topológica. É fundamental considerar sempre que possível a simplificação do modelo, prever sobre-metal no caso dos programas de otimização topológica que não permitam acrescentar material, determinar a densidade de malha conforme necessidade e representar as condições de contorno e carregamentos,

- Análise de otimização topológica. Convém definir a taxa de remoção de material e o número total de interações para a obtenção do modelo otimizado e inserir restrições a alguma característica necessária, por exemplo, a manutenção de uma área mínima de uma superfície para possibilitar a montagem de um componente. Deve-se observar que, acrescentando restrições ao programa de otimização, pode reduzir o ganho a ser obtido com a análise.

- Elaboração do modelo MEF conforme o resultado da análise de otimização topológica, representando a região compreendida pela área com material. Isso se torna necessário, pois o resultado da análise topológica apresenta, em alguns casos, contornos irregulares ou muito complexos de serem produzidos. É importante verificar a possibilidade de fabricação do suporte na criação ou na modificação do modelo e determinar a densidade de malha a ser aplicada e a representação das condições de contorno e carregamentos.

- Possibilidade de aplicação da malha com elementos de placa. Deve-se atender à relação $t / l \leq 0,1$; caso contrário, podem ser aplicados elementos sólidos ou proceder à alteração da geometria do modelo 
visando sua adequação aos critérios de espessura e de largura do elemento.

- Segundo os critérios de tensão de Von Mises, na análise MEF, é fundamental obter valores de tensão próximos ao valor de tensão admissível adotado ao material aplicado.

- Análise MEF de estabilidade à flambagem. Essa verificação torna-se necessária após a otimização da estrutura, pois pode, conforme descrito anteriormente, surgir regiões delgadas. Deve-se proceder a verificação segundo o critério $\sigma<\sigma c r$; caso necessário, pode-se optar pelo aumento gradativo da espessura ou pela aplicação de enrijecedores localizados. A inclusão de elementos enrijecedores está vinculada à necessidade de realizar novamente o ciclo de otimização topológica da estrutura, conforme descrito anteriormente.

- Verificação do atendimento aos critérios de projeto, principalmente no tocante as funções, massa, rigidez etc.

- Confirmação do atendimento dos critérios de fabricação e montagem. Devem ser verificados os processos envolvidos na obtenção do suporte, minimizando-os sempre que possível, propiciar a redução do número de componentes. No caso de suportes que envolvam peças soldadas entre si, é fundamental restringir a variação de espessuras das chapas, pois podem ocorrer problemas envolvendo a operação de soldagem entre chapas finas e grossas. Propor sempre que possível estruturas que permitam utilizar os processos produtivos existentes na planta produtiva, o que evita a necessidade de investimento em equipamentos ou materiais para atender a novos processos. Entretanto, convém ponderar a necessidade de investimentos em novos projetos com justificativas de custos ou relativas ao dimensionamento estrutural. É importante 
considerar o aproveitamento do material utilizado, o que reduz a geração de retalhos, ou seja, dispor, no caso, a peça planificada da melhor maneira para aproveitar ao máximo as dimensões da tira. Apesar de a aplicação dos conceitos de fabricação e montagem visar basicamente à simplificação dos produtos e aproveitamento dos recursos disponíveis na planta fabril, a sua utilização não impede o desenvolvimento e a fabricação de produtos inovadores.

- O ciclo de melhorias é finalizado após obter as características estipuladas na espiral de otimização, obtendo-se um suporte padrão otimizado.

Os procedimentos anteriormente descritos podem ser visualizados na representação gráfica da espiral de otimização, conforme mostrado na figura 4.4.

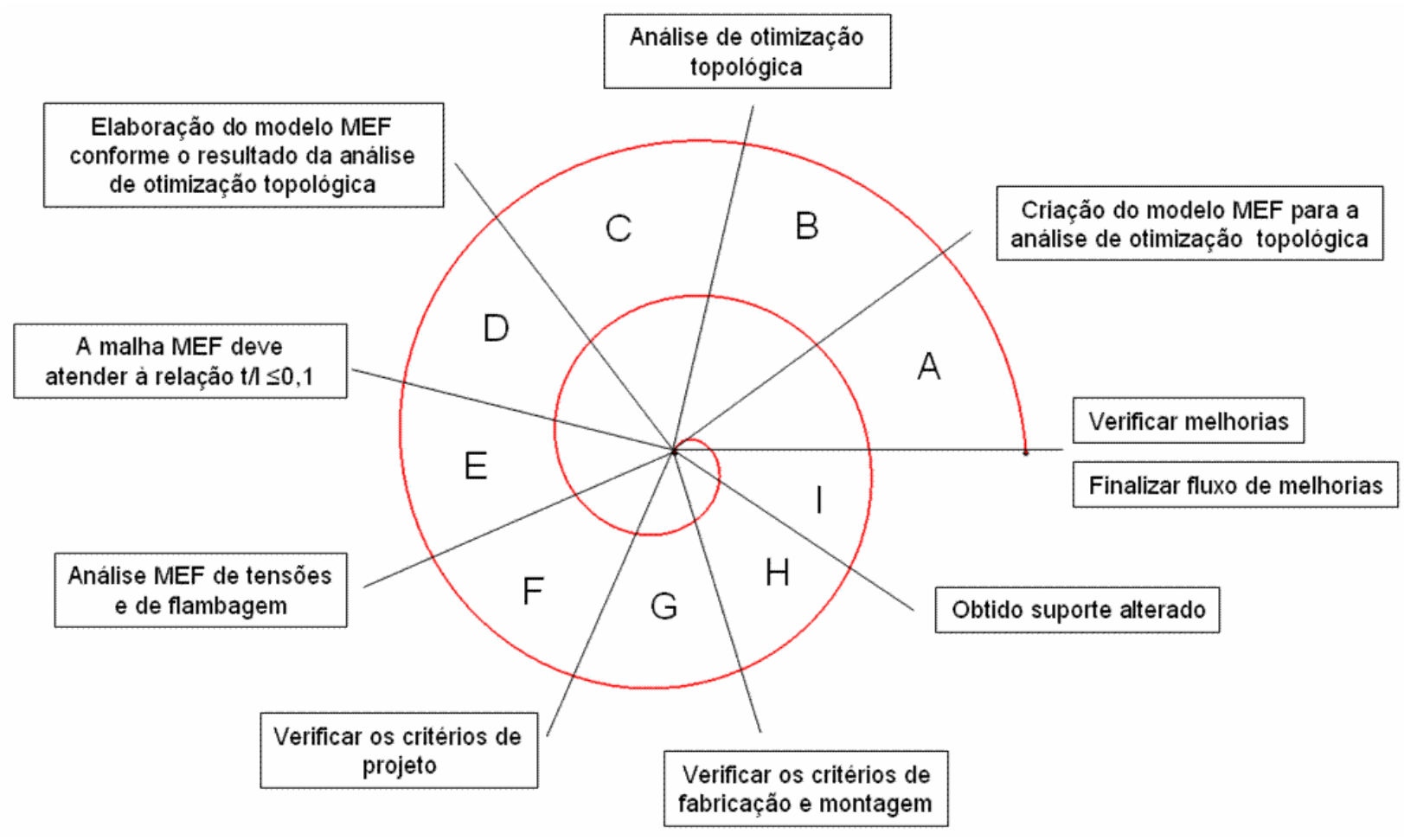

Figura 4.4 - Espiral de otimização 
Para uma melhor compreensão no uso da espiral de otimização, serão atribuídas letras na região central da espiral, representando as entradas e saídas em cada passo da espiral, conforme mencionado a seguir:
A - Entra o conceito do suporte padrão.
B - Sai o modelo MEF do suporte padrão.
C - Sai o suporte padrão otimizado.
D - Sai o modelo MEF modificado.
E - Sai a malha com elementos de placa ou sólidos.
F - Saem os valores de tensão de Von Mises e tensão crítica de flambagem.
G - Sai a estrutura que atende aos critérios do projeto.
$\mathrm{H}$ - Sai a estrutura que atende aos critérios de fabricação e montagem.
I - Obtém-se o suporte padrão e finaliza-se o fluxo de melhorias.

\subsubsection{Seleção da estrutura ótima}

Após a obtenção das propostas otimizadas que atendam aos requisitos descritos na espiral de otimização, inicia-se a análise das soluções observando-as de uma forma geral, considerando também os impactos gerados pelas propostas na estrutura completa. Caso a seleção da melhor proposta não seja trivial, torna-se necessária à utilização de uma matriz de decisão.

Entre os tipos de matrizes de decisão, verifica-se o conceito de Pugh (1996), no qual se baseia na comparação dos atributos das propostas, com a utilização de um conceito de referência. Realiza-se uma análise das vantagens (pontos positivos) com o uso do sinal "+" e das desvantagens (pontos negativos), aplicando o sinal "-" ou a igualdade ao conceito de referência utilizando o sinal "=" na matriz. A utilização dessa matriz permite a seleção do chamado conceito "vencedor", obtendo-se a melhor estrutura. 
Com o objetivo de exemplificar a aplicação do conceito de Pugh, verifica-se na tabela 4.1, a comparação das propostas A, B e C com uma estrutura de referência, atribuindo-se os sinais "+", "-" ou "=". Essas propostas são hipotéticas e não possuem referência com o estudo de caso do capítulo 5. A estrutura de referência é constituída de 5 peças soldadas, envolvendo os processos produtivos de estampagem e soldagem.

A proposta "A" refere-se a um suporte que envolve em sua fabricação basicamente o processo de corte e dobra da chapa, realizado em uma ferramenta progressiva. Na proposta "B" o suporte é constituído de 3 peças unidas por solda, enquanto na proposta "C" possui 4 peças unidas também por solda MAG. Verifica-se que a proposta "B" apresenta a melhor solução dentre as 3 propostas, somando 8 pontos positivos, seguidos pela proposta "C" com 6 e a proposta "A" com 4.

Tabela 4.1 - Seleção da proposta ótima (Pugh, 1996)

\begin{tabular}{ccccc}
\hline Atributo & Proposta A & Proposta B & Proposta C & Referência \\
\hline $\begin{array}{c}\text { omáx./massa } \\
\text { Número de }\end{array}$ & $=$ & +++ & +++ & + \\
componentes & +++ & ++ & + & - \\
Massa & -- & +++ & ++ & - \\
$\begin{array}{c}\text { Processos de } \\
\text { fabricação e }\end{array}$ & +++ & $=$ & $=$ & + \\
montagem & & & & 2 \\
Soma & 4 & 8 & 6 & Referência \\
Posição & 3 & 1 & 2 & \\
\hline
\end{tabular}

Schuyler (2001) propõe outro conceito de matriz de decisão, no qual são verificados os atributos para a aplicação da proposta segundo critérios a serem estabelecidos por meio de notas e pesos das características analisadas. Basicamente, realiza-se a somatória do produto dos pesos e das notas de cada coluna, obtendo-se a nota final de proposta. Realiza-se também o posicionamento das propostas e selecionase a de maior nota. As notas podem ser atribuídas de acordo com o que traz a tabela 4.2 . 
Tabela 4.2 - Critério de notas (Schuyler, 2001)

\begin{tabular}{cc}
\hline Critério & Nota \\
\hline Inviável & 0 \\
Pobre & 1 \\
Regular & 2 \\
Bom & 3 \\
Ótimo & 5 \\
\hline
\end{tabular}

Para exemplificar a aplicação da matriz de decisão de Schuyler na tabela 4.3, serão aplicadas as mesmas propostas utilizadas para demonstrar o conceito de Pugh. Inicia-se com os valores dos pesos que determinam a importância de cada requisito. A somatória dos pesos é igual a 1 , sendo que cada atributo recebe uma porcentagem do total, conforme o grau de importância definido pela política de desenvolvimento da empresa. A variação dos valores dos pesos pode alterar o resultado final da proposta. Em relação aos valores das notas, será realizada uma pequena explicação a seguir de como foram estabelecidas as notas aos atributos.

A comparação dos valores obtidos de omáx./massa das propostas possibilita a aplicação da maior nota a proposta que possuir o maior valor para a relação omáx./massa. A nota 5 foi aplicada às propostas $B$ e $C$ pois em ambos os casos os valores da relação encontrados foram elevados, enquanto na proposta "A" atribuiu-se a nota 2 devido ao baixo valor obtido.

No caso do número de componentes, a melhor proposta é a que possui o menor número de componentes. A proposta "A" recebeu a nota 5 , pois, conforme descrito anteriormente, é composta de apenas uma peça. A proposta "B", constituída de 3 peças, e a proposta "C", de 4 peças, receberam a nota 1.

Para o critério de massa, considera-se a melhor proposta a de menor massa. No entanto, caso necessário, deve ser verificada a necessidade do aumento da massa da estrutura, devido, por exemplo, a problemas de vibrações. As propostas "B" e "C" 
receberam a nota 5 , pois possuem o menor peso entre as 3 propostas. A proposta " $A$ " obteve a nota 1 , pois possui o maior peso.

No atributo de processos de fabricação e montagem, obtém a maior nota a proposta que utilizar o menor número de processos produtivos. Verifica-se a nota 5 para a proposta "A" obtida apenas por meio do processo de estampagem, enquanto as propostas "B" e "C" receberam respectivamente as notas 3 e 1 devido à utilização de processos de estampagem e soldagem.

No exemplo ilustrado na tabela 4.3, a proposta "B" foi selecionada por apresentar a nota mais elevada, representando a proposta que melhor atende aos atributos definidos. Será utilizada a matriz de decisão de Schuyler no capítulo referente à aplicação do procedimento de desenvolvimento de suportes no estudo do suporte do amortecedor.

Tabela 4.3 - Seleção da proposta ótima (Schuyler, 2001)

\begin{tabular}{ccccccccc}
\hline & \multicolumn{1}{c}{ Proposta A } & \multicolumn{2}{c}{ Proposta B } & \multicolumn{2}{c}{ Proposta C } \\
\hline Atributo & Peso & Nota & Notaxpeso & Nota & Notaxpeso & Nota & Notaxpeso \\
omáx./massa & 0,30 & 2 & 0,60 & 5 & 1,50 & 5 & 1,50 \\
$\begin{array}{c}\text { Número de } \\
\text { componentes }\end{array}$ & 0,20 & 5 & 1,00 & 1 & 0,20 & 1 & 0,20 \\
$\quad \begin{array}{c}\text { Massa } \\
\text { Processos de }\end{array}$ & 0,25 & 1 & 0,25 & 5 & 1,25 & 5 & 1,25 \\
fabricação e & 0,25 & 5 & 1,25 & 3 & 0,75 & 1 & 0,25 \\
montagem & & & 3,10 & & 3,70 & & 3,20 \\
Soma & 1,00 & & 3 & & 1 & & 2 \\
Posição & & & & & & & \\
\hline
\end{tabular}

Com o propósito de verificar a correta aplicação da metodologia de desenvolvimento de suportes otimizados, convém utilizar uma listagem de controle, de acordo com a tabela 4.4. As tarefas descritas nessa listagem podem ser alteradas conforme a necessidade, incluindo ou eliminando itens. 
Tabela 4.4 - Listagem de controle

Desenvolver o conceito do suporte padrão

Verificado as funções do suporte
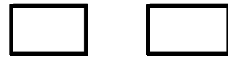

Conceituado a proposta

(definido o tipo de construção e união, efetuado a
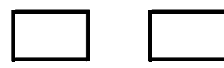
análise de montabilidade e dimensional)

Atendido as necessidades do projeto

Atendido os critérios de fabricação e montagem

Análise de otimização

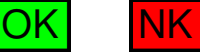

Aplicada a densidade e tipo de malha compatível

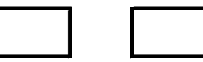

Aplicado o material

Aplicado as condições de contorno

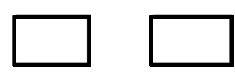

Aplicado os carregamentos

Definida a taxa de remoção ou determinado o $n^{-}$ total de interações

Análise MEF de tensões de Von Mises e de flambagem
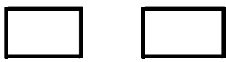

Aplicada a densidade de malha compatível
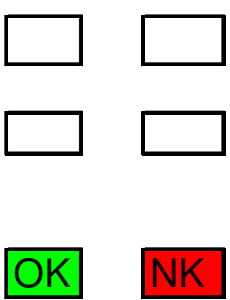

Aplicado o material

Aplicado as condições de contorno
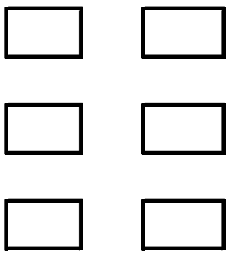

Aplicado os carregamentos

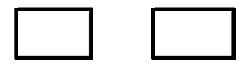

A malha atende a relação $t / l \leq 0,1$ ?

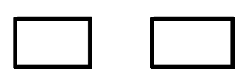

Modelagem com elementos sólidos

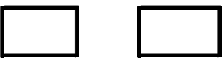

Submetido a análise MEF 
Atendido o critério de tensões $\sigma \leq \sigma a d m$

Atendido o critério de flambagem $\sigma<\sigma c r$

Incluído elementos enrijecedores

Alterado a espessura

Atendido aos critérios de fabricação e montagem

Obtido o suporte padão

Responsável

$\begin{array}{r}\text { Data } \\ 1+1 \\ \hline\end{array}$

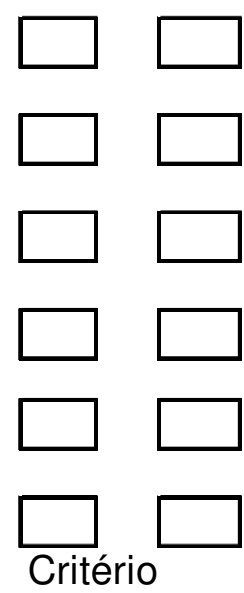

OK - aprovado

NK - reprovado 


\section{APLICAÇÃO DO PROCEDIMENTO DE DESENVOLVIMENTO DE SUPORTES NO ESTUDO DO SUPORTE DO AMORTECEDOR}

Serão aplicados no desenvolvimento de um suporte os procedimentos descritos no capítulo referente ao procedimento de desenvolvimento de suportes, com o intuito de exemplificar a utilização do método proposto na obtenção de estruturas otimizadas e viáveis de serem produzidas. No estudo será analisado o dimensionamento otimizado de um suporte, no qual seguirá os seguintes passos:

- Representar a falha no suporte.

- Analisar o suporte reforçado.

- Propor uma versão padrão com a aplicação da metodologia de otimização paramétrica em conjunto com a metodologia de otimização de forma.

- Obter um suporte padrão com o uso da metodologia de otimização topológica.

\subsection{ANÁLISE CONCEITUAL DO SUPORTE}

Considerou-se neste estudo a utilização de um suporte com histórico de falha devido à possibilidade de enriquecer a análise, obtendo-se soluções diferentes da utilizada pela equipe de projeto do veículo na ocasião. Portanto, trata-se do desenvolvimento de uma nova proposta de suporte a ser aplicada a uma estrutura veicular existente. Torna-se importante a verificação das necessidades e limitações existentes no projeto.

Para o desenvolvimento de um novo suporte de amortecedor, efetuou-se a sua análise funcional, obtendo-se as seguintes funções:

- Suportar o amortecedor. 
- Unir o amortecedor à estrutura do veículo.

- Suportar os carregamentos e prover resistência mecânica.

- Prover leveza.

O engenheiro de projeto deve considerar também o espaço necessário e o acesso para a montagem do amortecedor, permitindo a sua cinemática. Deve também prever o acesso para a realização da operação de soldagem e efetuar a pesquisa da carga máxima atuante ao dimensionar a estrutura.

Verificam-se problemas conceituais no suporte falho, pois ele não atende às funções básicas de um suporte de amortecedor. É importante a compreensão do funcionamento do sistema na ocasião do estabelecimento do conceito da estrutura, visando o entendimento do problema. Será exposta a seguir uma breve descrição da utilização do suporte.

O suporte do amortecedor é montado no chassi de ônibus articulado na região do eixo intermediário, conforme ilustra a figura 5.1, sendo aplicados quatro suportes no eixo.

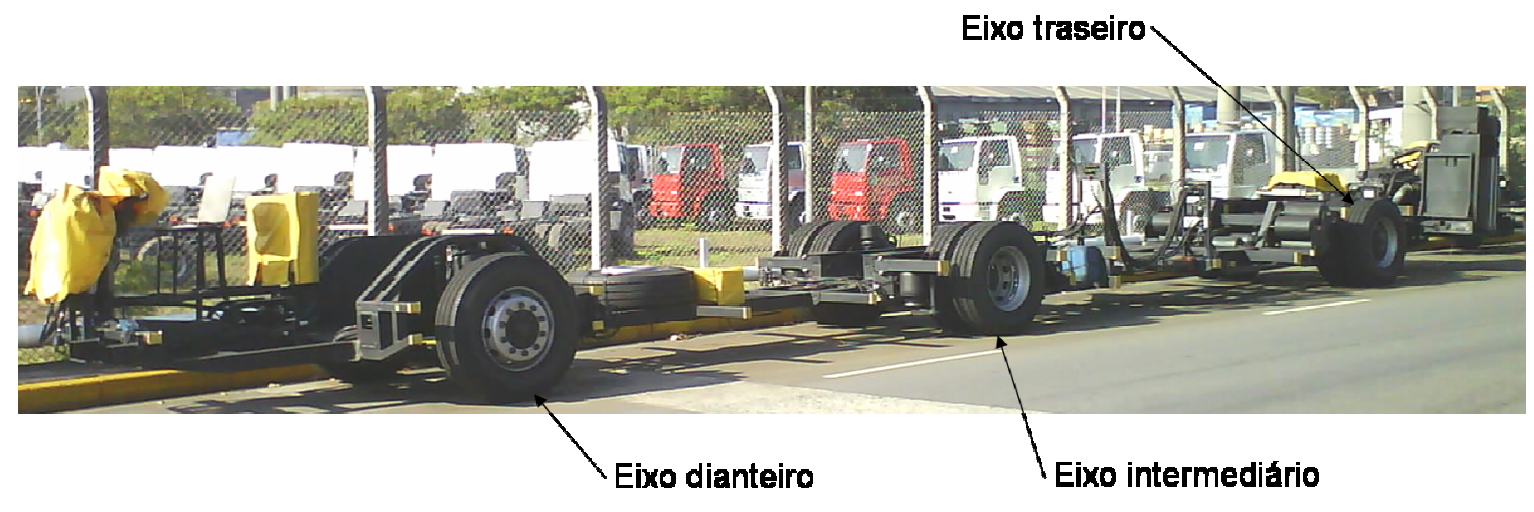

Figura 5.1 - Chassi de ônibus articulado de motor traseiro

Verifica-se em detalhe o suporte em questão na figura 5.2. A falha do suporte pode provocar problema de estabilidade ao veículo ao realizar uma curva, além de reduzir o conforto aos passageiros e provocar o desgaste irregular dos pneus. 


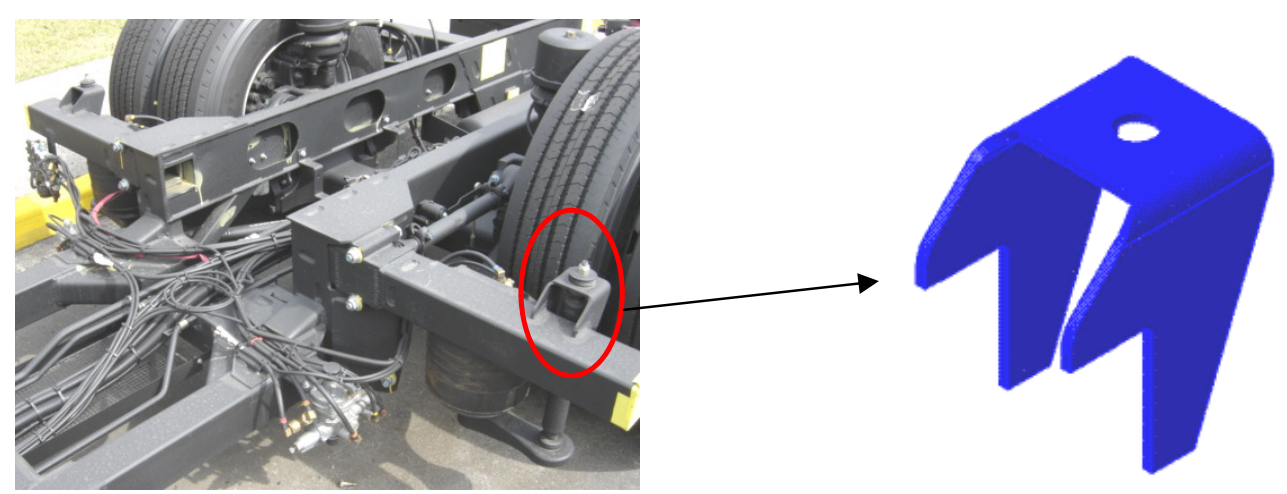

Figura 5.2 - Montagem do amortecedor e geometria do suporte do amortecedor

Em decorrência das características do projeto de suspensão, os suportes de amortecedores desse chassi possuem uma função adicional, sendo utilizado como batente final do curso inferior da suspensão. Ou seja, no momento em que a massa não suspensa do veículo (eixo, pneus, rodas e componentes da suspensão) tem um deslocamento para baixo devido à queda em uma depressão, o sistema, após utilizar todo o curso útil da suspensão, tem o final de curso no amortecedor totalmente distendido.

Dessa forma, é transmitido o carregamento ao suporte do amortecedor, que está fixo ao chassi. Portanto, uma porção da massa não suspensa do eixo é sustentada pelo suporte do amortecedor, além das demais funções descritas anteriormente no capítulo 3.

A falha no suporte do amortecedor em questão ocorreu prematuramente aos $28.000 \mathrm{~km}$, ainda na fase de testes de durabilidade fora de estrada com o veículo completo (carroçaria e chassi) carregado com a capacidade técnica de 28 ton (carregamento no qual o veículo foi dimensionado).

A quilometragem até a falha representa somente uma parte do total de 50.000 $\mathrm{km}$ necessário à aprovação estabelecida para o teste nesta empresa. O suporte na ocasião do teste estava instrumentado com extensômetros para mapear o nível de tensões na região. A tensão máxima medida na região da falha foi de $280 \mathrm{MPa}$. 
O detalhe "A" indicado na figura 5.3 apresenta o local da fratura do suporte. Verifica-se também a amplitude dos movimentos (a área cinza no suporte) do coxim de borracha montado entre o suporte e a arruela de fixação em razão das irregularidades severas da pista de testes. O veículo foi forçado a realizar torções e finais de cursos de suspensão superior e inferior.

O final de curso superior pode ser obtido quando o veículo transita sobre saliências na pista. Nesse caso, ocorre o final de curso nos batentes do interior das molas pneumáticas (bolsas de ar), sem transferência do esforço ao suporte do amortecedor. O suporte falho é constituído por uma peça única dobrada feita de chapa de aço NBR 6656 LNE 38 laminada a frio com espessura de $6 \mathrm{~mm}$.
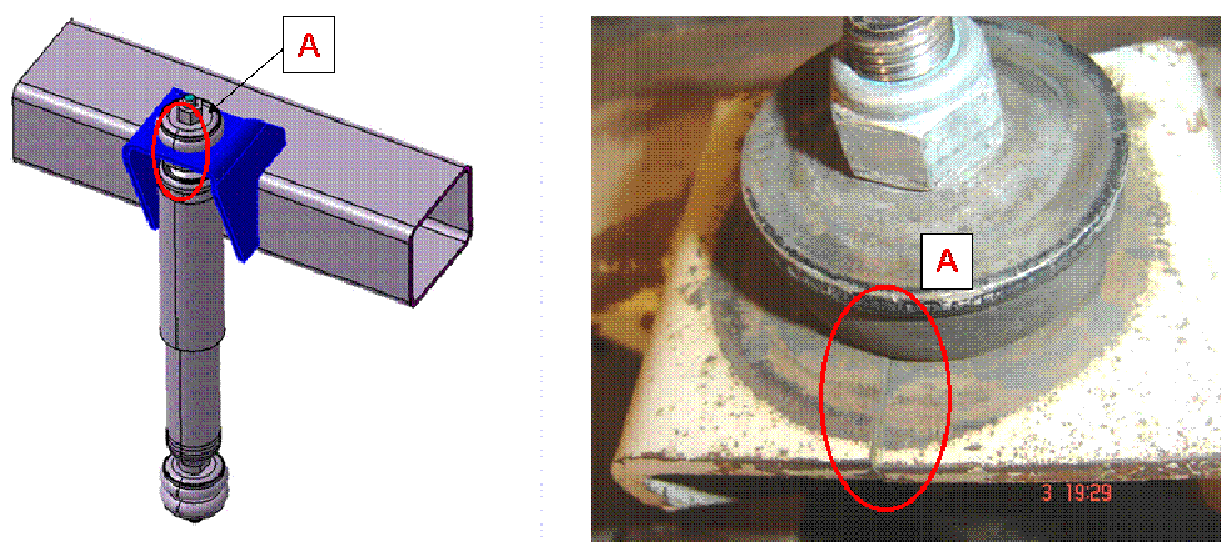

Figura 5.3 - Montagem do suporte com o amortecedor e detalhe da falha

\subsection{PROCEDIMENTOS PARA A REALIZACAO DA ANÁLISE MEF}

Inicialmente, verificou-se a possibilidade da aplicação de elementos de placa nos modelos MEF das propostas devido à facilidade de modelagem e à redução do tempo computacional. Porém, observando-se a relação $t / l \leq 0,1$, torna-se inviável a aplicação da malha com elementos de placa para a espessura de $6 \mathrm{~mm}$ do suporte em 
relação à densidade de malha aplicada. $\mathrm{O}$ atendimento da relação anteriormente exposta resultaria em uma malha extremamente grosseira.

Em decorrência da característica descrita, optou-se pela modelagem com elementos sólidos, sendo gerados por meio da extrusão da malha de placas de elementos quadriláteros de 4 nós, obtendo-se um modelo com elementos sólidos hexaédricos de 8 nós.

Com o objetivo de melhorar a precisão dos resultados, reduzir o tamanho do modelo assim como o tempo computacional, adotou-se o refinamento da malha em regiões de interesse. Com o intuito de definir a densidade da malha refinada, realizouse uma análise de valores de tensão obtidos com a variação do tamanho da malha.

O modelo aplicado para a análise consiste de uma malha representando a porção superior do suporte do amortecedor (denominada tampa), com os graus de liberdade e respectivas rotações restringidas nas laterais. Aplicou-se um carregamento de $1 \mathrm{MPa}$ distribuído na área da malha contida entre o furo de $\varnothing 25 \mathrm{~mm}$ e a circunferência de Ø55 mm. Esta região representa a área de aplicação de carga do coxim de borracha, conforme ilustrado na figura 5.4.

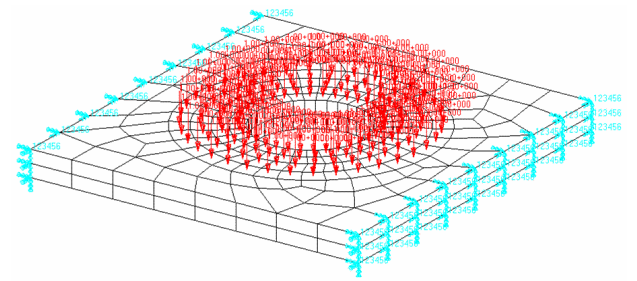

Figura 5.4 - Modelo para teste de densidade da malha

Para o refinamento da malha, dividiu-se radialmente o diâmetro do furo e da circunferência referente ao coxim e aplicou-se inicialmente uma malha mais grosseira com 20 nós até a utilização de uma malha mais refinada com 40 nós, gerando uma malha conforme indica a figura 5.5 . 


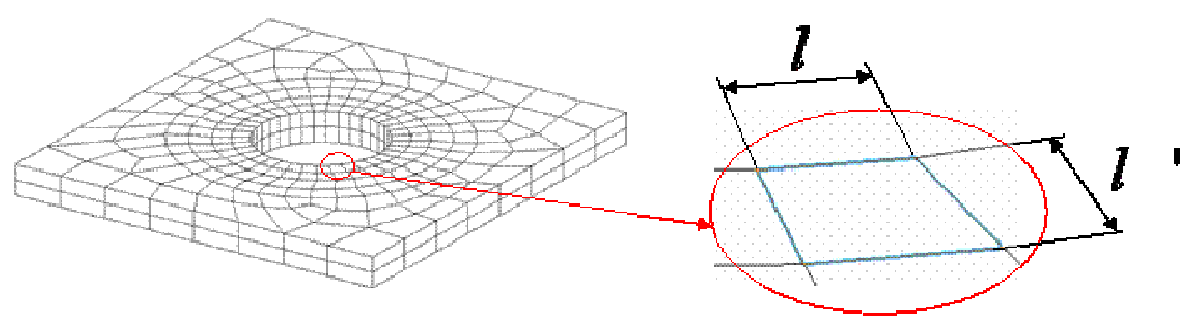

Figura 5.5 - Dimensões do elemento

Nota-se uma variação crescente nos valores de tensão ao reduzir o tamanho dos elementos da malha, obtendo-se, a partir do quinto teste, valores constantes de tensão. Dessa forma, adota-se a malha do teste número 5 , gerando elementos de 2,3×3,3 mm na região próxima ao furo, conforme mostra a tabela 5.1. Nas demais regiões, será aplicada uma malha geral de $10 \mathrm{~mm}$.

Tabela 5.1 - Testes de densidade de malha

\begin{tabular}{cccc}
\hline $\begin{array}{c}\text { Teste } \\
\text { n. }\end{array}$ & $\begin{array}{c}\text { Tamanho da Malha } l x l \\
(\mathrm{~mm})\end{array}$ & $\begin{array}{c}\text { Quantidade de nós } \\
\text { (no furo) }\end{array}$ & $\begin{array}{c}\text { Tensão } \\
(\mathrm{MPa})\end{array}$ \\
\hline 1 & $3,9 \times 4,9$ & 20 & 301 \\
2 & $3,3 \times 4,7$ & 24 & 312 \\
3 & $2,7 \times 4,4$ & 28 & 314 \\
4 & $2,5 \times 3,5$ & 32 & 322 \\
5 & $2,3 \times 3,3$ & 36 & 324 \\
6 & $1,9 \times 3,4$ & 40 & 324 \\
\hline
\end{tabular}

A figura 5.6 ilustra as dimensões principais do modelo do suporte de amortecedor. 


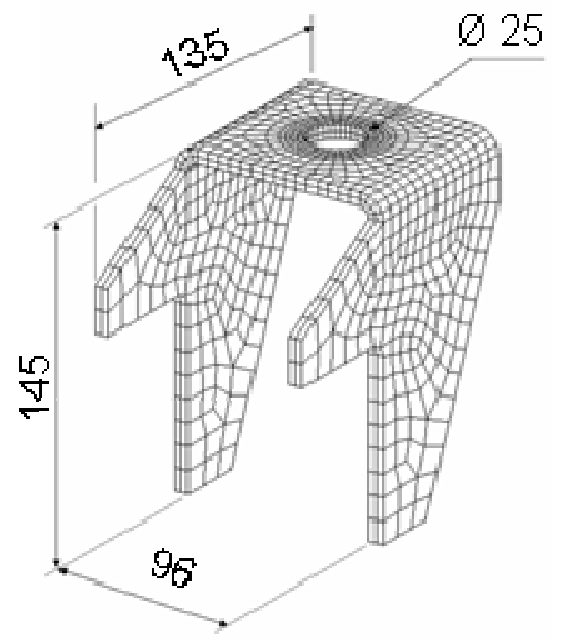

Figura 5.6 - Modelo de elementos finitos

Nas regiões de união entre as malhas da tampa, os raios e as laterais, utilizouse 0 artifício de coincidência dos nós, com o intuito de unir as partes da malha. $\mathrm{Na}$ figura 5.7, são representadas as regiões de união com retângulos em vermelho.

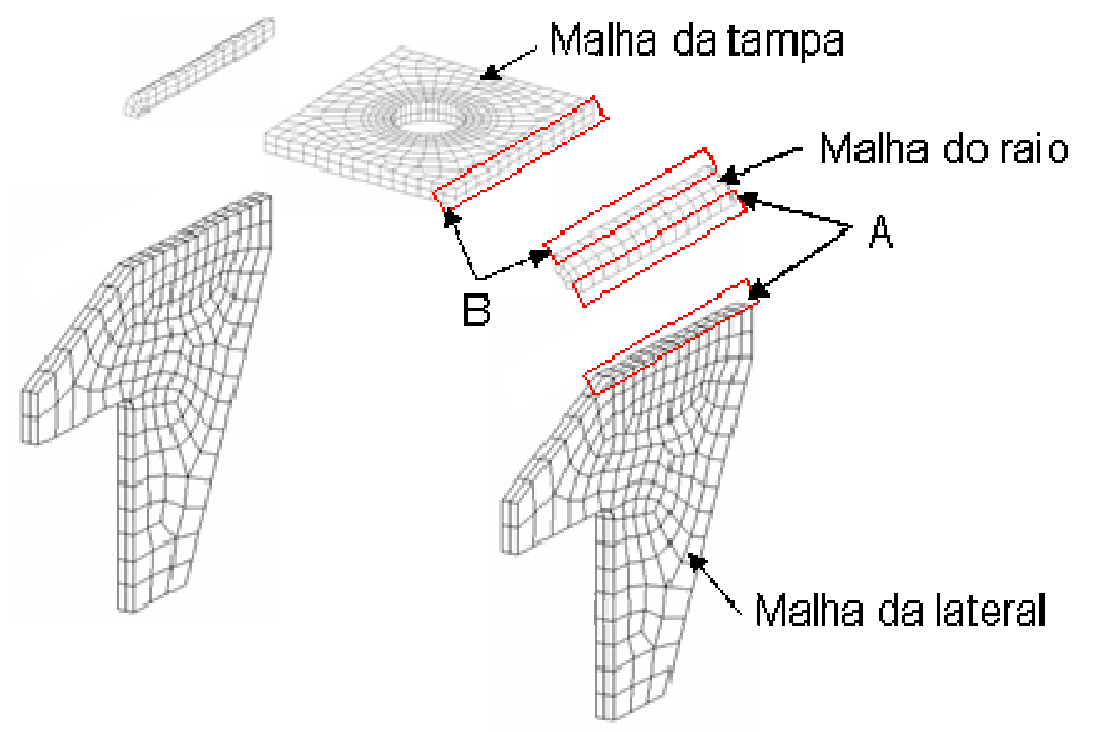

Figura 5.7 - Coincidência de nós da malha

$\mathrm{Na}$ análise do suporte do amortecedor, a região da tampa representa o local de maior interesse no estudo devido à falha em campo. Com o propósito de representar a 
falha com o uso de um modelo mais simples, realizou-se um estudo comparativo do valor de tensão máxima atuante de duas versões de modelo de elementos finitos com o uso da versão completa (suporte fixo ao tubo) e da versão simplificada do modelo MEF.

Na primeira análise, avaliou-se a versão de projeto que consiste basicamente no suporte fixo ao tubo conforme a figura 5.8, representando as condições de contorno similares às aplicadas ao veículo. Limitou-se o comprimento excedente do tubo em relação ao suporte em ambos os lados, sendo que a medida "B" representa duas vezes o valor da dimensão "A" do tubo (120 mm). Restringiram-se os graus de liberdade nos eixos $x, y$ e $z$ e as rotações em torno deles nas extremidades do tubo. Para a representação da união do suporte ao tubo, efetuou-se a coincidência dos nós da malha do suporte e do tubo, representando a região de solda, conforme descrito anteriormente.

Para a determinação do carregamento a ser aplicado na análise MEF, foi realizada inicialmente uma verificação das especificações em desenho, no qual constam as forças de reação do amortecedor. $O$ amortecedor apresenta as seguintes forças contrárias ao movimento: extensão $5634 \mathrm{~N}$ e compressão $913 \mathrm{~N}$ com um curso útil de $100 \mathrm{~mm}$. Utilizou-se o maior carregamento para o estudo (5634 N). Com base na força de extensão, foi calculada a pressão de 2,98 MPa distribuída na área circular compreendida entre o furo de $\varnothing 25 \mathrm{~mm}$ e a circunferência de $\varnothing 55 \mathrm{~mm}$.

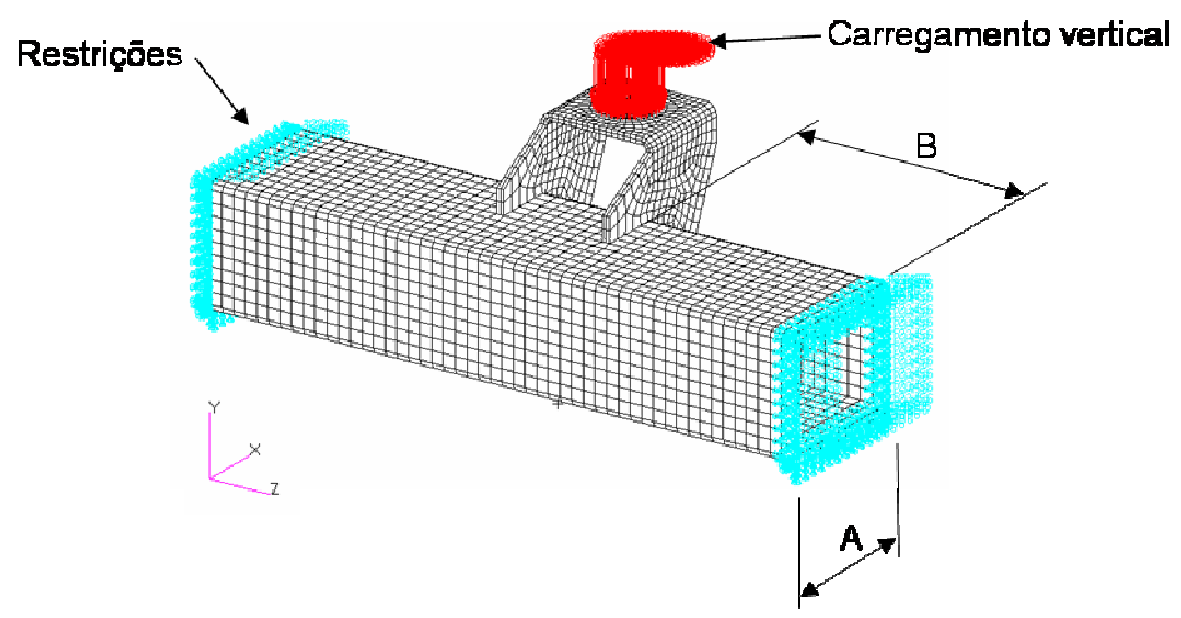

Figura 5.8 - Suporte fixo ao tubo (versão de projeto) 
Para a simulação da segunda proposta (versão simplificada), eliminou-se do modelo de MEF o tubo retangular e transferiram-se os engastes diretamente para o suporte a ser analisado. Realizou-se também a restrição aos graus de liberdade e aplicou-se o carregamento (conforme descrito na primeira proposta), obtendo-se uma geometria menor e mais simples como apresentado na figura 5.9.

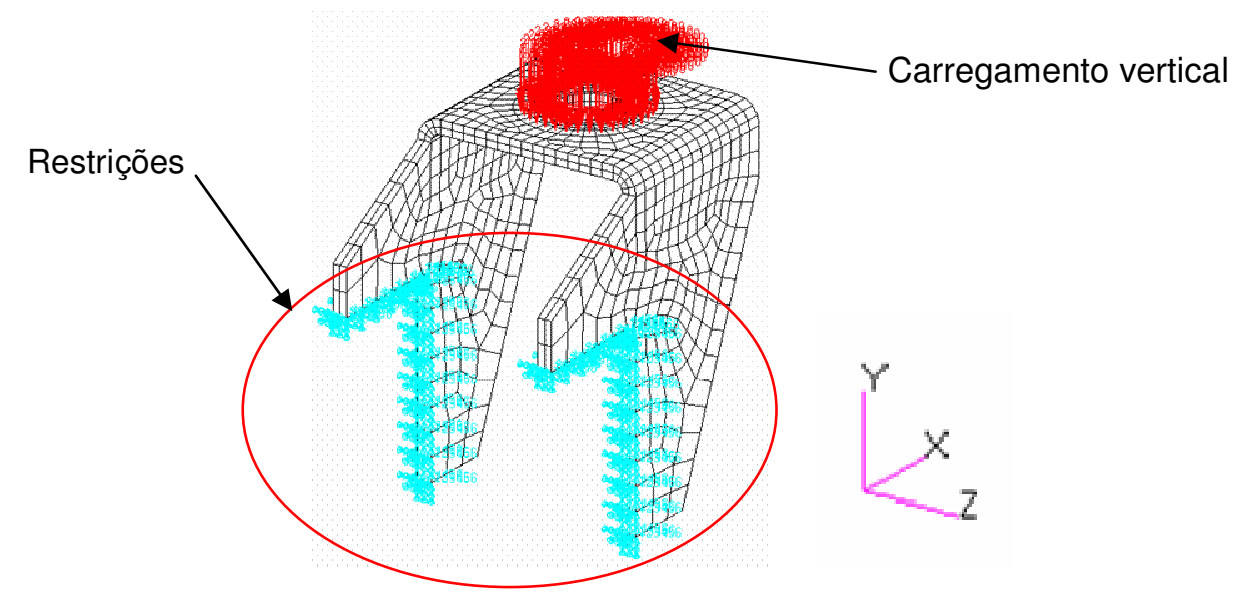

Figura 5.9 - Aplicação das restrições e do carregamento vertical (versão simplificada)

Analisando-se os resultados obtidos nas duas versões, ilustrados nas figuras 5.10 e 5.11, verifica-se que a simplificação do modelo, apesar de divergir da realidade do projeto, apresenta-se bastante precisa, pois os resultados obtidos variaram apenas $1,4 \%$ em relação à tensão máxima, e a redução do tempo computacional obtida é da ordem de $39 \%$, conforme indica os dados da tabela 5.2 .

Porém, apesar da elevada redução percentual do tempo computacional, ele é reduzido de 10,72 Seg para 4,21 Seg, tornando a simplificação da estrutura MEF, nesse caso, importante somente para a diminuição do volume de trabalho na obtenção do modelo MEF. Serão adotados modelos simplificados apenas com o suporte do amortecedor nas seguintes análises deste capítulo. 


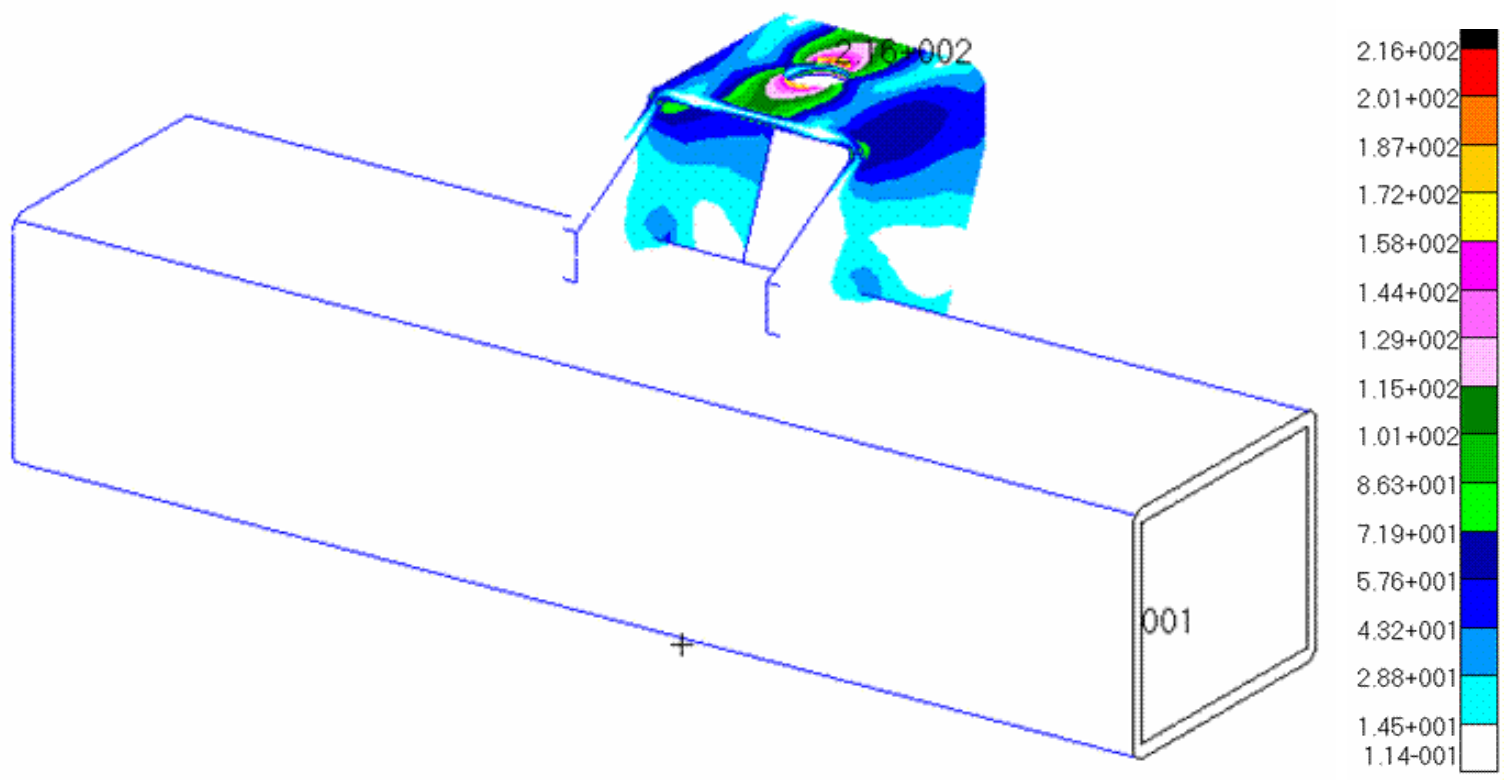

Figura 5.10 - Suporte falho com tubo (versão de projeto) - Tensões em MPa

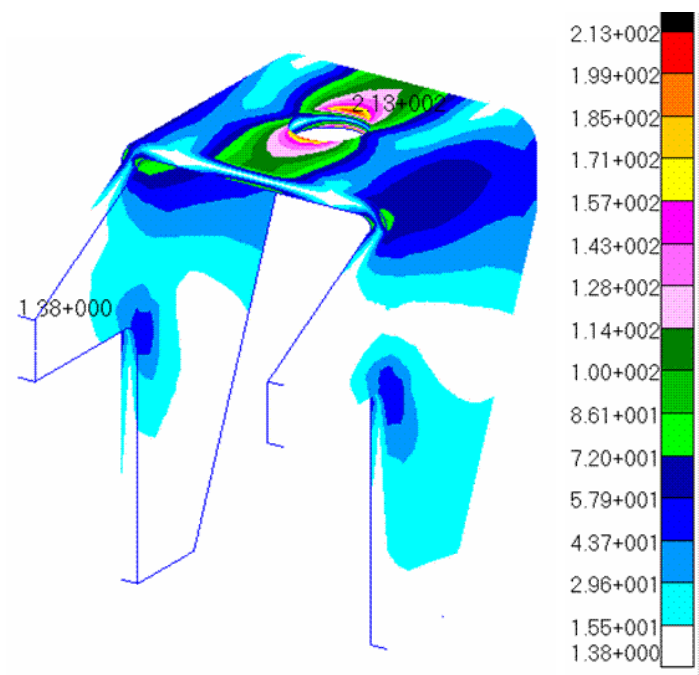

Figura 5.11 - Suporte falho (versão simplificada) - Tensões em MPa

Analisando-se as tensões máximas obtidas, observa-se que apenas a aplicação do carregamento descrito anteriormente se torna insuficiente para representar a tensão obtida de $280 \mathrm{MPa}$ na medição do veículo com falha. Após a análise MEF, nota-se um valor de tensão de $213 \mathrm{MPa}$, conforme mostra a figura 5.11 , tornando-se necessária a calibração do carregamento para o modelo MEF. 
Tabela 5.2 - Tempo computacional das análises

\begin{tabular}{cccc}
\hline Suporte & $\begin{array}{c}\text { Tensão máxima } \\
\text { atuante (MPa) }\end{array}$ & $\begin{array}{c}\text { Variação no } \\
\text { valor de tensão } \\
(\%)\end{array}$ & $\begin{array}{c}\text { Tempo } \\
\text { computacional } \\
(\text { Seg) }\end{array}$ \\
\hline Versão de projeto & 216 & 0 & 10,72 \\
Versão simplificada & 213 & $-1,4$ & 4,21 \\
\hline
\end{tabular}

5.2.1 Calibração do modelo de elementos finitos

Em decorrência da não obtenção do valor de tensão máxima de $280 \mathrm{MPa}$, foram realizadas simulações de elementos finitos para se conseguir a correlação de tensões entre o teste de durabilidade e a simulação de elementos finitos. Como resultado, foi obtido um fator de correlação de aproximadamente 1,3 , que equivale à utilização de uma pressão atuante de $3,92 \mathrm{MPa}$, substituindo o carregamento anterior de 2,98 MPa.

Esse fator foi aplicado ao longo desta pesquisa e tornou-se necessário o seu uso para representar a parcela de carregamento devido ao batente de final de curso inferior da suspensão sobre os suportes dos amortecedores. Verifica-se na figura $5.12 \mathrm{a}$ obtenção do valor de tensão de $280 \mathrm{MPa}$, conforme as medições do veículo que apresentou a falha. 


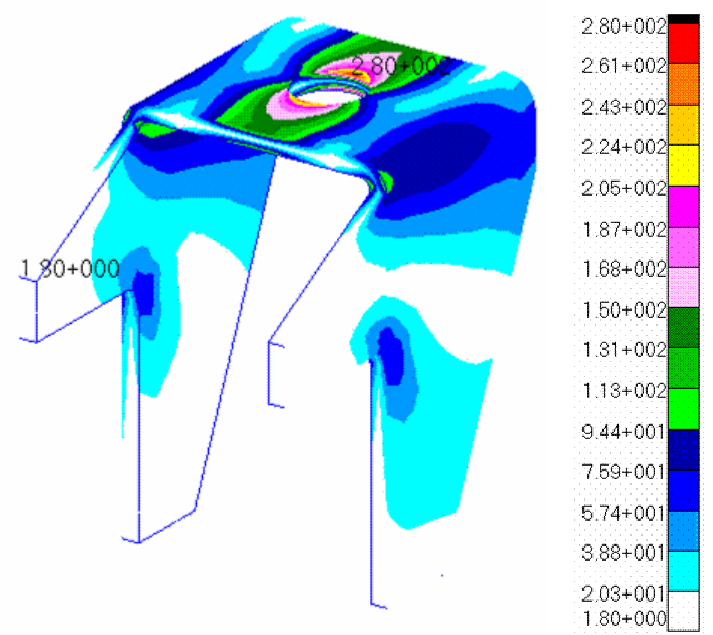

Figura 5.12 - Suporte falho com carregamento calibrado - Tensões em MPa

Foi estipulado que o limite máximo de tensão atuante no suporte do amortecedor não deva ultrapassar o valor de $250 \mathrm{MPa}$, tensão limite determinado pelo laboratório de materiais e ensaios mecânicos da empresa. Empregou-se na fabricação do suporte o valor de tensão admissível para o aço NBR 6656 LNE 38.

\subsection{ANÁLISE DO SUPORTE REFORÇADO}

Para o reinício dos testes de aprovação do veículo o mais breve possível, utilizou-se o suporte reforçado como uma solução paliativa, devido à ocorrência de falha em campo. O suporte reforçado é composto por chapas de reforço dianteira e traseira e disco superior aplicado à versão inicial de suporte (que apresentou falha) unidos por meio de solda MAG, conforme ilustra a figura 5.13. 

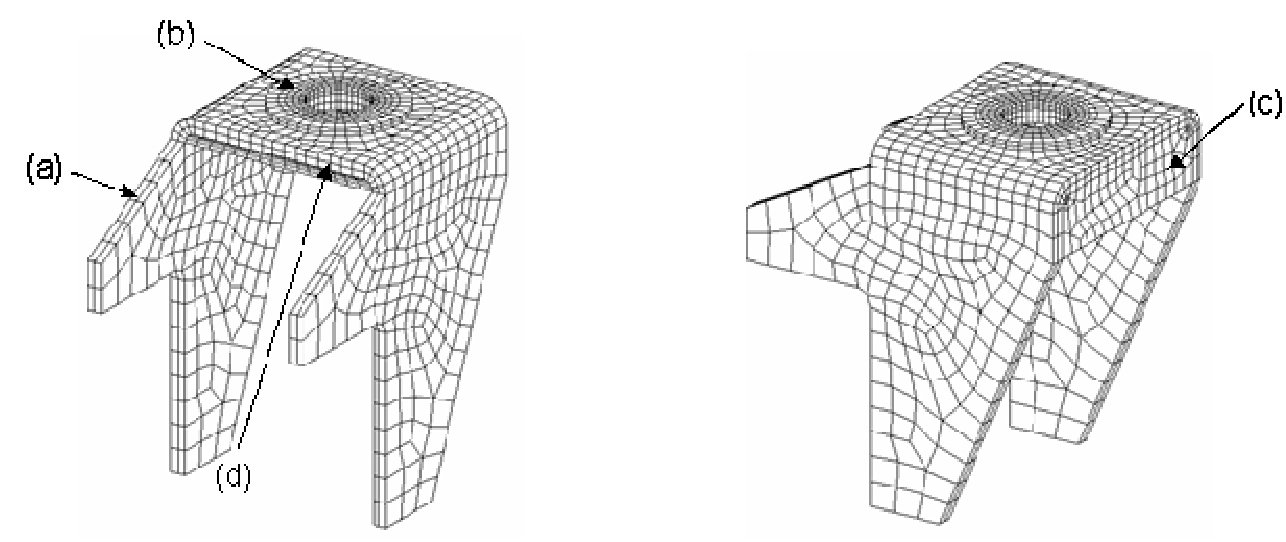

Figura 5.13 - Suporte reforçado, (a) Suporte, (b) Disco, (c) Chapa traseira e (d) Chapa dianteira

Com base no carregamento e nas condições de contorno estabelecidos no estudo anterior, realizou-se a modelagem e simulação do suporte liberado para a montagem no veículo após a quebra da primeira versão. Os valores de tensão máxima atuantes obtidos na simulação do suporte reforçado são da ordem de $149 \mathrm{MPa}$, conforme mostra a figura 5.14. Apresentam-se níveis de tensão admissível abaixo do valor estabelecido de $250 \mathrm{MPa}$, sendo, portanto, superdimensionado para esse uso.

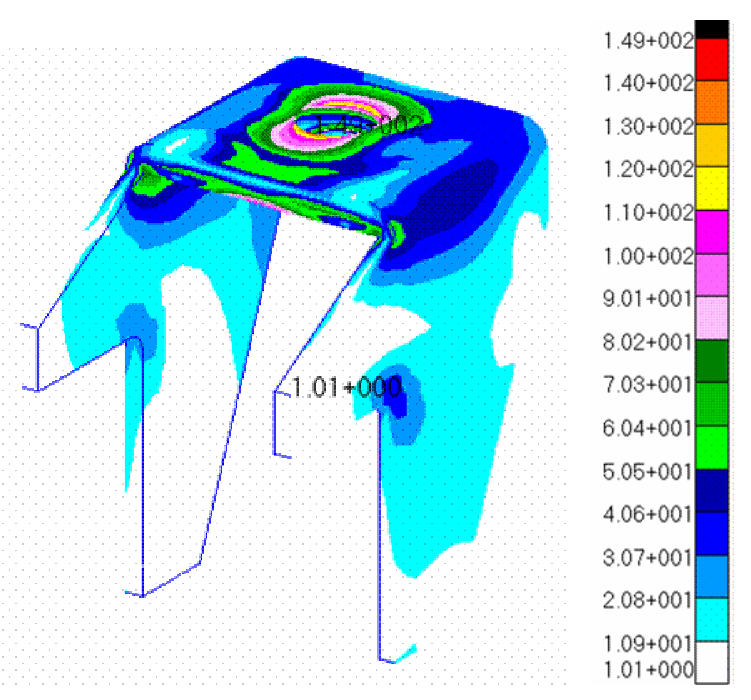

Figura 5.14 - Suporte reforçado - Tensões em MPa 


\subsection{PROPOSTAS DE SUPORTES PADRÕES UTILIZANDO A METODOLOGIA DE OTIMIZAÇÃO PARAMÉTRICA E DE FORMA}

$\mathrm{Na}$ análise do suporte reforçado, nota-se a necessidade de um estudo criterioso para obter a peça ótima, adequada à fabricação e com conseqüente redução de peso e economia de matéria-prima. Apesar de a metodologia de otimização paramétrica e de forma serem apresentadas separadamente no capítulo inicial, aqui a sua utilização será em conjunto devido às possibilidades de variar tanto a forma quanto as bitolas dos materiais.

O emprego dessas metodologias em conjunto está difundido nas áreas de projeto, com seus conceitos aplicados no cotidiano das empresas.

\subsubsection{Modelagem MEF PATRAN / NASTRAN}

Foram utilizados modelos MEF simplificados nas propostas de suporte do amortecedor nas análises a seguir, com as características de malha e refinamentos conforme descrito anteriormente. Visando maior flexibilização das possibilidades de variações de forma e espessuras, o suporte foi inicialmente composto de duas chapas laterais e uma chapa superior (tampa), unidas entre si por solda MAG, tornando-se uma das principais características desse modelo.

Com o objetivo de representar as uniões soldadas dos elementos sólidos hexaédricos da malha, utilizou-se a técnica de coincidência dos nós conforme descrito anteriormente. No modelo MEF, as malhas laterais da tampa possuem propriedades do material e espessura independentes uma das outras. Portanto, na análise MEF do suporte, podem-se variar as propriedades das partes independentemente, como mostra a figura 5.15. Contudo, essas partes interagem entre si. 


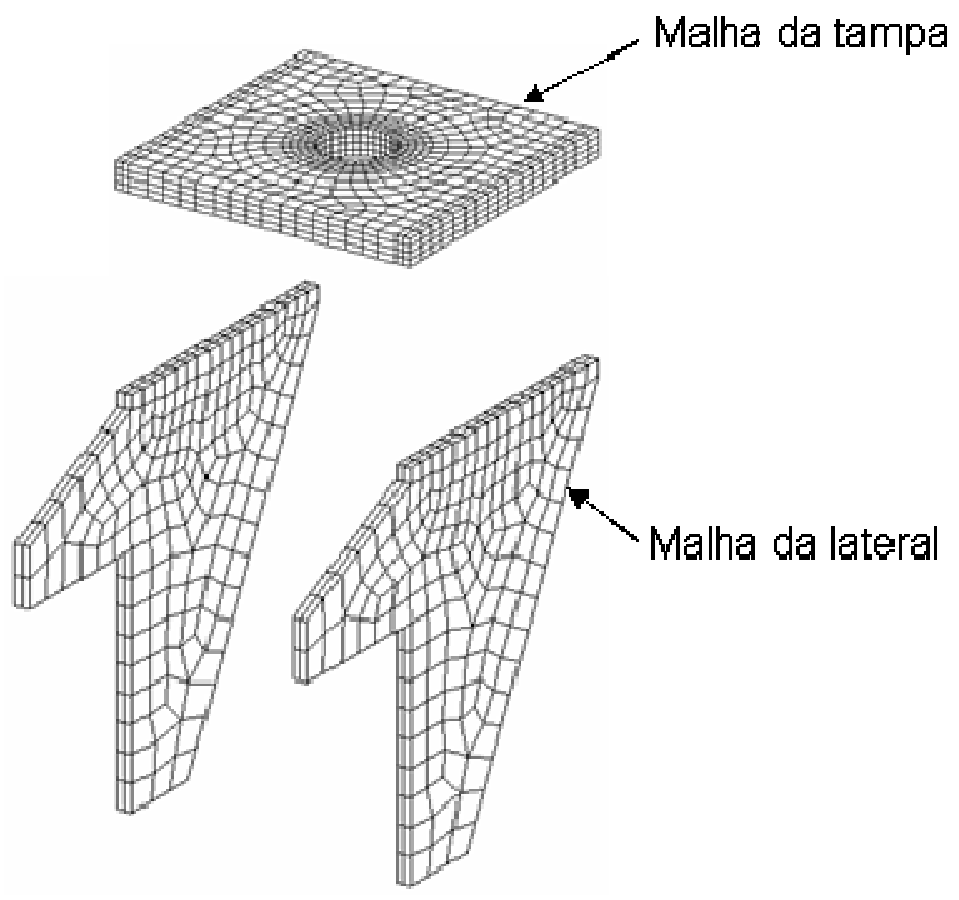

Figura 5.15 - Malha do suporte versão de chapas soldadas

\subsubsection{Avaliação dos resultados MEF PATRAN}

Em relação ao superdimensionamento apresentado no suporte proposto para saneamento em campo, conforme mostra a figura 5.14, realizou-se a otimização paramétrica e de forma. Foram geradas diversas soluções com tensões limites da ordem de $250 \mathrm{MPa}$, porém, com base nos critérios de projeto para fabricação e montagem, foram selecionadas duas propostas viáveis do ponto de vista de dimensionamento, fabricação e custos.

Com o intuito de obter as duas propostas de suporte padrão, foram analisados os carregamentos e as dimensões dos amortecedores existentes na empresa em questão, utilizados na fabricação de chassi de ônibus. Os valores máximos obtidos foram: diâmetro externo de 76 mm e carga máxima de 7981 N. Realizada a seqüência 
referente à modelagem e à análise MEF propriamente dita, obteve-se a primeira proposta otimizada, conforme mostra a figura 5.16.

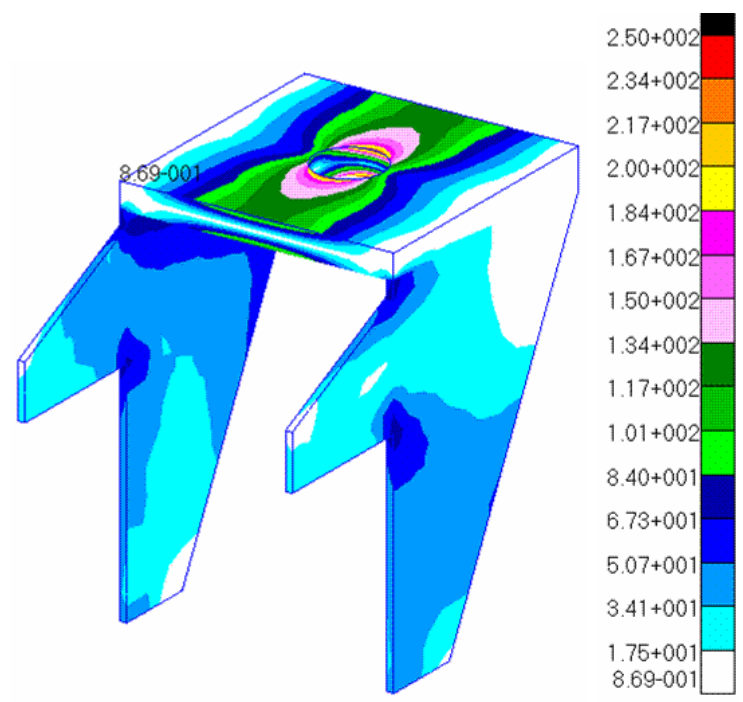

Figura 5.16 - Suporte otimizado primeira proposta "A" (laterais de 2,5 mm) - Tensões em MPa

\subsubsection{Análise de estabilidade quanto à flambagem}

Apesar de o suporte apresentar níveis de tensão aceitáveis nas análises MEF, conforme ilustrado na figura 5.16, obtiveram-se resultados negativos nos estudos de flambagem das peças laterais devido ao uso de espessuras reduzidas $(2,5 \mathrm{~mm})$. A estrutura comporta-se como um pórtico conforme apresentado na figura 5.17.

Para o cálculo de flambagem da estrutura, utilizaram-se os programas Patran e o Nastran, obtendo-se uma tensão crítica de flambagem da ordem de $67 \mathrm{MPa}$, sendo menor que a tensão atuante de $84 \mathrm{MPa}$, ocorrendo, portanto, o fenômeno de flambagem. Porém, como verificado no capítulo referente à metodologia de desenvolvimento de suportes, o valor de tensão crítica de flambagem deve ser maior que o maior valor de tensão atuante no suporte, com o objetivo de eliminar o risco da ocorrência de flambagem. 
Seria possível optar pela aplicação de elementos enrijecedores nas extremidades das placas laterais, porém, a diferença da espessura da tampa $(9,5 \mathrm{~mm})$ com a das laterais $(2,5 \mathrm{~mm})$ pode comprometer a eficiência das uniões soldadas. Portanto, optou-se pelo aumento da espessura das paredes laterais.

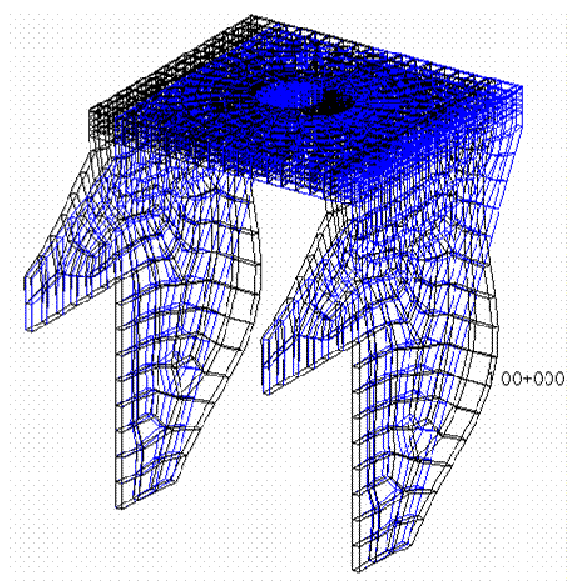

Figura 5.17 - Verificação quanto à flambagem do suporte

Nas demais propostas de suportes, será imposta a espessura mínima das paredes laterais em $5 \mathrm{~mm}$ em razão dos problemas relacionados ao processo de soldagem do suporte. Na proposta ilustrada na figura 5.18, foram utilizadas as chapas laterais com $5 \mathrm{~mm}$ de espessura, eliminando-se o problema relacionado à instabilidade quanto à flambagem.
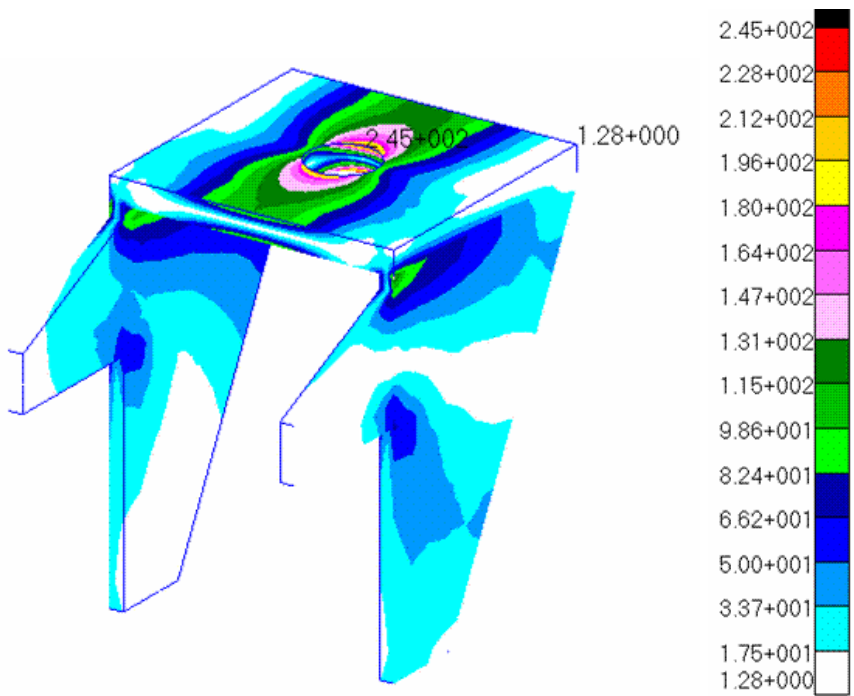

Figura 5.18 - Suporte otimizado primeira proposta "B" (laterais de 5mm) - Tensões em MPa 
Para a análise MEF da segunda proposta, é necessário fazer a modelagem de uma nova malha, devido às alterações geométricas apresentadas no suporte. Nessa versão, o suporte é constituído de apenas uma peça.

Essa proposta visa atender aos critérios de fabricação e montagem, pois se elimina a operação de solda utilizada na primeira proposta de suporte. Porém, verificam-se, na figura 5.19, valores de tensão acima do valor estabelecido de $250 \mathrm{MPa}$ na região próxima ao furo. Com o objetivo de atingir o limite de tensão, realizou-se a alteração da espessura na proposta ilustrada na figura 5.20. Como se trata de uma peça única, a alteração atinge todo o suporte, promovendo aumento na massa do suporte.

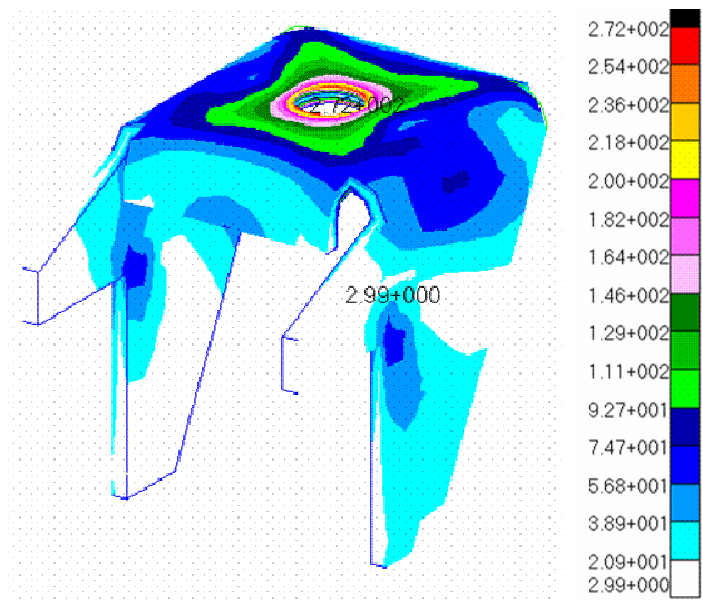

Figura 5.19 - Suporte otimizado segunda proposta "A" -Tensões em MPa

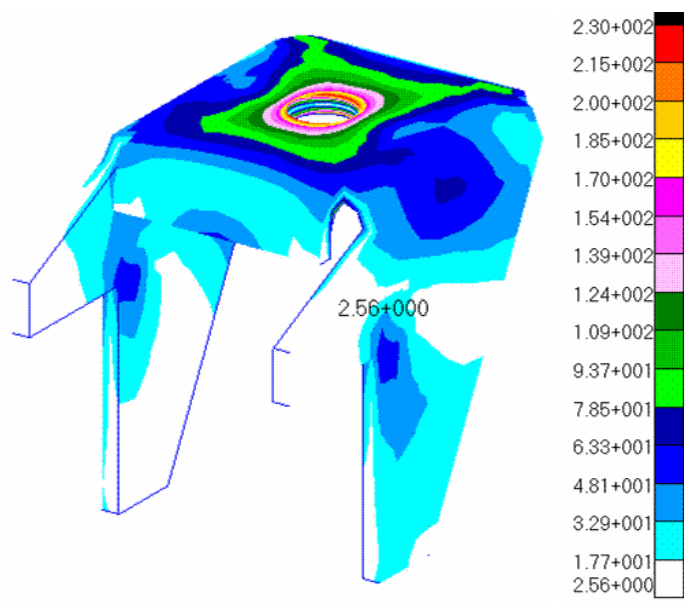

Figura 5.20 - Suporte otimizado segunda proposta "B" - Tensões em MPa 
A seleção da melhor proposta a ser aplicada está vinculada principalmente à análise de custos e à estratégia produtiva da empresa. Os resultados das análises até então efetuadas estão compilados na tabela $5.3 \mathrm{com}$ o intuito de facilitar a tomada de decisão.

Verifica-se que o uso do suporte otimizado (primeira proposta "B") é bastante vantajoso, pois atende a toda gama de amortecedores com um acréscimo de massa de $18 \%$ em relação ao suporte falho. Nota-se um acréscimo de massa de aproximadamente $37 \%$ com o uso do suporte otimizado (segunda proposta "B").

Tabela 5.3 - Resultados das análises MEF e otimização paramétrica e de forma

\begin{tabular}{cccc}
\hline Proposta de suporte & $\begin{array}{c}\text { Pressão } \\
\text { aplicada (MPa) }\end{array}$ & $\begin{array}{c}\text { Tensão máxima } \\
\text { atuante (MPa) }\end{array}$ & $\begin{array}{c}\text { Massa } \\
(\mathrm{Kg})\end{array}$ \\
\hline Falho carregamento calibrado & 3,92 & 280 & 1,27 \\
Reforçado & 3,92 & 149 & 1,43 \\
Otimizado primeira proposta "A" & 5,48 & 250 & 1,13 \\
Otimizado primeira proposta "B" & 5,48 & 245 & 1,55 \\
Otimizado segunda proposta "A" & 5,48 & 272 & 1,94 \\
Otimizado segunda proposta "B" & 5,48 & 230 & 2,00 \\
\hline
\end{tabular}

\subsection{PROPOSTA DE SUPORTE PADRÃO UTILIZANDO A METODOLOGIA DE OTIMIZAÇÃO TOPOLÓGICA}

A utilização da otimização topológica está vinculada principalmente à obtenção de uma nova disposição da peça, com maior redução de peso em comparação aos resultados obtidos com a otimização paramétrica e de forma, conforme descrito no subitem 2.1 (Introdução e conceitos básicos em otimização). 
A metodologia de otimização topológica pode ser aplicada diretamente na obtenção da estrutura ótima, porém, neste estudo, realizou-se inicialmente a análise paramétrica e de forma com o intuito de comparar os resultados obtidos. Essa análise prévia serviu também de base para a análise topológica.

\subsubsection{Modelagem MEF PATRAN / PERMAS}

Basicamente, a modelagem adotada foi a mesma utilizada nas análises MEF até então realizadas, com a diferença de considerar-se malha com sobre-metal nas propostas, conforme verifica-se na figura 5.21. O intuito desse artifício é possibilitar a retirada de elementos a cada interação da análise de otimização topológica.

O algoritmo utilizado no programa PERMAS a despeito das ferramentas já apresentadas na revisão bibliográfica, tais como BESO e MESO, não possui a capacidade de adicionar elementos, ou seja, incluir material em regiões com necessidade. Porém, possui filtros para a redução do aparecimento de problemas relacionados à instabilidade do tabuleiro e à dependência de malha.

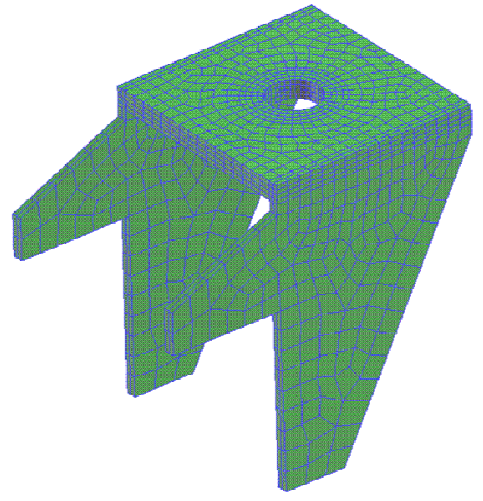

(a)

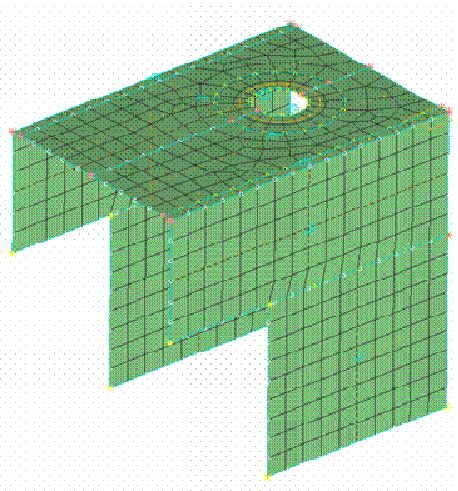

(b)

Figura 5.21 - (a) Malha suporte otimizado primeira proposta "B", (b) Malha com sobre-metal

Com o objetivo de realizar a otimização topológica do suporte do amortecedor, as dimensões da malha da primeira proposta "B", conforme ilustra a figura 5.21 (a), 
foram aumentadas, resultando na nova malha com adição de material, como mostra a figura $5.21(b)$.

A nova malha foi gerada no programa PATRAN e inserida no programa MEDINA (pré-processador) e foram adicionadas as condições de contorno, carregamento e material, conforme descrito anteriormente. Após a preparação prévia do modelo, ele é submetido à seqüência de interações de otimização topológica do programa solver PERMAS. Os resultados obtidos são visualizados no programa MEDINA.

\subsubsection{Avaliação dos resultados MEF PATRAN}

A análise da proposta com a aplicação da metodologia de otimização topológica está vinculada à existência de um número reduzido de restrições, possibilitando grandes alterações em relação ao domínio de projeto. As restrições implementadas foram basicamente:

- Largura e altura do suporte, com o intuito de permitir a montagem, desmontagem e o funcionamento do amortecedor.

- Área da tampa, na qual deve conter o tamanho mínimo para o apoio do coxim de borracha do amortecedor mais folgas referentes à cinemática de funcionamento do amortecedor.

As demais medidas ou formas estão livres para serem modificadas. Utilizou-se na análise topológica o programa MEDINA (pós-processador) e o solver PERMAS.

Foi inserido no programa PERMAS a quantidade de 12 interações necessárias para a obtenção da máxima rigidez estrutural com o mínimo volume de material, resultando em formas ótimas para estrutura, com melhor distribuição de tensão, como ilustra a figura 5.22 . 


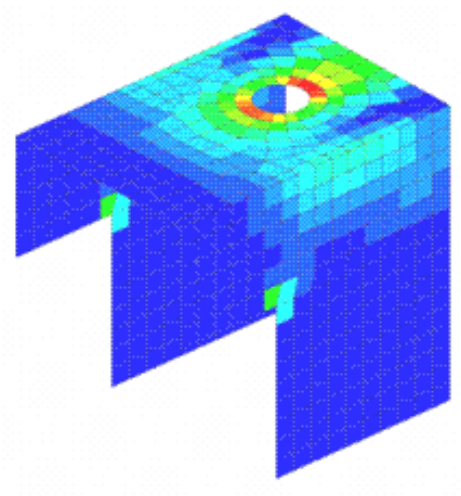

(a)

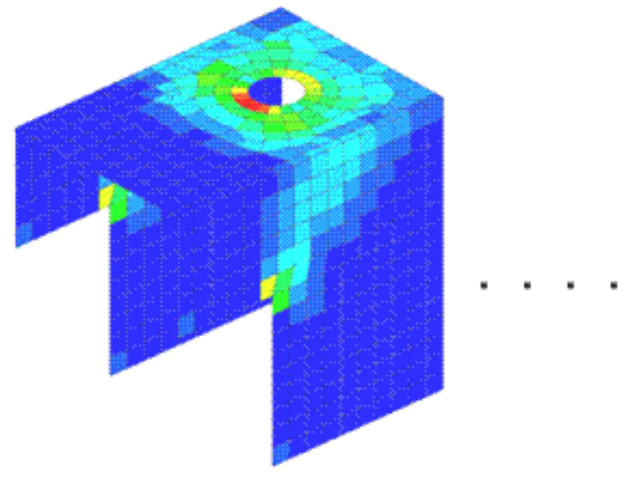

(b)

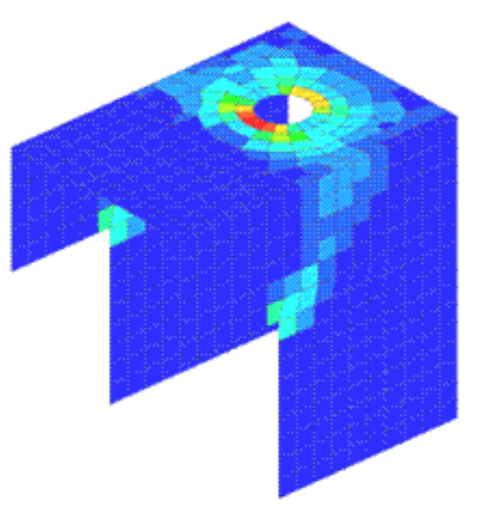

(c)

Figura 5.22 - (a) $1^{\underline{a}}$ Interação, (b) $2^{\underline{a}}$ Interação e (c) $12^{\underline{a}}$ Interação

Inicialmente, é selecionada para estudo a proposta obtida na segunda interação da otimização topológica, com o intuito de obter-se um melhor entendimento sobre o comportamento do modelo e as condições de contorno, devido à semelhança de resultado com a primeira proposta "B". Nota-se que a correta interpretação do modelo gerado é de suma importância.

Para ficar evidente, o contorno da peça foi delineado com traços em preto e remodelada a nova malha baseada na $2^{\underline{a}}$ interação, com o uso do programa PATRAN, como mostra a figura 5.23 (a) e (b). Na seqüência, o modelo é submetido à análise das tensões pelo critério de Von Mises, com o uso dos programas NASTRAN e PATRAN.

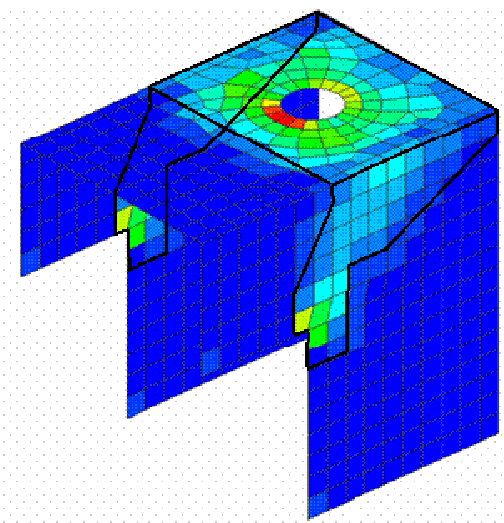

(a)

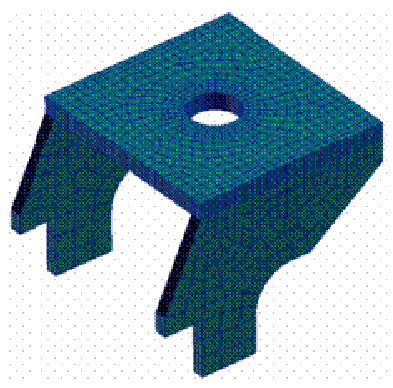

(b)

Figura 5.23 - (a) Malha obtida na $2^{\mathrm{a}}$ interação e (b) Nova malha 
Após a análise MEF realizada no PATRAN, obteve-se o resultado da otimização topológica, em que somente foram alteradas as espessuras, mantendo-se a forma básica obtida na segunda interação. Na figura 5.24 (a), observa-se o valor de tensão máxima em torno de $239 \mathrm{MPa}$, abaixo do valor de tensão limite de $250 \mathrm{MPa}$, estando, portanto, aprovada.

Verifica-se na figura 5.24 (a), no detalhe "A", uma redução das dimensões utilizadas na região do engaste do suporte. Essa redução pode provocar problemas, pois a carga se torna mais concentrada no engaste com o tubo. Decidiu-se, portanto, manter a área de engaste de acordo com o domínio de projeto do suporte falho, ilustrado na figura 5.24 (b), no detalhe "B", distribuindo de maneira mais uniforme os carregamentos no tubo da estrutura. $\mathrm{O}$ suporte com a região de engaste prolongado está aprovado com valor de tensão máxima de $239 \mathrm{MPa}$.

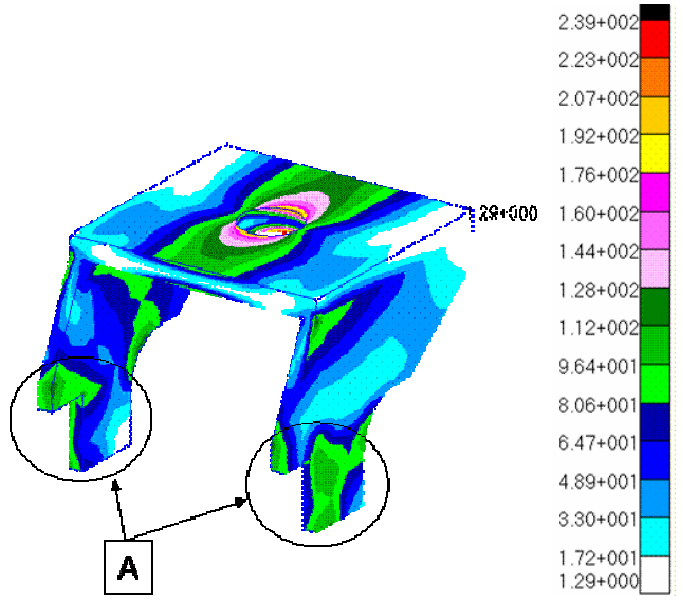

(a)
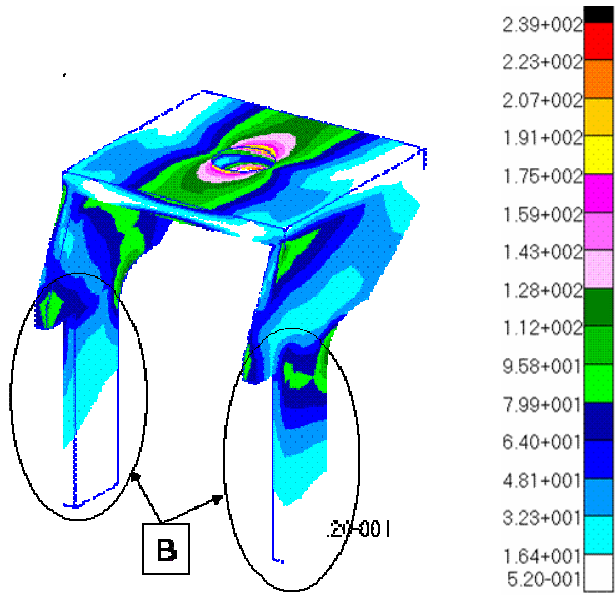

(b)

Figura 5.24 - (a) Suporte otimizado $2^{\underline{a}}$ interação e (b) Suporte otimizado $2^{\underline{a}}$ interação modificada Tensões em MPa

Para a análise topológica final do suporte gerado na $12^{\underline{a}}$ interação, foi utilizado o procedimento já exposto no caso da $2^{\underline{a}}$ interação. Nota-se uma mudança maior na topologia da peça sinalizando a possibilidade de maior redução de massa. A versão apresentada na figura 5.25 (a) representa a solução obtida com o uso do programa de otimização PERMAS, visualizado no programa MEDINA (pós-processador). A figura 
5.25 (b) representa a solução obtida com a análise MEF, com o uso dos programas PATRAN e NASTRAN. Verifica-se que os valores de tensão estão dentro do limite estipulado de projeto, de acordo com a tabela 5.4.

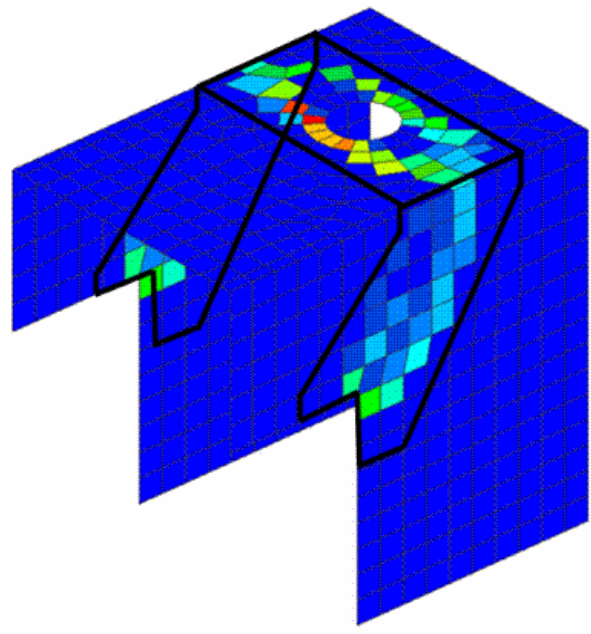

(a)

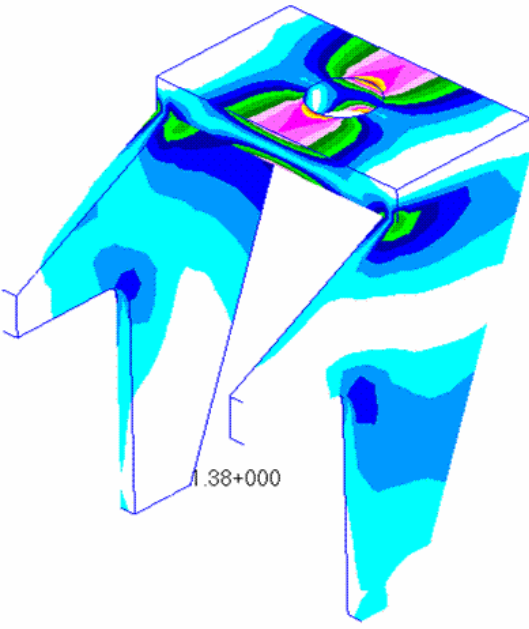

(b)

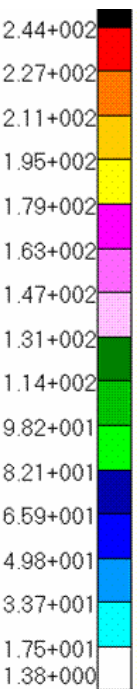

$1.38+000$

Figura 5.25 - (a) Malha obtida na $12^{\mathrm{a}}$ interação e (b) Otimização topológica da $12^{\mathrm{a}}$ interação

Tabela 5.4 - Resultados das análises de otimização topológica

\begin{tabular}{cccc}
\hline Suporte & $\begin{array}{c}\text { Pressão } \\
\text { aplicada }(\mathrm{MPa})\end{array}$ & $\begin{array}{c}\text { Tensão Máxima } \\
\text { atuante }(\mathrm{MPa})\end{array}$ & $\begin{array}{c}\text { Massa } \\
(\mathrm{Kg})\end{array}$ \\
\hline $2^{\underline{a}}$ interação & 5,48 & 239 & 1,22 \\
$2^{\underline{a}}$ interação modificada & 5,48 & 239 & 1,40 \\
$12^{\underline{a}}$ interação & 5,48 & 244 & 1,33 \\
\hline
\end{tabular}

\subsection{AVALIAÇÃO FINAL DAS PROPOSTAS}

As análises otimizadas resultaram em propostas viáveis segundo critérios de tensão e flambagem, porém a seleção da melhor proposta a ser aplicada depende da verificação de diversos fatores, tais como: quantidade de componentes envolvidos, 
análise de meios produtivos, massa e espessura das chapas, conforme descrito anteriormente.

As propostas receberam as seguintes denominações: Proposta $A$ - suporte otimizado primeira proposta "B", Proposta B - suporte otimizado segunda proposta "B" e Proposta C - suporte obtido com a otimização topológica, como ilustra a figura 5.26.

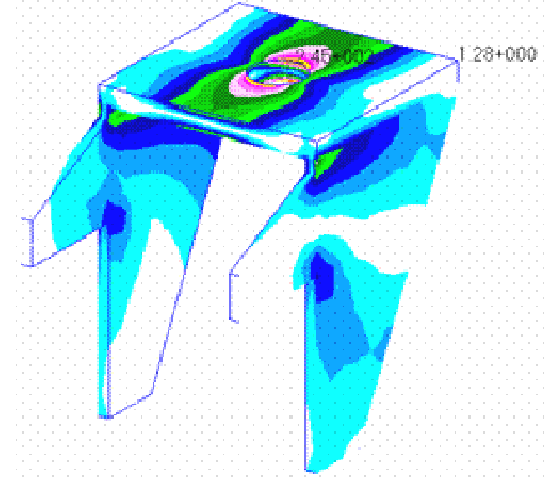

Proposta A

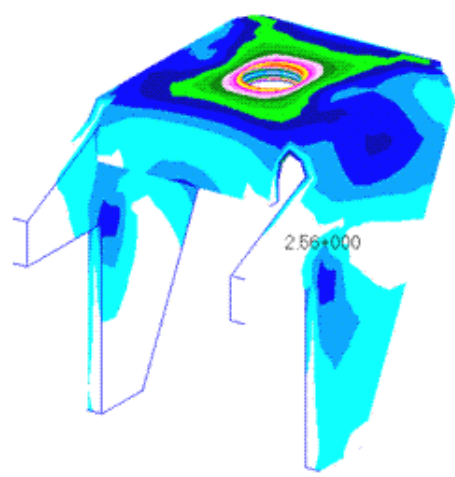

Proposta B

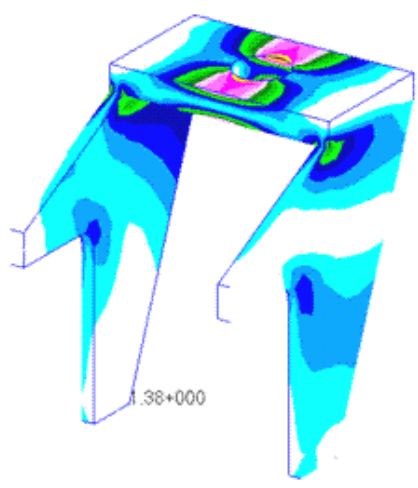

Proposta C

Figura 5.26 - Propostas A, B e C

As propostas $\mathrm{A}$ e $\mathrm{C}$ possuem três componentes cada uma. Como se repete o uso dos componentes (paredes laterais), elas são compostas de apenas duas peças diferentes. A verificação da facilidade de fabricação e montagem considera a quantidade de processos e meios produtivos envolvidos na fabricação e montagem do suporte. O suporte da proposta $B$ é formado por uma peça única.

Será realizado um breve comentário sobre pesos e notas, ilustrados a seguir, na tabela 5.5, a qual é utilizada na seleção do suporte de amortecedor padrão a ser aplicado a uma família de veículos, conforme proposto na metodologia de desenvolvimento. As notas serão atribuídas de 0 (inviável) a 5 (ótima), conforme descrito anteriormente.

A atribuição dos pesos possui grande influência nos resultados a serem obtidos na matriz de decisão. Para a determinação dos pesos, são verificados os diversos 
atributos contidos na matriz. No caso do atributo omáx./massa, aplicou-se o peso 0,35 , devido à sua importância na obtenção de uma estrutura otimizada. O número de componentes recebeu o peso 0,15 , e os atributos massa e processos de fabricação e montagem receberam o peso 0,25 por causa de sua importância na obtenção da estrutura ótima. Na seqüência, serão explicados os valores das notas atribuídas às propostas.

No caso do atributo omáx./massa, essa relação deve apresentar o maior valor possível. Pois normalmente a estrutura deve ser capaz de resistir aos carregamentos a ela aplicados com o menor valor de massa possível. A nota 5 foi aplicada às propostas $A$ e $C$, que apresentaram um valor elevado da relação omáx./massa, enquanto a proposta B obteve a nota 2 em decorrência de seu valor inferior.

No caso do número de componentes, a nota 5 pertence à proposta $B$ constituída de uma peça única, e a nota 3 é atribuída às propostas $\mathrm{A}$ e $\mathrm{C}$, referentes aos suportes soldados, pois são compostos de duas peças diferentes, conforme já exposto.

A massa representa um fator importante no desenvolvimento do suporte padrão. Na aplicação da metodologia proposta, deve-se obter um suporte otimizado, ou seja, com a menor quantidade de material possível. A aplicação da nota 5 foi dedicada ao suporte da proposta $\mathrm{C}$, que apresentou a menor massa dentre as três propostas. As propostas A e B receberam notas 3 e 2 , respectivamente, devido ao acréscimo de massa em comparação à proposta $\mathrm{C}$.

Quanto ao atributo processos de fabricação e montagem, podem representar o êxito ou não da proposta. Nesse caso, verificou-se a nota 5 para a proposta $B$, em que a peça foi obtida utilizando-se apenas um processo produtivo (estampagem). A peça pode ser obtida com o uso de uma ferramenta progressiva de corte e dobra. As propostas $\mathrm{B}$ e $\mathrm{C}$ receberam a nota 2 , pois, além da operação de estampagem (referente ao corte do perfil da parede lateral e da tampa), é necessária a operação de soldagem 
para a obtenção do conjunto montado. Nesse caso, o processo de soldagem depende do dispositivo de solda, bem como do equipamento de solda e um soldador qualificado.

De acordo com os resultados ilustrados na tabela 5.5, verifica-se que a proposta C (obtida com a utilização da otimização topológica) representa a melhor solução a ser aplicada no desenvolvimento do suporte do amortecedor.

Tabela 5.5 - Avaliação das propostas

\begin{tabular}{cccccccc}
\hline & \multicolumn{4}{c}{ Proposta A } & \multicolumn{2}{c}{ Proposta B } & \multicolumn{2}{c}{ Proposta C } \\
\hline Atributo & Peso & Nota & Notaxpeso & Nota & Notaxpeso & Nota & Notaxpeso \\
omáx./massa & 0,35 & 5 & 1,75 & 2 & 0,70 & 5 & 1,75 \\
$\begin{array}{c}\text { Número de } \\
\text { componentes }\end{array}$ & 0,15 & 3 & 0,45 & 5 & 0,75 & 3 & 0,45 \\
$\quad \begin{array}{c}\text { Massa } \\
\text { Processos de }\end{array}$ & 0,25 & 3 & 0,75 & 2 & 0,50 & 5 & 1,25 \\
fabricação e & 0,25 & 2 & 0,50 & 5 & 1,25 & 2 & 0,50 \\
montagem & & & 3,45 & & 3,20 & & 3,95 \\
Soma & 1,00 & & 2 & & 3 & & 1 \\
Posição & & & & & & & \\
\hline
\end{tabular}

Nota-se que a aplicação da proposta está atrelada à obtenção de um suporte padrão a ser utilizado em toda a família de chassi de ônibus. Os valores atribuídos de peso devem estar em conformidade com a política de desenvolvimento da empresa. Não é conveniente ser tendencioso ao estabelecer as notas referentes às propostas.

Com o intuito de finalizar o processo de desenvolvimento do suporte padrão, é preenchida a lista de verificação para evitar que seja desprezada alguma etapa preestabelecida na metodologia de desenvolvimento de suportes, conforme mostra a tabela 5.6. 
Tabela 5.6 - Listagem de controle

\section{Denominação}

SUPORTE PADRÃO

\section{Desenvolver o conceito do suporte padrão}

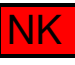

Verificado as funções do suporte

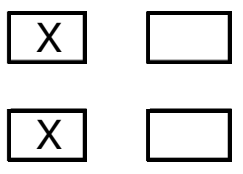

Conceituado a proposta

(definido o tipo de construção e união, efetuado a análise de montabilidade e dimensional)

Atendido as necessidades do projeto

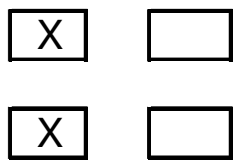

Atendido os critérios de fabricação e montagem

\section{Análise de otimização}

Aplicada a densidade e tipo de malha compatível

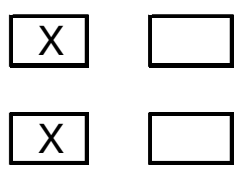

Aplicado as condições de contorno

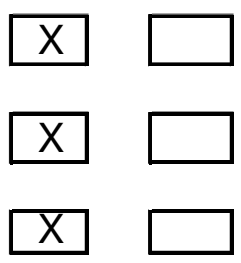

Definida a taxa de remoção ou determinado o $n^{\circ}$ total de interações

\section{Análise MEF de tensões de Von Mises e de flambagem}

Aplicada a densidade de malha compatível

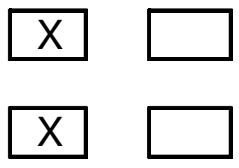

Aplicado o material

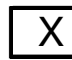

Aplicadas as condições de contorno

Aplicados os carregamentos

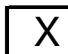

A malha atende a relação $t / 1 \leq 0,1$ ?

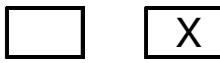

Modelagem com elementos sólidos

Submetido à análise MEF 
Atendido o critério de tensões $\sigma \leq \sigma a d m$

Atendido o critério de flambagem $\sigma<\sigma c r$

Incluído elementos enrijecedores

Alterado a espessura

Atendido aos critérios de fabricação e montagem

Obtido o suporte padão

Responsável

PAZIAN
Data

$15 / 12 / 2009$

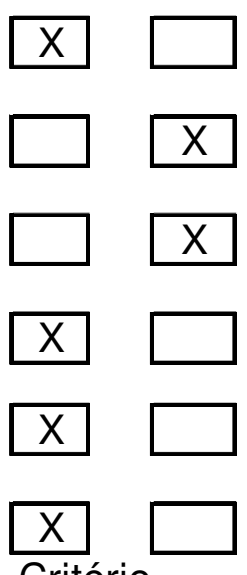

Critério

OK - aprovado

NK - reprovado 


\section{CONCLUSÕES E TRABALHOS FUTUROS}

O objetivo principal desta pesquisa é possibilitar a obtenção de suportes padrões otimizados para condições preestabelecidas de carregamentos e de contorno. Ao longo deste estudo, teve-se o cuidado de representar adequadamente a estrutura física do suporte com a utilização do método de elementos finitos.

Primeiro, realizou-se a calibração do modelo de elementos finitos por meio da representação da falha no suporte do amortecedor. Esse modelo serviu de base para a análise das propostas otimizadas na seqüência, melhorando a confiabilidade dos resultados obtidos com a aplicação desse recurso.

Realizaram-se também estudos propondo a simplificação do modelo MEF, obtendo-se redução percentual elevada do tempo computacional, conforme apresentado na tabela 5.2. Porém, os tempos foram reduzidos de 10,72 Seg para 4,21 Seg. A simplificação neste caso serve apenas para diminuir o tamanho do modelo. Entretanto, quanto maior e mais complexo o modelo MEF, mais importante se torna a sua simplificação.

Para a verificação do suporte falho, utilizou-se o carregamento calibrado do amortecedor em questão. Com o propósito de conseguir maior redução de custos, foi proposta a utilização de um amortecedor com maior carga, obtendo-se, portanto, uma solução ótima a ser aplicada a toda a família de chassi, ou seja, uma solução padrão.

Nos estudos iniciais, verificou-se a necessidade de aplicação de elementos sólidos no modelo MEF em razão da espessura das peças e da densidade de malha aplicada, tornando-se inviável a aplicação de elementos de placa nas análises seguintes. No procedimento proposto, porém, deve ser sempre verificado a possibilidade de uso da malha com elementos de placa devido às vantagens apresentadas. 
A estrutura obtida com a aplicação do programa de otimização topológica apresentou a forma ótima com máxima rigidez e menor quantidade de material após 12 interações, como ilustra a tabela 5.4.

Verificou-se que a obtenção das estruturas otimizadas pode gerar geometrias delgadas, provocando problemas relativos à flambagem, o que torna necessário incluir a análise de estabilidade quanto à flambagem na metodologia de desenvolvimento de suportes. Isso resulta na necessidade de implementar modificações no modelo MEF, caso apresente problemas relativos à flambagem.

Diversos fatores são analisados para a seleção da estrutura a ser utilizada. Para tanto, realizou-se a verificação das propostas com base nos critérios de fabricação e montagem, obtendo-se propostas otimizadas. Utilizou-se uma matriz de decisão com pesos e notas para auxiliar a seleção da melhor proposta otimizada.

Espera-se que a aplicação do procedimento proposto neste estudo propicie a obtenção de resultados satisfatórios e tenha contribuído, mesmo que modestamente, para o desenvolvimento de novos produtos, tornando-se um procedimento a ser utilizado.

Como estudo futuro, sugere-se a inclusão de análises dinâmicas ao desenvolvimento de suportes, visando à verificação da fadiga. Para isso, é necessária a obtenção de dados experimentais do comportamento dinâmico do veículo para efetuar a calibração do modelo MEF. Sugerem-se também a criação de modelos de elementos finitos parametrizados e a adoção de banco de dados de soluções padronizadas para diversas aplicações de suportes. 


\section{REFERÊNCIAS}

ABOLBASHARI, M.H.; KESHAVARZMANESH, S. On various aspects of application of the evolutionary structural optimization method for 2D and 3D continuum structures. Finite Elements in Analysis and Design, v. 42, p. 478-491, 2006.

AMBROSIO, L.; BUTTAZZO, G. An optimal design problem with perimeter penalization, Calculus of Variations and Partial Differential Equations, v.1, p. 55-69, 1993.

ARORA, J.S. Introduction to optimum Design. $2^{\text {nd }}$ ed. California: Elsevier Academic Press, p. 377, 2004.

BENDS $\varnothing \mathrm{E}$, M.P. Optimization of structural topology, Shape, and Material, Springer, Berlin, 1995.

BENDS $\varnothing \mathrm{E}$, M.P.; KIKUCHI, N. Generating optimal topologies in industrial design using a homogenization method, Computer Methods in Applied Mechanics and Engineering, v. 71, p.197-224, 1988.

BOOTHROYD, G; DEWHURST, P; KNIGHT, W. Product design for manufacture and assembly. $1^{\text {st }}$ ed. New York. Marcel Dekker Inc., p. 540, 1994.

BOOTHROYD, G. Product design for manufacture and assembly. Computer-Aided Design. v. 26, p. 505-520, 1994.

BROWNING, R.T; HEATH, R.D. Reconceptualializing the effects of lean on production costs with evidence from the F-22 program. Journal of Operations Management, v. 27, p. 23-44, 2009.

BRUGGI, M. On the solution of the checkerboard problem in mixed-FEM topology optimization. Computer and Structures, v. 86, p. 1819-1829, 2008. 
CHODRAUI, G.M.B.; MALITE, M. Flambagem por distorção da seção transversal em perfis de aço formados a frio submetidos à compressão centrada e flexão. São Carlos: EESC-USP. 2007, Caderno de Engenharia de Estruturas, v. 9, p. 27-47.

DIAZ, A.; SIGMUND, O. Checkerboard patterns in layout optimization, Structural and Multidisciplinary Optimization, v. 10, p. 40-45, 1995.

DORN, W.C; GOMORY, R.E; GREENBERG, H.J. Automatic design of optimal structures. Journal de Mecanique, v.3, p. 25-52, 1964.

EDWARDS, K.L. Towards more strategic product design for manufacture and assembly: priorities for concurrent engineering. Materials and Design, v. 23, p. 651-656, 2002.

FUCHS, M.B.; MOSES, E. Optimal structural topologies with transmissible loads. Structural and Multidisciplinary Optimization, v. 19, p. 263-273, 2000.

HABER, R.B.; JOG, C.S.; BENDSOE, M.P. A new approach to variable-topology shape design using a constraint on the perimeter, Structural Optimization, v. 11, p. 1-12, 1996.

HAFTKA, R.T.; GÜRDAL, Z. Elements of structural optimization. $3^{\text {rd }}$ ed. London: Kluwer Academic Publishers, p. 481, 1992.

HAMMER, V.B.; OLHOFF, N. Topology optimization of continuum structures subjected to pressure loading. Structural and Multidisciplinary Optimization, v. 19, p. 85-92, 2000.

HUANG, X.; XIE, Y.M. Topology optimization of nonlinear structures under displacement loading. Engineering Structures, v. 30, p. 2057-2068, 2008.

INTES Gmbh. PERMAS workshop (topology optimization). Germany, [2007]. 206p.

KAMINSKI, P.C. Desenvolvendo produtos planejamento, criatividade e qualidade. 1 ed. Rio de Janeiro : Livros Técnicos e Científicos, p. 132, 2000.

KHALAF, A.A.; SAKA, M.P. Evolutionary structural optimization of steel gusset plates. Journal of Constructional Steel Research, v. 63, p. 71-81, 2007. 
MACNEAL, R.H. Finite elements: their design and performance, $1^{\text {st }}$ ed. New York: Marcel Dekker Inc., v.1, p. 259, 1994.

MICHELL, A.G. The limits of economy of material in frame-structures. Philosophical Magazine, v. 8, n.47, p. 589-597, 1904.

MILES, L.D. Technics of value analysis and engineering, $3^{\text {rd }}$ ed. Published by Eleanor Miles Walker, p. 300, 1989.

NIEMANN, G. Elementos de Máquinas, 6. ed. São Paulo. Editora Edgard Blücher Ltda., 1971. v. 1.

NIORDSON, F. Optimal design of elastic plates with a constraint on the slope of the thickness function. International Journal of Solids Structures. v. 19, p. 141-151, 1983.

POULSEN, T.A. A simple scheme to prevent checkerboard patterns and one-node connected hinges in topology optimization, Structural and Multidisciplinary Optimization, v. 24, p. 396-399, 2002.

PUGH, S. Creating innovative products using total design: the living de legacy of Stuart Pugh, $1^{\text {st }}$ ed. Addison Wesley Longman, p.544, 1996.

QUERIN, O.M.; YOUNG, V.; STEVEN, G.P; XIE, Y.M. Computational efficiency and validation of bi-directional evolutionary structural optimization. Computer Methods in Applied Mechanics and Engineering. v. 189, p. 559-573, 2000.

SCHUYLER, J; R. Risk and decision Analysis in Projects. $2^{\text {nd }}$ ed. Newtown Square, Pa: Project Management Institute, p. 259, 2001.

SIGMUND, O. Design of material structures using topology optimization. Ph.D. Thesis, Department of Solid Mechanics, Technical University of Denmark, 1994.

SIGMUND, O. On the design of compliant mechanisms using topology optimization. Mechanics of Structures and Machines, v. 25, p. 493-524, 1997. 
SIGMUND, O; PETERSSON, J. Numerical instabilities in topology optimization: A survey on procedures dealing with checkerboards, mesh-dependencies and local minima. Structural Optimization. v. 16, p. 68-75, 1998.

SILVA, E.C.N. Otimização aplicada ao projeto de sistemas mecânicos. São Paulo: Epusp, S/D. 43 p. Apostila para disciplina de pós-graduação do Departamento de Engenharia Mecatrônica, PMR 5215 - Otimização aplicada ao projeto de sistemas mecânicos.

SILVA, M.E. Planejamento e controle de projetos. Escola de Engenharia de Piracicaba, 2007. 92 p. Apostila para disciplina de graduação do Departamento de Engenharia Mecânica.

SPYRAKOS, C. Finite element modeling in engineering practice, 2. ed. Pittsburgh, PA: Argor INC., 322p, 1996.

TANSKANEN, P. A. multiobjective and fixed elements based modification of the evolutionary structural optimization method. Computer Methods in Applied Mechanics and Engineering. v. 196, p. 76-90, 2006.

VICTORIA, M.; MARTÍ, P; QUERIN, O.M. Topology design of two-dimensional continuum structures using isolines. Computers and Structures. v. 87, p.101-109, 2009.

XIE, Y.M.; STEVEN, G.P. A simple evolutionary procedure for structural optimization, Computers and Structures. v. 49, p. 885-896, 1993.

YANG, X.Y; XIE, Y.M.; STEVEN, G.P; QUERIN, O.M. Bidirectional evolutionary method for stiffness optimization. AIAA Journal, v. 37, p.1483-1488, 1999.

YANG, X.Y; XIE, Y.M.; LIU, J.S; PARKS, G.T; CLARKSON, P.J. Perimeter control in the bidirectional evolutionary optimization method. Structural and Multidisciplinary Optimization. v. 24, p. 430-440, 2003.

YANG, X.Y; XIE, Y.M.; STEVEN, G.P. Evolutionary methods for topology optimization of continuous structures with design dependent loads. Computer and structures. v. 83, p. 956-963, 2005. 